Jhon Jairo Trejos Parra (Pereira, Risaralda, Colombia, 1963).

Doctor en Psicología de la Universidad España de Durango (México). Magíster en Educación y Desarrollo Comunitario, CINDE \& Universidad Surcolombiana. Médico,Universidad Tecnológicade Pereira. Psicólogo, Universidad Nacional Abierta y a Distancia.

Docente Titular en la Facultad Ciencias de la Salud

Coautor de los libros: Anatomía para profesiones afines a la salud (1998), Recreación psicoterapéutica: conceptos básicos (2005), Programa de educación experiencial para mejorar el trabajo en equipo en/as organizaciones (2020).

Miembro del grupo de investigación Cultura delaSalud

jtrejos@utp.edu.co

Sandra Milena Bedoya Gaviria (Pereira, Risaralda, Colombia, 1976).

Maestría en Pedagogía y Desarrollo Humano (Universidad Católica de Pereira). Especialista en Pedagogía y Desarrollo Humano (Universidad Católica de Pereira). Psicóloga (Universidad Minuto de Dios). TerapeutaRespiratoria(UniversidadCatólica deManizales)

Docenteasistente de laFacultad Ciencias de laSalud.

Coautora del libro: ABP y Simulación Clínica comomediadores delaprendizaje en ciencias delasalud (2019).

Grupodeinvestigación urgencias, emergencias ysimulación GIRUS.

samibega@utp.edu.co
Claudia Patricia Cardona Triana (Santa Rosa de Cabal, Risaralda, Colombia, 1977).

Aspirante a Doctora en Ciencias de la Administración (Universidad Nacional Autónoma de México). Magister en Administración del Desarrollo Humano y Organizacional,Universidad Tecnológica de Pereira. Especialista en Gerencia del Deporte y la Recreación, Universidad Tecnológica de Pereira. Profesional en Ciencias del Deporte y la Recreación, Universidad Tecnológica de Pereira.

Docente Asociada en la Facultad Ciencias de la Salud

Coautora de los libros: Perfil del cliente de los gimnasios y centros de acondicionamiento físico caso Pereira (2019). Programa de educación experiencial para mejorar el trabajo en equipo enlas organizaciones (2020).

Miembro del grupo de investigación Cultura dela Salud

claudiacardona@utp.edu.co

La Editorial de la Universidad Tecnológica de Pereira tiene como política la divulgación del saber científico, técnico y humanístico para fomentar la cultura escrita a través de libros y revistas científicas especializadas.

Las colecciones de este proyecto son:

Trabajos de Investigación, Ensayos, Textos Académicos y Tesis Laureadas.

Este libro pertenece a la Colección Trabajos de Investigación. 


\title{
Programa modelo de educación experiencial orientado al desarrollo de personalidad resistente en estudiantes de atención prehospitalaria
}

\author{
Jhon Jairo Trejos Parra \\ Sandra Milena Bedoya Gaviria \\ Claudia Patricia Cardona Triana
}

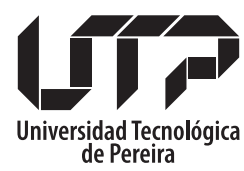

Colección Trabajos de Investigación

Facultad Ciencias de la Salud

2021 


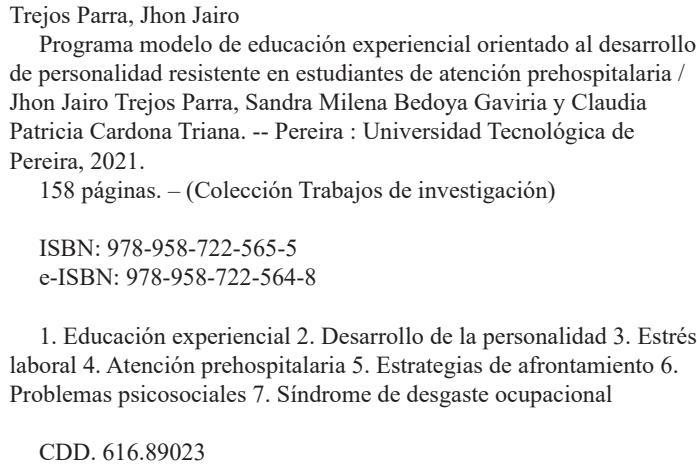

C Jhon Jairo Trejos Parra, 2021

(C)Sandra Milena Bedoya Gaviria, 2021

CClaudia Patricia Cardona Triana, 2021

CUniversidad Tecnológica de Pereira

Primera edición

Proyecto de investigación: Programa modelo de educación experiencial orientado al desarrollo de personalidad resistente en estudiantes de atención prehospitalaria codigo VIIE es: 5-19-11

Universidad Tecnológica de Pereira

Vicerrectoría de Investigaciones, Innovación y Extensión

Editorial Universidad Tecnológica de Pereira

Pereira, Colombia

\section{Coordinador editorial:}

Luis Miguel Vargas Valencia

luismvargas@utp.edu.co

Teléfono 3137381

Edificio 9, Biblioteca Central "Jorge Roa Martínez"

Cra. 27 No. 10-02 Los Álamos, Pereira, Colombia

www.utp.edu.co

Montaje y producción:

David Restrepo Suárez y

Centro de Recursos Informáticos y Educativos CRIE, diseno@utp.edu.co

Universidad Tecnológica de Pereira

Imagen de cubierta: Laura María Trejos Betancur

Pereira

Reservados todos los derechos 


\section{Agradecimientos}

Agradecemos en primer lugar a Dios por ser nuestro motor y guía de vida y de este libro. Agradecemos a nuestras familias por la paciencia que nos tuvieron por el tiempo que no les pudimos entregar al estar dedicados a esta investigación. Agradecemos a Victor Rodríguez Pérez, Doctor en Psicología, por la Dirección de esta Tesis, y en general a

la Universidad Autónoma España de Durango (México). Agradecemos a todos los colaboradores de la Universidad Tecnológica de Pereira que hicieron posible la realización de la investigación, en especial a Alejandra Galvis Valencia, Paula Andrea Ramírez

y Lina María García Llanos. Y a la Vicerrectoría de Investigaciones, Innovación y Extensión por financiación para la publicación de este libro.. 



\section{CONTENIDO}

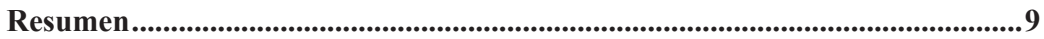

Introducción ..................................................................................................11

1. Planteamiento del problema ....................................................................................14

2. Objetivos................................................................................................................19

2.1 Objetivo general.....................................................................................19

2.2 Objetivos específicos ......................................................................................19

3. Antecedentes..........................................................................................................21

3.1 Antecedentes contextuales.....................................................................21

3.1.1 Atención prehospitalaria en Colombia..............................................21

3.1.2 Programa de atención prehospitalaria de la UTP...........................21

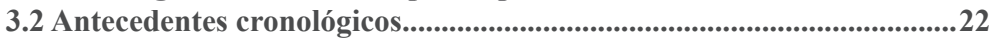

3.2.1 Atención prehospitalaria ......................................................................22

3.2.2 Educación experiencial..............................................................................23

3.2.3 Personalidad resistente...............................................................................224

3.3 Antecedentes investigativos de EE para PR .........................................25

4. Fundamentación teórica ...........................................................................29

4.1 Estrés laboral ...............................................................................................29

4.1.1 Modelo demanda-control-apoyo social de Karasek........................29

4.1.2 Modelo de desequilibrio esfuerzo-recompensa de Siegrist..............31

4.1.3 Síndrome desgaste ocupacional (SDO) ................................................32

4.2 Personalidad resistente (PR)................................................................33

4.2.2 Concepto de PR...................................................................................34

4.2.3 Actitudes resistentes......................................................................................35

4.2.4 Afrontamiento resistente ...........................................................................36

4.2.5 Actitudes y afrontamiento resistente .................................................39

4.3 Necesidades psicológicas ..................................................................................40

4.3.1 Motivación intrínseca ...................................................................................40

4.3.2 Autonomía.................................................................................................41

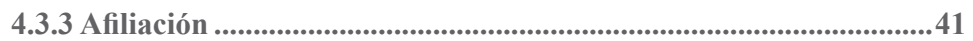

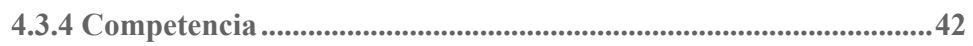

4.3.5 Experiencia de flujo .............................................................................44

4.4 Integración ......................................................................................................44

4.4.1 Demanda laboral..........................................................................................44

4.4.2 Recursos psicológicos.....................................................................................44

4.4.3 Efectos psicosociales ..............................................................................45

4.5 Educación experiencial........................................................................47

4.5.1 Modelos pedagógicos ..................................................................................4 47

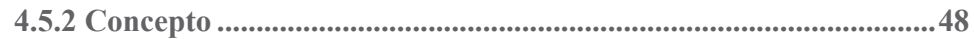

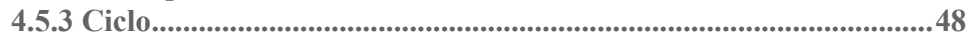

4.5.4 Trabajo en equipo ........................................................................................49

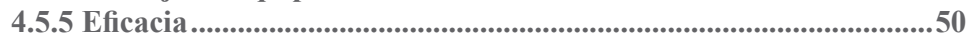

4.6 Tesis propuesta ................................................................................51

5. Metodología..........................................................................................................................53

5.1 Hipótesis ............................................................................................53 
5.1.1 Componente cuantitativo .....................................................................53

5.1.2 Componente cualitativo.................................................................53

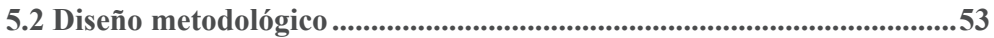

5.2.1 Paradigma y tipo de investigación.......................................................53

5.2.2 Componente cuantitativo .....................................................................55

5.2.3 Componente cualitativo....................................................................55

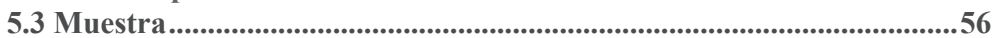

5.4 Técnicas e instrumentos de recolección de información .........................57

5.4.1 Cuantitativas .................................................................................57

5.4.2 Cualitativas ..........................................................................................58

6. Programa de educación experiencial .......................................................60

6.1 Programa general ...................................................................................60

6.1.1 Población en aprendizaje ..............................................................60

6.1.2 Conocimientos, habilidades y actitudes .............................................61

6.1.3 Situaciones cotidianas.......................................................................62

6.1.4 Estrategias formativas ...........................................................................63

6.1.5 Talento humano .........................................................................................664

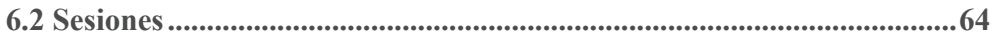

6.2.1 Preliminares.....................................................................................64

6.2.2 Fase de apertura.........................................................................65

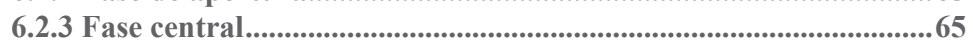

6.2.4 Fase de cierre...................................................................................66

6.2.5 Descripción de las sesiones ..............................................................67

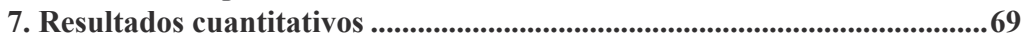

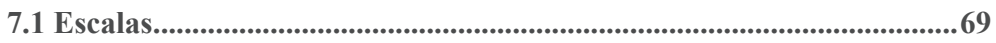

7.1.1 Escala de actitudes resistentes .....................................................69

7.1.2 Escala de estilos y estrategias de afrontamiento al estrés ..............70

7.2 Variables demográficas................................................................................70

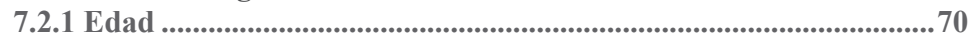

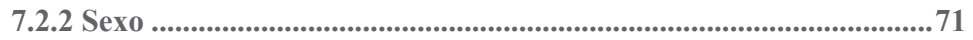

7.3 Preprueba ..............................................................................................................71

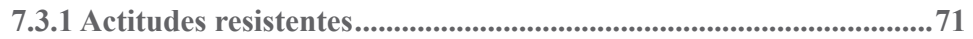

7.3.2 Estrategias de afrontamiento ...........................................................72

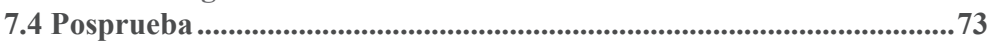

7.4.1 Pruebas estadísticas .............................................................................73

7.4.1 Resultado global de actitudes resistentes ..........................................73

7.4.2 Resultado por cada actitud resistente ...................................................75

7.4.3 Resultado global de estrategias de afrontamiento ..............................76

7.4.4 Resultado por cada estrategia de afrontamiento ...............................78

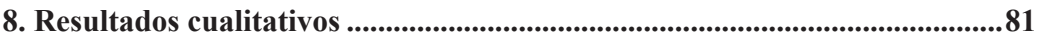

8.1 Mapa categorial ............................................................................................81

8.2 Programa de educación experiencial ...................................................82

8.2.1 Sensibilización ........................................................................................882

8.2.2 Experiencia ....................................................................................................83

8.2.3 Reflexión ................................................................................................83

8.2.4 Conceptualización .............................................................................84

8.2.5 Experimentación .................................................................................84

8.3 Aprendizajes ...............................................................................................85 


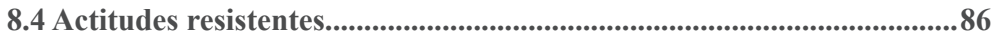

8.4.1 Compromiso ...................................................................................................86

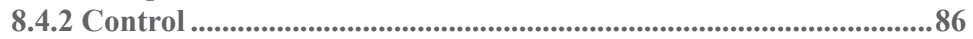

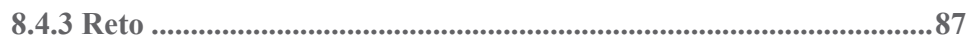

8.5 Estrategias de afrontamiento.........................................................................8 87

8.5.1 Evitación ............................................................................................................87

8.5.2 Búsqueda de soluciones ..............................................................................88

8.5.3 Resignificación o reevaluación positiva..............................................88

8.6 Interacción social de apoyo .....................................................................89

8.6.1 Apoyo cognitivo ........................................................................................89

8.6.2 Apoyo emocional ...................................................................................89

8.7 Trabajo en equipo .....................................................................................................90

8.7.1 Planeación.............................................................................................90

8.7.2 Organización ..................................................................................................91

8.7.3 Dirección ...........................................................................................................92

8.7.4 Control ................................................................................................................92

8.8 Satisfacción de necesidades psicológicas.................................................92

8.9 Desafío óptimo..............................................................................................93

8.9.1 Realimentación positiva ....................................................................93

8.9.2 Experiencia de flujo ........................................................................99

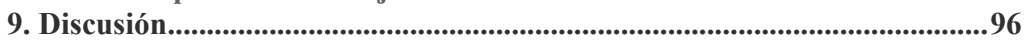

10. Conclusiones................................................................................................................... 103

11. Bibliografía............................................................................................106

12. Sesiones...........................................................................................................................130

12.1 Sesión 1 ............................................................................................................... 130

10.2 Sesión 2 ....................................................................................................132

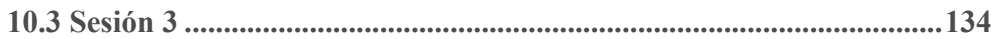

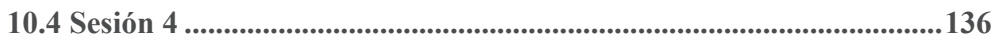

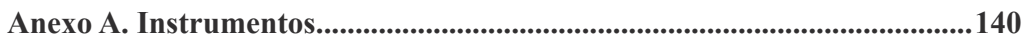





\section{Resumen}

Se diseñó un programa de educación experiencial (EE) orientado al desarrollo de personalidad resistente (PR) en estudiantes de atención prehospitalaria (APH), dada la alta incidencia del Síndrome de Desgate Ocupacional (SDO) en esta población. La revisión teórica realizada sobre los principales modelos teóricos en estrés laboral mostró como principales categorías "demanda laboral", "recursos psicológicos" incluida la PR y efectos psicosociales; dichos recursos están orientados a la satisfacción de necesidades psicológicas, por lo que demandas medias o altas exigen recursos medios o altos para lograr un desafío óptimo gratificante de estas necesidades, el cual aporta a la prevención del SDO. El Programa de EE se sometió a una investigación mixta secuencial, primero cuasiexperimental con grupo experimental $(\mathrm{n}=20)$ de control $(\mathrm{n}=36)$ preformados, pre y posprueba, para evaluar su eficacia, y luego a un estudio cualitativo de caso para contextualizar los hallazgos cuantitativos. Se eligieron la "escala de personalidad resistente" y la "escala de estilos y estrategias de afrontamiento al estrés", se le hicieron pequeños ajustes, se aplicaron a 115 estudiantes APH y se encontró una confiabilidad alta de Cronbach: 0.815 y 0.866 respectivamente. Luego de una capacitación sobre el conocimiento pertinente y una sensibilización para concientizar la pertinencia del Programa, se brindaron 4 sesiones de EE orientada al desarrollo de PR que comprendían las etapas de experiencia, reflexión, conceptualización y experimentación propuestas por Kolb, en un ambiente realista envolvente y de trabajo en equipo. Se encontraron diferencias significativas entre las pospruebas con ambos instrumentos y los estudiantes expresaron el desarrollo en ellos de una PR que trascendía a su vida cotidiana y laboral.

Palabras clave: educación experiencial, personalidad resistente, estrategias de afrontamiento, atención prehospitalaria, síndrome de desgaste ocupacional. 



\section{Introducción}

Actualmente, los profesionales sanitarios están sometidos a cargas laborales excesivas durante las cuales deben enfrentar continuamente el sufrimiento y la muerte, lo que les generan altos niveles de estrés crónico. Este hecho aunado a los salarios relativamente bajos y a la falta frecuente de reconocimiento social de su labor lleva a la aparición del sindrome de desgaste ocupacional (SDO) o burnout, incluso en una tercera parte de ellos. Este síndrome comprende agotamiento emocional, despersonalización de la atención (alejamiento emocional de los atendidos) y baja realización personal (Grau et al., 2008, p. 77) y afecta en todos los ámbitos de la persona: cognitivo, emocional, somático, conductual, social y laboral (Manging-Valverde y CsizmadiaViteri, 2017, pp. 9-12).

Dado lo anterior, es imperioso producir y aplicar conocimiento orientado a la prevención del SDO. Esto es especialmente importante en el personal sanitario encargado de la atención de urgencias en el espacio prehospitalario, ya que aquí está sometidos a mayores estresores por las situaciones complejas e imprevistas, sin los recursos intrahospitalarios 
y con alto riesgo de muerte en los atendidos, por lo que este síndrome es aún más frecuente en este personal (Sanchez-Vera, Loli-Ponce y Sandoval-Vegas, 2015, pp. 120-121).

De acuerdo con lo anterior, en la presente investigación se construyó y evaluó un programa orientado al desarrollo de la "Personalidad Resistente" (PR), que comprende actitudes, afrontamiento, interacción social y autocuidado resistentes, dado que se ha encontrado que constituye un factor de prevención del SDO (Vagni, Giostra, Maiorano, Santaniello, \& Pajardi, 2020; Ha, 2018; Rajaei, Shafizadeh, Babaeiamiri, \& Amirfakhr, 2017; Park, 2017; Rahim-Zadega, Kohan, \& Jarahi, 2016).

Como estrategia educativa se utilizó la "Educación experiencial" (EE) que consiste en vivenciar situaciones similares a la realidad, de acuerdo con objetivos previamente definidos, y luego reflexionar sobre estas situaciones, para lograr el aprendizaje, o sea, el cambio cognitivo, actitudinal y conductual, a partir de la experiencia (Céspedes Lainez, Gonzales Ustrilla, Jacoby Mesina y Santivañez Salazar, 2017, pp. 7273). 
$1 \begin{aligned} & \text { Planteamiento } \\ & \text { del problema }\end{aligned}$ 


\section{Planteamiento del problema}

Hoy en día, el SDO es altamente frecuente en los profesionales sanitarios debido a las cargas laborales excesivas, con turnos que afectan el ciclo vigilia-sueño y que implican el enfrentamiento continuo del sufrimiento y la muerte, en contraste con una retribución salarial relativamente baja en la gran mayoría y la falta de refuerzo social, e incluso desvaloración, por parte de pacientes, compañeros y jefes (Grau et al., 2008, p. 77). La situación es aún más difícil en los paramédicos o tecnólogos en atención prehospitalaria (TAPH) quienes presentan más factores estresantes: necesidad de atención en el menor tiempo posible, con riesgo vital alto, frecuente presión psicosocial de allegados y en situaciones demasiado variadas, complejas e impredecibles, sin contar con el talento humano diverso y los recursos tecnológicos intrahospitalarios, por lo que este síndrome llega a afectar a dos terceras partes de esta población (Sanchez-Vera et al., 2015, pp. 120-121).

Este SDO impacta todas las esferas de la persona produciendo manifestaciones cognitivas: como dificultad para la concentración, memorización, razonamiento y el juicio; manifestaciones emocionales: como distanciamiento afectivo, irritabilidad, ansiedad y depresión; síntomas psicosomáticos: como trastornos dolorosos, del sueño, gastrointestinales, cardiovasculares y fatiga crónica; problemas conductuales: como comportamientos temerarios y abuso de sustancias; repercusiones familiares y sociales: como aislamiento, conflictos, violencia y separaciones; repercusiones laborales: como deterioro del ambiente laboral, del rendimiento y la calidad del trabajo (lo que es muy grave si es en salud y más aún en situaciones críticas de atención prehospitalaria), y puede llevar finalmente a ausentismo laboral y abandono de la profesión (Manging-Valverde y Csizmadia-Viteri, 2017, pp. 9-12).

Dado lo anterior, se hace necesario y urgente encontrar una forma de aumentar la resistencia psicológica en los TAPH ante estas difíciles condiciones laborales, para aportar a la prevención del SDO. Es de resaltar que, al revisar la literatura científica, se encuentra una correlación negativa entre la personalidad resistente (PR) y el SDO (Vagni, Giostra, Maiorano, Santaniello, \& Pajardi, 2020; Ha, 2018; Rajaei, Shafizadeh, Babaeiamiri, \& Amirfakhr, 2017; Park, 2017; 
Rahim-Zadega, Kohan, \& Jarahi, 2016); y en las escasas publicaciones experimentales existentes ha mostrado su utilidad en la prevención del SDO (ver el punto 3.3).

En cuanto a la PR (“hardiness"), esta fue propuesta inicialmente por Suzanne Kobasa y Salvatore Maddi como un conjunto de tres actitudes resistentes (AR) que facilitan el afrontamiento de las crisis psicosociales. La primera es el compromiso, definido como la disposición a dar importancia a la superación de las dificultades en concordancia con los valores personales; la segunda es el control, es decir, la disposición a creer en las propias capacidades para superar las crisis; y la tercera es el reto, que consisten en la disposición a ver los cambios como desafíos que al ser superados aportarán positivamente al crecimiento personal, convirtiendo así los "problemas" en "oportunidades de desarrollo" (Maddi y Martínez-Martí, 2009,pp. 218-219). Posteriormente incluyeron como parte integral de la PR los siguientes factores: (a) afrontamiento resistente, que comprende las estrategias de afrontamiento (EA) para convertir las situaciones estresantes en oportunidad de desarrollo, como son la búsqueda de soluciones y la reevaluación positiva del problema; (b) interacción social resistente, que consiste en solicitar y dar ayuda de los demás, tanto cognitiva para la solución del problema como emocional para el sustento psicológico del afectado, y que otros autores consideran como una de las EA; y (c) autocuidado resistente, que consiste en la adopción de estilos de vida orientados a mantener un buen funcionamiento corporal, tales como: ejercicio regular, dieta apropiada y ejercicios de relajación (Maddi, 2013, p. 9).

Con base en lo anterior, surge la pregunta: ¿cómo desarrollar la PR en TAPH, con la finalidad de aportar a la prevención del SDO? En primer lugar, debe aclararse que, como el autocuidado resistente comprende hábitos de vida, su desarrollo requiere un largo proceso educativo. En cambio, las actitudes resistentes y las estrategias de afrontamiento (incluida la interacción social resistente), sí podrían promoverse con un programa más corto, que podría brindarse con educación experiencial (EE). Esta consiste en un proceso de construcción de conocimiento subjetivo mediante la transformación de la vivencia a través de cuatro etapas: (1) experiencia concreta, en la cual la persona tiene una vivencia diseñada según los objetivos de aprendizaje; (2) observación reflexiva, en la cual se facilita la concienciación de los propios pensamientos, 
emociones y conductas que emergieron durante la experiencia; (3) conceptualización abstracta, en la cual se reflexiona sobre las observaciones con base en la teoría sobre el objeto de aprendizaje; (4) experimentación activa, en la cual se promueve la generación de nuevas formas de pensamiento y acción con base en la reflexión anterior (Kolb \& Kolb, 2009, p. 44). De esta forma, la educación experiencial podría permitir la concienciación las propias actitudes y estrategias de afrontamiento, ante las dificultades laborales, y su desarrollo para disminuir el impacto sobre la persona, lo que constituiría un factor protector del SDO (Céspedes Lainez, Gonzales Ustrilla, Jacoby Mesina, \& Santivañez Salazar, 2017, pp. 72-73).

Sin embargo, no hay investigaciones sobre educación experiencial para el desarrollo de la PR en atención prehospitalaria, interacción que constituye el objeto de investigación de esta tesis. Y este vacío en el conocimiento es a la vez teórico y metodológico, es decir, no hay un planteamiento conceptual que relacione con claridad estos conceptos ni un programa con sustento empírico que demuestre utilidad. Dado todo lo anterior, la pregunta de esta investigación es: ¿cómo debe ser un programa de educación experiencial orientado al desarrollo de la personalidad resistente en estudiantes de atención prehospitalaria, de la Universidad Tecnológica de Pereira (UTP), Colombia? Una vez construido y validado, este programa se constituirá en un modelo que puede ser aplicado a poblaciones similares para aportar a la prevención del SDO, que afecta tan gravemente al personal sanitario y, en especial, al personal de atención prehospitalaria.

Esta investigación fue factible porque se tenía el talento humano (Aspirante a Doctor en Psicología, con apoyo de docentes y de estudiantes de último semestre del Programa Ciencias del Deporte y la Recreación - UTP), la población (estudiantes de atención prehospitalaria de la Universidad Tecnológica de Pereira - UTP), la infraestructura (campus de la UTP) y los recursos logísticos necesarios para su realización. La limitación principal es el tamaño reducido de la muestra a la que se tenía acceso, dados los recursos restringidos, lo que disminuye la generalización de los datos; la otra limitación fue, la no aleatorización en la selección de los grupos experimental y control, fueron grupos preformados, por la necesidad de evitar la contaminación experimental, además de razones logísticas. Al mismo tiempo, sí constituye un primer 
Programa modelo de educación experiencial orientado al desarrollo de personalidad resistente en estudiantes de atención prehospitalaria

avance en la fundamentación teórica que relaciona los conceptos implicados y en el desarrollo de propuestas metodológicas aplicables a esta población que necesita urgentemente el desarrollo de la fortaleza psicológica de la PR. 


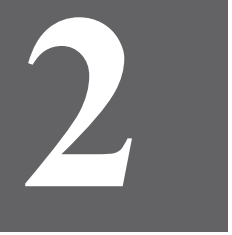

Objetivos 


\section{Objetivos}

\subsection{Objetivo general}

Diseñar y validar un programa modelo de educación experiencial orientado al desarrollo de la personalidad resistente en estudiantes de Atención Prehospitalaria de la Universidad Tecnológica de Pereira, Colombia.

\subsection{Objetivos específicos}

- Identificar las actitudes resistentes en un grupo de estudiantes de Atención Prehospitalaria de la Universidad Tecnológica de Pereira, Colombia.

- Identificar las estrategias de afrontamiento en un grupo de estudiantes de Atención Prehospitalaria de la Universidad Tecnológica de Pereira, Colombia.

- Diseñar un programa de Educación Experiencial orientado al desarrollo de actitudes resistentes y estrategias de afrontamiento.

- Validar el programa de Educación Experiencial orientado al desarrollo de actitudes resistentes y estrategias de afrontamiento en un grupo de estudiantes de Atención Prehospitalaria de la Universidad Tecnológica de Pereira, Colombia. 


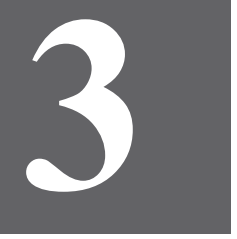

Antecedentes 


\section{Antecedentes}

\subsection{Antecedentes contextuales}

\subsubsection{Atención prehospitalaria en Colombia}

Actualmente, se rige en Colombia por la resolución 926 de 2017 del Ministerio de Salud y Protección Social en el cual se crea el Sistema de Emergencias Médicas (SEM), el cual consiste en un modelo general integrado para brindar una oportuna atención médica de urgencias. El SEM incluye el servicio en salud: notificación, atención prehospitalaria, transporte básico y medicalizado, atención hospitalaria de urgencias y coordinación por parte del Centro Regulador de Urgencias y Emergencias; y también la promoción de educativa y de formación del talento humano (Ministerio de Salud y Protección Social, 2017).

La atención prehospitalaria es un campo emergente en la atención de pacientes lesionados o gravemente enfermos, cobrando mayor grado de importancia en la intervención oportuna y eficaz del personal paramédico y su impacto en la disminución de discapacidades y eventos mortales (Bedoya-Gaviria et al., 2016, p. 1536).

De acuerdo con el Sistema Nacional de Información Superior, actualmente existen 10 programas activos de Tecnología en Atención Prehospitalaria (Ministerio de Educación de Colombia, 2021).

\subsubsection{Programa de atención prehospitalaria de la UTP}

El programa de Atención Prehospitalaria lleva 12 años desde su creación y surgió a partir de las necesidades vividas en y después del terremoto del eje cafetero (departamentos de Caldas, Risaralda y Antioquia) en 1999. La Universidad Tecnológica de Pereira es la única que ofrece este programa en la región, por lo que tiene un gran impacto ya que esta es una zona de muy alto riesgo sísmico. Así, brinda a los Tecnólogos en Atención Prehospitalaria una formación holística en sus dimensiones científicas, tecnológicas y humanistas, acorde con las políticas y directrices de la Universidad (Universidad Tecnológica de Pereira, 2019). 
Esta Tecnología, que actualmente cuenta con unos 220 estudiantes, tiene una duración de 6 semestres académicos y tiene tres énfasis: administrativo, clínico prehospitalario y psicosocial, para garantizar al estudiante una formación integral, investigativa y crítica. Para este Programa es preciso que el estudiante tome su desempeño laboral como un estilo de vida y que asuma un rol fundamental en la cadena de supervivencia básica y avanzada, de forma que se constituya en un líder en la prevención y atención de emergencias, que interioriza los aspectos éticos de su labor con actitud responsable y emprendedora (Universidad Tecnológica de Pereira, 2018).

\subsection{Antecedentes cronológicos}

\subsubsection{Atención prehospitalaria}

A Dominique Jean Larrey (1766-1842) se le llama "el padre de la cirugía militar". Este cirujano francés observó que a los soldados heridos durante las guerras napoleónicas se les dejaba en el campo de batalla hasta después de terminar el combate. Entonces diseñó e implementó el triage (clasificación de pacientes), la atención inmediata de los heridos y el retiro mediante camillas y una carreta denominada "ambulancia voladora". Años después se utilizaron vehículos de transporte de pacientes con cólera en Londres y con diversas urgencias en Estados Unidos. Después de la primera guerra mundial, el presidente de este país, Lyndon B. Johnson, ordenó crear un sistema de atención prehospitalaria de emergencias con equipos y personal capacitado. En la década de 1970, se estandarizó el currículo de formación de los técnicos en emergencias médicas y paramédicos en Estados Unidos (Sanjay \& Abhilash, 2019, p. 42).

En Colombia, antes de 1980, los organismos de socorro Cruz Roja y Defensa Civil recibían un curso corto de primeros auxilios y eran los encargados de atender a las víctimas de desastres, sin un sistema organizado de transporte a los centros asistenciales. En 1988 se ofertó el primer programa de formación en atención prehospitalaria ofrecido por la Universidad del Valle, el cual se fue fortaleciendo con los años y cuyos egresados fueron incorporados inmediatamente en los equipos médicos extramurales, en las centrales de comunicación en salud y en los comités de salud ocupacional de empresas y centros educativos. En 
los años siguientes, se aprobó la legislación correspondiente y varias universidades del país crearon y ofrecieron la formación de tecnólogos en atención prehospitalaria (Ramos, Quintero y Gómez, 2016, pp. 1030). En el año 2007 se crea el Programa de Atención Prehospitalaria de la Universidad Tecnológica de Pereira.

\subsubsection{Educación experiencial}

El psicólogo estadounidense John Dewey (Estados Unidos, 1859-1952) se considera el padre de la educación experiencial. Él proponía que se debía superar el dualismo mente/conducta, de forma que el conocimiento se producía al realizar la comprobación de los pensamientos mediante acciones. Y puso este principio en práctica en la "Escuela Experimental de la Universidad de Chicago" que fundó en 1896, la cual se constituyó como un experimento de democracia. En esta Escuela se crearon las bases de la educación experiencial, al sostener que para el aprendizaje se requiere el involucramiento de los estudiantes a través de experiencias dentro y fuera del aula, en temas relevantes para su presente y futuro, de forma que se facilita la planificación de las acciones y la superación de los obstáculos para alcanzar las metas. Simultáneamente el educador Kurt Hahn (Alemania, 1886-1974) consideraba que debía educarse a las personas para crear una sociedad basada en principios éticos como la honestidad, la responsabilidad, la justicia, la equidad, etc., los cuales se convirtieron en pilares de

la educación experiencial. Él creó en 1920 la Escuela de Salem (que significa paz) y en 1930 publicó su filosofía y método de educación en las "siete leyes de Salem", que incluían: el autodescubrimiento, el conocimiento del fracaso y del éxito, el sacrificio por una causa común, los espacios de reflexión, los juegos con un objetivo, y la comprensión de la pobreza. Antes de la II guerra mundial tuvo que emigrar a Inglaterra y durante la misma creó el programa "Outward Bound" para los marineros británicos, que enfatizaba los retos físicos para el entrenamiento y aprendizaje. Después, este programa se convirtió en una organización independiente que se difundió por el mundo, en la cual son centrales las experiencias reales en excursiones marítimas y de montaña. También el fundador de la psicología social Kurt Lewin (Alemania 1890 - Estados Unidos 1947) aportó bases para la educación experiencial al apartarse de la psicología individualista tradicional y comenzar a teorizar sobre la dinámica de los grupos sociales, con las 
interacciones y procesos de liderazgo y aprendizaje que se dan en su interior. En 1970 Jerry Pieh, director de un colegio de Massachusetts, conocía bien Outward Bound, pero consideraba que era demasiado costoso y largo para sus estudiantes, por lo que adaptó la estrategia al entorno escolar y lo llamó "Project Adventure". En este, el escenario de aventura es simulado, por ejemplo, no se trabaja con las cuerdas de las velas de los barcos sino con "cuerdas altas" colocadas entre árboles o estructuras artificiales. El "Proyecto Aventura" se difundió por el mundo como un modelo de educación basado en experiencias colectivas de reto. Finalmente, David Kolb (Estados Unidos, 1939-) construyó la teoría del "aprendizaje experiencial", en la cual describe cómo las experiencias concretas primero se reflexionan, luego se convierten en generalizaciones y conceptos abstractos, que después se plasman en acciones; una vez realizadas, estas constituyen una nueva experiencia concreta que reinicia el ciclo en espiral, en el cual se va ganando conocimiento con cada vuelta. Así, las experiencias concretas llevan a conceptos y generalizaciones que son útiles para cualificar la conducta y la planeación del futuro. (Cavert, 2012)

\subsubsection{Personalidad resistente}

En 1975, Maddi y Kobasa comenzaron un estudio de 12 años sobre el impacto del estrés en los gerentes de la empresa telefónica de Illinois. En 1981, esta enorme empresa presentó una crisis catastrófica. Estos autores encontraron que todos los gerentes de la empresa estaban sometidos a mucho estrés, pero que los que tenían actitudes, que denominaron: compromiso, control y reto, presentaban menos enfermedad mental y física. El compromiso lo conceptualizaron como la predisposición para involucrarse en las actividades laborales en vez de retirarse; el control, como la predisposición para intentar superar las dificultades en vez de resignarse pasivamente; y el reto, como la predisposición para ver las situaciones difíciles como oportunidades de aprendizaje. En las investigaciones siguientes, estos autores encontraron que el apoyo social, el ejercicio físico y las estrategias a afrontamiento tenían un efecto sinérgico con las actitudes ya identificadas en la amortiguación del estrés, es decir, la presencia de estas variables potenciaba la resistencia psicológica, por encima de la simple suma del aporte de cada uno. Dado esto, determinaron como dimensiones en la PR, que interactúan entre sí como un sistema y que brindaban protección frente 
al estrés, a las siguientes: actitudes resistentes, afrontamiento resistente, apoyo social y hábitos de vida (Maddi, 2002, pp. 173-174).

\subsection{Antecedentes investigativos de EE para PR}

Son muy escasas las investigaciones sobre educación experiencial para la PR, actitudes resistentes o estrategias de afrontamiento. Luego de buscar en los últimos 10 años en las bases de datos Jstor, Oxford University Press, OvidSP, SAGE Publishing, Scopus, Springer y Web of Science, se encontraron las siguientes.

Impacto del método de aprendizaje experiencial en el conocimiento, actitud y estrategias de afrontamiento de los acompañantes de pacientes con cáncer en la sucursal Java de la Fundación contra el cáncerdeIndonesia.Investigaciónpre-experimentalen 27 acompañantes de pacientes con cáncer, a quienes se les brindó un programa de educación experiencial. Se encontró que mejoraron significativamente los niveles de conocimiento y actitud de afrontamiento, pero no las estrategias de afrontamiento (Dewi, Qur'aniati, \& Apriliyanti, 2018). Sin embargo, no se presenta la duración y demás características del programa, sólo se dice que tuvo cuatro partes de 30-45 minutos cada una, dando la impresión de una sola sesión.

Aprendizaje experiencial adaptado para desarrollar habilidades de resolución de problemas en estudiantes de ingeniería sordos y con dificultades auditivas. Investigación experimental con pre y posprueba de grupos preestablecidos de primer año de universidad, 40 estudiantes en el grupo experimental y 34 en el control, con la metodología de intervención planificar-hacer-verificar-actuar, similar a la de Kolb, cuatro sesiones durante un mes. Las habilidades fueron evaluadas por tres jurados mediante consenso y desconociendo la pertenencia de cada estudiante al grupo experimental o control. Se encontró una mejoría del $15 \%$ en la capacidad de resolución de problemas que se mantuvo en el seguimiento a un año (Marshall, Carrano, \& Dannels, 2016).

Manejo del estrés en la clase de educación física: un enfoque experiencial para mejorar las habilidades de afrontamiento y reducir la percepción del estrés en los adolescentes. Se brindó un programa educativo con enfoque experiencial orientado a mejorar 
el afrontamiento en estudiantes de educación física, 4 grupos experimentales y 4 grupos control. No menciona el número de sesiones. Se encontró mejoría estadísticamente significativa después de la intervención y en el seguimiento a los 6 meses y disminución del estrés por el desarrollo de las habilidades de afrontamiento (Lang et al., 2015, p. 149).

Efectos de estrategias de aprendizaje experiencial en la capacidad de resolución de problemas de adolescentes desde la perspectiva de la personalidad resistente ("hardiness"). Investigación experimental aleatorizada y controlada con pre y posprueba, con un diseño factorial de 2 × 2, a 260 estudiantes adolescentes, con alto y bajo nivel de personalidad resistente. Se brindó educación experiencial al grupo experimental y enseñanza tradicional al grupo control, 40 sesiones de 1 hora durante 50 días. Se encontró interacción estadísticamente significativa entre personalidad resistente y educación experiencial, de forma que el grupo con alta personalidad resistente y educación experiencial mejoró significativamente su capacidad de resolución de problemas en relación con el grupo de baja personalidad resistente y enseñanza tradicional (Bansal, 2014).

Afrontamiento y bienestar psicológico de los jugadores universitarios de rugby. Investigación mixta exploratoria secuencial, en que se realizó un estudio cualitativo exploratorio (con ensayos y entrevistas individuales y a grupos focales) para determinar los temas críticos por trabajar en relación con el afrontamiento y bienestar psicológico; y luego, con esta base, uno experimental controlado con pre y posprueba para determinar la eficacia de la intervención. A 41 jugadores universitarios de rugby se les brindaron seis sesiones de 1 hora durante 2 semanas de aprendizaje experiencial en estrategias de afrontamiento: motivación, establecimiento de objetivos, manejo del tiempo, afrontamiento de lesiones, afrontamiento centrado en las emociones y zona individual de funcionamiento óptimo. Se aplicaron cinco escalas: afectómetro, escala de autoeficacia de afrontamiento, escala de actitud proactiva, cuestionario de fortaleza y cuestionario de evaluación cognitiva; y se realizaron ensayos y entrevistas a grupos focales de jugadores, y entrevistas individuales a entrenador y psicólogo deportivo. El grupo experimental mostró mejorías significativas en todas las estrategias, en comparación con el grupo control (Laureano, 2008). 
En síntesis. En las cinco investigaciones experimentales encontradas, se encontró útil el aprendizaje experiencial para mejorar la personalidad resistente o las habilidades de resolución de problemas, excepto en la de Dewi con estrategias de afrontamiento, pero en esta no se presenta el programa implementado por lo que es difícil de valorar su validez. De todas formas, son muy pocas las investigaciones experimentales publicadas como para asegurar la eficacia del aprendizaje experiencial en la PR, por lo que se requieren más estudios de calidad.

Número de sesiones. Se observa que en la investigación de Dewi se utilizó una sola sesión y mostró eficacia parcial, y la de Marshall, 4 sesiones y mostró eficacia. Al revisar la literatura relacionada, se encuentra que cuatro sesiones de educación experiencial han mostrado ser eficaces para generar cambios en variables psicológicas, por ejemplo: (Siami-Namin, Flores, Tavakoli, Siami-Namin, \& Jones, 2021; Bianco, y otros, 2019; Peterson-Ahmad, 2018; Alvarez \& Jobst-Hendrik, 2018; Barta, Flores, \& Edwards, 2018). 


\section{$\triangle$ Fundamentación \\ Teórica}




\section{Fundamentación teórica}

\subsection{Estrés laboral}

La palabra "estrés" se utilizaba originalmente en la física para referirse al desgaste o deformación de materiales por agentes externos; luego el fisiólogo norteamericano Walter B. Cannon lo aplicó con similar significado en relación con el cuerpo humano (Cruz-Pérez, 2018, pág. 605). La Asociación Psicológica Americana (2020) define "estrés" como la respuesta psicológica o fisiológica a estresores internos o externos.

Sin embargo, esta relación estresor/respuesta está mediada por una valoración cognitiva: una situación puede interpretarse positivamente, como un reto, por lo que el organismo se prepara para superarla y constituye así un estrés que ayuda a la persona a enfrentar las circunstancias, lo que se ha denominado "eustrés"; en cambio, la situación puede interpretarse negativamente y generar emociones negativas (como temor, tristeza, frustración, etc.), lo que produce malestar psicológico y disminuye la capacidad de la persona para enfrentar el suceso, lo que se ha denominado "distrés". En la actualidad, este último es frecuente por el estilo de vida occidental, en el que se exige a las personas estudiar o trabajar demasiado y con excelencia, lo que va deteriorando con el tiempo su capacidad psicofísica (Moscoso, 2015).

En relación con el estrés específicamente en el espacio laboral, los modelos más utilizados para estudiarlo son: demanda-control de Karasek y esfuerzo-recompensa de Siegrist (Osorio y Cárdenas-Niño, 2017).

\subsubsection{Modelo demanda-control-apoyo social de Karasek}

El modelo "demanda-control" de Robert Karasek hace referencia a la tensión psicológica crónica, inmersa en de la complejidad de las organizaciones humanas productivas, que no amenaza directamente la existencia sino la calidad de vida de las personas. Este investigador propone que el estrés laboral depende de dos variables: las demandas psicológicas, provenientes de la carga intrínseca de trabajo y de la 
exigencia del entorno social laboral, y la libertad de decisión, que abarca las habilidades personales y la posibilidad de control de las actividades; este último se refiere a la autonomía del trabajador tanto para elegir la forma de realización de las tareas asignadas como para participar en espacios sociales que ayudan a liberar la tensión, como la pausa para el café. En este modelo cuando las demandas laborales son altas pero la libertad de decisión es baja, se produce tensión excesiva con consecuencias negativas sobre la salud mental y física de las personas. En cambio, cuando estas demandas son altas (no excesivas) y la libertad de decisión también lo es, se da un estado activo de elección y aprendizaje de estrategias efectivas de afrontamiento, con una apropiada resolución de problemas y motivación laboral, y poca tensión residual. Finalmente, las situaciones de baja demanda y bajo control producen desmotivación $\mathrm{y}$, a la larga, impotencia aprendida porque los superiores no aceptan las iniciativas del trabajador, lo que genera finalmente tensión laboral. Todo esto puede resumirse en la siguiente figura (Karasek, 1998, pp. 34.6-34.7).

Figura 1. Modelo de demanda psicológica vs. libertad de decisión de Karasek.

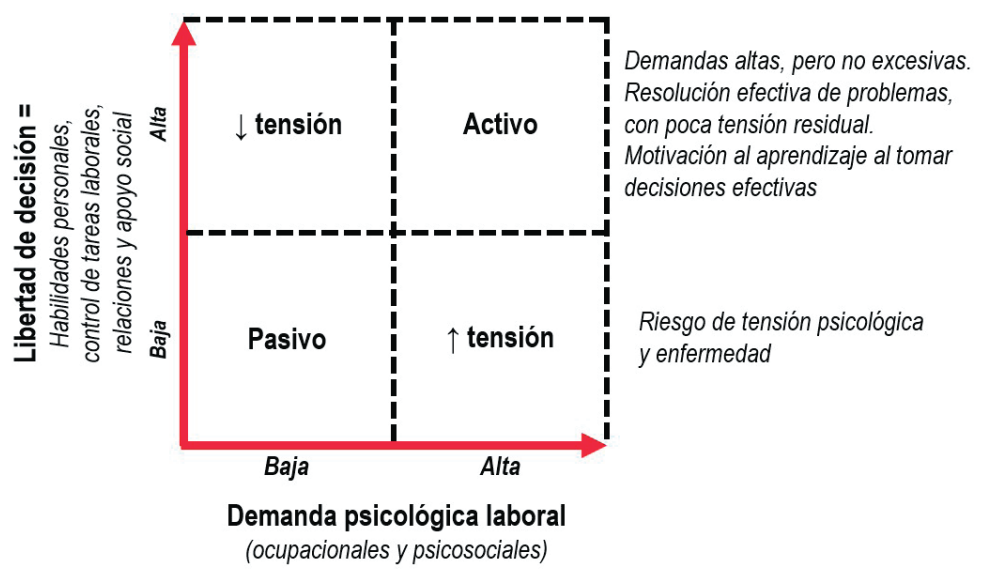

Nota. Adaptado de: "Demand / control model: a social, emotional, and physiological approach to stress risk and active behaviour development", por Robert Karasek, R. (1998), en J. M. Stellman, Encyclopaedia of occupational health and safety (p. 34.7), Geneva: International Labour Organization. 
Karasek, además, enfatiza el efecto positivo del apoyo social, esto es, afirma que una apropiada interacción social y emocional permite soportar mejor el estrés; por lo tanto, los trabajos más tensionantes, y por lo mismo con mayor riesgo de enfermedad subsecuente, son lo que tienen alta demanda, bajo control y bajo apoyo social. Por esta razón, se incorporó a su modelo como una nueva dimensión: demanda-controlapoyo social (Karasek \& Töres, 1990, p. 75).

Este modelo sobre estrés laboral ha tenido una amplia aceptación y es el que ha sido más investigado, con al menos 106 estudios (Luchman \& González-Morales, 2013, p. 2). Sin embargo, se le ha criticado que la mayoría de las investigaciones están basadas en autoinformes y no en mediciones objetivas, que son transversales y no longitudinales, y con inconsistencias en la forma de medición (Fila, 2016, p. 15). No obstante, se ha encontrado la asociación esperada, esto es, "control" y "apoyo" están fuertemente relacionados con "satisfacción laboral", y "demandas" con "agotamiento" (Fila, Purl, \& Bracken, 2013).

\subsubsection{Modelo de desequilibrio esfuerzo-recompensa de Siegrist}

Según este modelo, el estrés crónico laboral se produce por el desequilibrio entre un alto costo y una baja ganancia, lo que lleva a alteraciones emocionales como depresión y físicas como enfermedad coronaria. Esto es más evidente en el modo de producción actual con altas demandas psicosociales en contraste: con bajas recompensas financieras, escasas recompensas sociales (falta de seguridad y promoción laboral) y débiles recompensas socioemocionales (poco reconocimiento al buen desempeño). Se ha encontrado que este desequilibrio impacta el sistema cerebral de esfuerzo/recompensa inhibiendo la producción de los neurotransmisores del placer y la satisfacción, como dopamina y oxitocina, que atenuarían el estrés. Y este último se incrementa más aún si se impide al trabajador tener control sobre las decisiones que le atañen (Siegrist, 2016).

Se han realizado múltiples investigaciones que sustentan estas afirmaciones y cómo este desequilibrio esfuerzo/recompensa produce un estrés crónico que afecta los sistemas nervioso autónomo, endocrino, inmunitario y cardiovascular, y genera trastornos depresivos (Siegrist \& Wahrendorf, Work stress and health in globalized economy: the model 
of effort-reward imbalance, 2016). En esta línea, se ha encontrado asociación significativa del desbalance esfuerzo/recompensa con: la producción de colesterol (Penz et al., 2019), el síndrome de desgaste ocupacional (Jachens, Houdmont, \& Thomas, 2019) y el síndrome de desgaste académico (Kim, Kim, \& Lee, 2017); en este último se encontró que las estrategias de afrontamiento centradas en el problema tuvieron un efecto moderador tanto del desequilibrio esfuerzo/recompensa como del desgaste académico.

\subsubsection{Sindrome desgaste ocupacional (SDO)}

De acuerdo con la Organización Mundial de la Salud:

Es un síndrome conceptualizado como resultado del estrés crónico en el lugar de trabajo que no se ha manejado con éxito. Se caracteriza por tres dimensiones: 1) sentimientos de falta de energía o agotamiento; 2) aumento de la distancia mental con respecto al trabajo, o sentimientos negativos, o cínicos con respecto al trabajo; y 3) eficacia profesional reducida. E1 síndrome de desgaste ocupacional se refiere específicamente a los fenómenos en el contexto laboral y no debe aplicarse para describir experiencias en otras áreas de la vida (2018, pág. QD85).

Según lo anterior, el estrés laboral crónico puede llevar al SDO o burnout que comprende: agotamiento, que es el sentimiento de consunción de los recursos emocionales y físicos que aparece en el transcurso de muchos años de sobrecarga y excesivo estrés laboral; cinismo, que es la actitud de desapego del trabajo como una forma de autoprotección, un "amortiguador emocional", pero que puede convertirse en hostilidad y deshumanización, y constituye la dimensión interpersonal del síndrome; e ineficacia profesional, que es la disminución en la evaluación de la autoeficacia, la apreciación de una disminución en la propia capacidad productiva. Diversos investigadores han propuesto reducir las dimensiones quitando la ineficacia profesional, o esta y el cinismo; sin embargo, dejar sólo la primera ya no sería SDO sino sólo "agotamiento crónico", dado que el concepto de SDO implica la desconexión emocional con las personas y con el trabajo. Al mismo tiempo, se ha propuesto su relación con el concepto "compromiso", de 
forma que para algunos es el extremo opuesto de un continuum; sin embargo, se considera más bien que este es un concepto independiente, aunque sí relacionado negativamente con el SDO (Maslach \& Leiter, 2016, pp. 351-353).

Por otro lado, se han identificado seis características de la vida laboral que tienen una relación directa con la aparición del SDO, que son los siguientes. La carga de trabajo, cuando es crónica, excesiva y con poco descanso. El control, cuando hay baja o nula autonomía y recursos en relación con las actividades laborales. La comunidad, cuando hay apoyo social escaso, interacción problemática y dificultad para resolver conflictos. La equidad, cuando cada cual no recibe según sus méritos sino según otros intereses. La retribución, cuando esta es insuficiente en relación con su nivel de esfuerzo. Los valores, que implica la desconexión motivadora entre los valores del trabajador y los objetivos de la organización. (Maslach \& Leiter, 2016, págs. 354-355) Aunque los conceptos estrés y SDO están relacionados, presentan unas diferencias importantes. El estrés se origina a partir de amenazas de muy diversa índole que aparecen a veces en forma impredecibles, se desarrolla rápidamente, $\mathrm{y}$ puede impactar en forma positiva o negativa, según su intensidad y duración, a nivel fisiológico y psicológico. En cambio, en el SDO las amenazas son laborales, relativamente estables y predecibles, se desarrolla a lo largo de varios años y siempre impactan en forma negativa, básicamente a nivel psicosocial (Xu, Wang, Guo, \& Jiang, 2012). Además, mientras que en el estrés hay una excesiva implicación laboral y una hiperactividad fisiológica, en el SDO la implicación está reducida y, en vez de la hiperactividad fisiológica, hay un desgaste básicamente emocional (López-González, Posadas-Tello, \& León-Noris, 2018).

\subsection{Personalidad resistente (PR)}

\subsubsection{Fundamentos de psicología existencial}

La psicología existencial es una aproximación a la comprensión e intervención del comportamiento humano, proveniente de la psicología y la filosofía como una alternativa a los determinismos conductista y psicoanalítico, que afirma que el ser humano es libre de hacer elecciones según sus propias motivaciones (Vicente-Pestana, 2017, p. 124). 
La psicología existencial se fundamenta en los siguientes conceptos. Actitud natural: los seres humanos asumen el mundo como un hecho tal como lo perciben, sin concientizar necesariamente que es una interpretación del mundo lo que realmente están haciendo ni reflexionar sobre esto. Intencionalidad: los seres humanos siempre se relacionan con el mundo de acuerdo con un propósito y, de acuerdo con este, lo interpretan, dotándolo así de un significado personal; por lo tanto, sólo se entiende la conducta si se comprende su sentido en la conciencia de la persona. Co-construcción: los seres humanos no están separados del mundo sino inmersos en él, de forma que al interactuar con el mundo se produce una influencia mutua de creación en ambos sentidos (DeCastro-Correa, García-Chacón, \& González-Ternera, 2017, pp. 16-19).

\subsubsection{Concepto de PR}

Maddi refiere que consideraron que la psicología existencial era un fundamento más apropiado para la PR que el psicoanálisis y el conductismo, que eran las corrientes imperantes en esa época, ya que estas tienen un carácter determinista. En cambio, para la psicología existencial las personas tienen libertad de interpretar la realidad e ir tomando decisiones de acuerdo con su propósito de vida y en interacción con los otros, aunque una vez creadas las interpretaciones se requiere de concienciación y esfuerzo para cambiarlas. Esto sustenta la posibilidad de desarrollar la PR a través de programas orientados a la interpretación y toma de decisiones acordes con las cuatro dimensiones de la PR, como evidenciaron en un programa de 15 sesiones con gerentes (2002, pp. 175-176).

El modelo actual de PR comprende: actitudes resistentes, afrontamiento resistente, apoyo social resistente y prácticas resistentes en salud; estas últimas abarcan: relajación, nutrición, ejercicio y medicación (Maddi, 2013). Como se verá más adelante, en esta investigación se trabajarán sesiones grupales que se orientarán hacia la mejoría en las actitudes, afrontamiento y apoyo social resistentes, ya que se pueden concientizar y reflexionar para promover su cualificación, pero no en las prácticas resistentes en salud que exigen otros escenarios, orientación y duración. Se describirán enseguida las actitudes, afrontamiento y apoyo social resistentes. 


\subsubsection{Actitudes resistentes}

"Actitud" es la predisposición derivada de la evaluación general y relativamente estable de un determinado elemento, de negativa a positiva, que está integrada por cogniciones, emociones y conductas en relación con este, pero que pueden cambiar mediante reaprendizaje (Corsini, 2016; American Psychological Association, 2010).

La PR comprende las actitudes de compromiso, control y reto. El compromiso es la predisposición para buscar soluciones a los problemas que se le presentan a la persona en su vida cotidiana y laboral, siguiendo sus valores y metas personales, por lo que considera necesario implicarse en vez de renunciar, aunque la situación sea muy estresante. El control es la predisposición para considerar las propias capacidades como suficientes para solucionar estos problemas, de forma que se buscan sus causas, se identifica la propia participación en ellos y se interviene para cambiar favorablemente su curso, en vez de dejarse llevar por la impotencia y la pasividad. El reto es la disposición para ver los problemas como desafíos por superar, esto es, oportunidades de desarrollo de las propias capacidades con la satisfacción consecuente, en vez de verlos como amenazas aplastantes, por lo que se considera la vida como naturalmente estresante (Maddi, 2013, p. 8).

Numerosas investigaciones muestran una correlación negativa significativa entre PR y SDO, tanto en forma global como en sus componentes, de forma que altos niveles de PR se correlacionan con bajos niveles de SDO, por lo que se sugiere implementar programas orientados a mejorar la PR para prevenir el SDO, tal como muestran los siguientes estudios en: médicos (Tarrillo Mendoza, 2016, p. 5; Liping, Xuhong, \& Shilin, 2016); enfermeras (Babaieamiri, Gaghighatdost, \& Ashori, 2016, p. 120; Babaeiamiri, 2016, p. 1; Park, 2017, p. 397; Hatamipour, Hoveida, Rahimaghaee, Babaeiamiri, \& Ashoori, 2017, p. 22; Rajaei, Shafizadeh, Babaeiamiri, \& Amirfakhr, 2017, p. 1); consejeros en salud mental (Richards, 2017, pp. 71-72); cuidadores de pacientes con discapacidad mental (Asli-Azad, Rajaei, Farhadi, \& Aghasi, 2017, p. 24); estudiantes de internado (Fahmi \& Widyastuti, 2018, p. 66); bibliotecarios (Hosseinzadeh-Bandaghiri, Seyd-AliAsghar, \& Fazelli, 2018, p. 479); mandos medios (Ayala Calvo \& Manzano García, 2018, p. 362); y agentes de policía (Septilla \& Syifa Maryanti, 2020, p. 127). 
Sin embargo, se requiere un nivel alto de las tres dimensiones para que actúe como factor de prevención del SDO, ya que las personas solamente con un alto compromiso se involucrarían en la solución de problemas, pero con una actuación sin eficacia y sin reflexión ni aprendizaje; un alto control solamente llevaría a las personas a solucionar problemas, pero sin sentirse realmente involucrados ni buscar el desarrollo de sus capacidades; un alto reto sería un gran impulso hacia la novedad, pero sin eficacia ni compromiso con sus valores y proyecto de vida (Maddi, 2013, pp. 8-9; Ladstätter, y otros, 2018, p. 1).

Adicionalmente, en un estudio sobre resistencia al agotamiento en enfermeras, se encontró que cuando los estresores son débiles, el impacto psicológico también es débil, indistintamente del nivel de PR; en cambio, cuando los estresores son fuertes, el impacto aumenta drásticamente en individuos con baja PR (Ladstätter, Garrosa, \& Dai, 2014).

Se encontraron solo dos investigaciones de tipo experimental sobre PR y SDO. Una tenía un diseño controlado y aleatorizado en 50 personas, a las que se les brindó 12 sesiones de 90 minutos de "instrucción" (sin más detalle en el informe) acerca de la PR; en la posprueba se encontró disminución del nivel de SDO e incremento en el desempeño (Farahani, Soufi, Keshavarz, \& Bastami, 2014). La otra tenía un diseño controlado con 30 empleadas hospitalarias, que participaron en 8 sesiones de 45 minutos, 3 por semana, según el "modelo cubano Sah" de entrenamiento en PR ( $\sin$ más detalle); en la posprueba se observaron diferencias significativas entre ambos grupos en satisfacción con la vida $(\mathrm{p}<0.001)$, SDO $(\mathrm{p}=0.007)$ y calidad de vida $(\mathrm{p}<0.001)$ (Pazan \& Esfahani-Asl, 2019).

\subsubsection{Afrontamiento resistente}

Hay dos acepciones en el concepto de afrontamiento. La primera considera que los "estilos de afrontamiento" son las disposiciones habituales que tiene cada persona para enfrentar las situaciones amenazantes y cada estilo abarca diversas estrategias. La segunda propone que las "estrategias de afrontamiento" son los procesos de manejo de las amenazas con los recursos de que se dispone, lo que implica evaluaciones sucesivas de la situación y conductas de respuesta. 
Sin embargo, estas acepciones no son excluyentes porque cada persona tiene unas disposiciones habituales para enfrentar situaciones amenazantes, pero estas no son rasgos inamovibles de la personalidad, sino que se deben adaptar según la evaluación de las circunstancias (Otero-López, 2015, pp. 391-395).

Históricamente, Abascal fue uno de los primeros en estudiar las estrategias de afrontamiento y las agrupó en estilos, definidos como tendencias preferidas de responder ante el estrés, de acuerdo con tres criterios. El primero es el "método" que incluye: estilo de afrontamientos activo, cuando hay esfuerzo; pasivo, cuando hay inhibición de la acción; o de evitación, cuando se intenta huir del problema y sus consecuencias. El segundo es el "foco" del afrontamiento: en la solución del problema, en el control emocional o en la evaluación de la situación. El tercero es el "tipo de actividad": cognitiva o conductual. La combinación de los anteriores arroja 18 estrategias de afrontamiento. (Fernández-Abascal y Palmero, 1999, p. 10) Sin embargo, desde entonces se han realizado análisis factoriales que muestran un menor número de estilos; luego de una amplia revisión teórica se presenta el siguiente resumen.

Afrontamiento enfocado en el problema. Abarca a su vez dos subestilos. (1) Orientado a la resignificación, que incluye las estrategias orientadas al cambio en la apreciación del problema y, por lo tanto, al manejo inteligente de las emociones, para evaluar el problema como positivo y promotor del desarrollo personal. (2) Orientado a la solución del problema, incluye las estrategias de análisis racional de la situación, y de planeación y ejecución de opciones de solución. Este estilo enfocado en el problema se correlaciona con un bajo estrés y, coherentemente, con un menor riesgo de SDO.

Afrontamiento enfocado en el apoyo social. Abarca las estrategias orientadas a buscar la ayuda de los demás, sea soporte emocional o aportes cognitivos a la solución del problema, que requiere la utilización de una comunicación asertiva para pedir ayuda. Igualmente, implica brindar ayuda a los demás en una actitud cooperativa, no competitiva, de trabajo colectivo. Aunque los estudios sobre afrontamiento lo incluyen como uno de los estilos de este, Maddi lo considera tan importante que pone el "apoyo social resistente" como un componente separado de la PR. Este tipo de afrontamiento también favorece la disminución del estrés. 
Afrontamiento enfocado en la evitación. Abarca tres subestilos. (1) Orientado a la evitación cognitiva, que incluye las estrategias de negación, desconexión mental (mediante pensamientos distractores) y distanciamiento emocional del problema. (2) Orientado a conductas pasivas, como son la evitación comportamental (no actuación), procrastinación y aceptación precoz del fracaso. (3) Orientado a conductas activas, incluyendo la desconexión comportamental (mediante actividades distractoras) y la realización de acciones placenteras pero perjudiciales, tales como comer en exceso, beber o fumar. Este estilo de afrontamiento evitativo se correlaciona con alto estrés y mayor riesgo de SDO.

Afrontamiento enfocado en las emociones negativas. Solo algunos análisis factoriales incluyen las estrategias centradas en la experimentación propia o manifestación a otros de las emociones negativas vivenciadas, que se correlacionan con mayor estrés y riesgo de SDO.

Referencias utilizadas para esta revisión sobre afrontamiento resistente. (Tanta-Luyo, Quispe-Fernández, Serpa-Barrientos y Ardiles-Guevara, 2019; Quezada-Berumen, Moral de la Rubia, IbarraGonzález y González-Ramírez, 2018; Alva López y Yánac Cierto, 2017, p. 59; González-W, Ortega-de-Gómez, Castillo-de-Lemos, Whetsell y Cleghorn Spencer, 2017; Lo, 2017; Zorrilla-Antaurco, 2017; GómezMaqueo, Durán-Patiño y Romero-Godínez, 2016; García-Conde, Miaja-Avila, Romero-Retes, Ibáñez-Guerra y Soriano-Pastor, 2016; Reich, Costa-Ball y Remor, 2016.

Religión. La estrategia de afrontamiento "religión" se ha mostrado inconsistente, ya que en algunos estudios corresponde a un afrontamiento dirigido al problema y por lo tanto útil, pero en otros a un improductivo afrontamiento de evitación (González y Landero, 2007, p. 193). Se ha encontrado que esto se debe a que "religión" no es una variable unidimensional, sino que el afrontamiento religioso comprende dos tipos: el activo, en que se actúa ante el problema mientras la creencia de la existencia y presencia de Dios da soporte emocional; y el pasivo, en que se evita actuar dejando toda la responsabilidad de la solución del problema a Dios. Estos corresponden a los estilos de afrontamiento enfocado en el problema y en la evitación, respectivamente, el primero 
disminuye el estrés y el segundo no (Fabricatore, Handal, Rudio, \& Gilner, 2004). Esto es coherente con otras investigaciones sobre el tema, como metaanálisis (Ano \& Vasconcelles, 2004), estudios longitudinales (García, Páez, Reyes-Reyes y Álvarez, 2017), estrés en adolescentes (Van Dyke, Glenwick, Cecero, \& Kim, 2009) y síndrome de SDO (Montestruque Orbegoso, 2018, p. 23).

Humor. La estrategia de afrontamiento "humor" también es multidimensional e incluye cuatro tipos diferentes. Los positivos son: autoafirmativo, que fortalece el yo, y afiliativo, que fortalece las relaciones con los demás; los negativos son: autodescalificativo, que debilita el yo, y agresivo, que debilita las relaciones con los demás (Martin, Puhlik-Doris, Larsen, Gray, \& Weir, 2003). Estos tipos de humor corresponden a los estilos de afrontamiento: enfocado en el problema, en el apoyo social, en la evitación y en las emociones negativas, respectivamente (Lillo, 2007, pp. 105-107). Coherentemente, los dos positivos se relacionan con mayor involucramiento ("engagement") y menor SDO (Van den Broeck, Van den Broeck, Dikkers, De Lange, \& De Witte, 2012).

\subsubsection{Actitudes y afrontamiento resistente}

El "afrontamiento resistente", como parte de la "personalidad resistente", se refieren a las formas de hacerles frente a los eventos estresantes: encararlos, buscarles los aspectos positivos, pedir ayuda, evitarlos o inmovilizarse centrándose en las propias emociones, lo que corresponde a las opciones observadas en el mundo animal: lucha, huida o congelamiento, que esencialmente son actitudes más que estrategias cognitivas (Almario, 2016, p. 9). Coherentemente, las actitudes de personalidad resistente (compromiso, control y reto) y las estrategias de afrontamiento, agrupadas en estilos, están asociados significativamente (Ainan \& Coralia, 2016); (Jamal, 2017, p. 141). Así, los estilos de afrontamiento hacen referencia a la actitud natural de las personas en sus vidas cotidianas, que tiene como intención resolver de la mejor forma una situación estresante que se le presenta y cuya actuación consecuente lleva a una forma de construcción de la realidad social, por lo que tienen, igual que las actitudes de personalidad resistente, un fundamento fenomenológico existencial (Castro-Correa, GarcíaChacón y González-Ternera, 2017, p. 17). 
Al revisar la psicología existencial se encuentra que esta se centra en la búsqueda de sentido del ser humano, pero no desde la necesidad de alcanzar una idea comprensiva universal que explique la esencia en sí del hombre (idealismo), ni desde la reducción del ser humano por un materialismo que lo describe como un fenómeno cosificado (un ente biológico por un lado y una mente por otro lado), sino hacia la búsqueda de sentido que el ser humano tiene de su existencia. Para hacer una diferenciación, mientras la psicología cognitiva centra la experiencia humana en un acto de la mente, la psicología existencial se enfoca en la existencia ontológica, en lo corporal como intermediario para una necesidad interna de la existencia, lo que implica considerar a la persona como un ser integral, situado en el contexto, activo frente a este, con una percepción profunda y compleja de su yo con el entorno (Dasilva, 2010).

\subsection{Necesidades psicológicas}

Se ha propuesto que las necesidades psicológicas son el resultado de la evolución porque han permitido la sobrevivencia del ser humano, ya que nuestros antepasados necesitaban: ser competentes en la modificación del medio, como la vivienda, el vestido y las herramientas de caza; tener autonomía para poder identificar y desarrollar las habilidades individuales, en que cada uno tenía un mejor desempeño, llevando así a una mayor efectividad en las labores de supervivencia grupal; y afiliarse, dado que en el período de la infancia se requiere el apoyo del familia y clan, y que la sinergia del trabajo en equipo hace más eficiente y eficaz la búsqueda de la supervivencia. Así, se definieron como necesidades psicológicas: competencia, autonomía y afiliación (Cirino-Gerena, 2013, pp. 131-136).

\subsubsection{Motivación intrínseca}

Estas necesidades fueron presentadas por primera vez por Ryan y Deci en un largo proceso investigativo para especificar los factores implicados en la motivación intrínseca. Si bien la motivación hace relación a los procesos que brindan energía intensa y persistente al comportamiento en dirección a un determinado logro, la motivación intrínseca se refiere más específicamente a la tendencia innata de los seres humanos al ejercicio y desarrollo de las propias capacidades, por lo 
que es una motivación "autotélica", es decir, es en sí misma gratificante independientemente de las recompensas extrínsecas. En primer lugar, se encontró la necesidad de competencia; pero en estudios posteriores encontraron que esta última se satisfacía sólo si iba acompañada de la percepción de la autodeterminación de la conducta, lo que corresponde a la necesidad de autonomía, y que las personas que tenían relaciones estrechas y seguras desde la infancia tenían una mayor motivación intrínseca, lo que corresponde a la necesidad de afiliación (Ryan \& Deci, 2000). Estas mismas necesidades siguen vigentes actualmente. Frustrar cualquiera de estas tres necesidades básicas se ha encontrado perjudicial para la motivación y el bienestar (Ryan \& Deci, 2020, pág. $1)$.

\subsubsection{Autonomía}

La necesidad psicológica de autonomía o autodeterminación hace referencia al deseo ser el protagonista o agente causal principal de la propia conducta, de iniciarla y regularla, según los propios valores, intereses y deseos. Hoy en día se considera como el componente principal de la motivación intrínseca porque es el que organiza y da fuerza a la acción. La autonomía depende de tres cualidades experienciales: (1) locus de control, que es el lugar percibido de causalidad de la conducta y va en un continuo de lo interno a lo externo; (2) volición, que es la libertad de acción y va de libre a coaccionada; (3) elección percibida, que es la posibilidad de optar entre varias opciones y va de ilimitadas a ninguna. Hay más autonomía a más interno sea el locus de control, más libertad de acción y mayores opciones de elección. (Obergoso, 2016) Hay ambientes sustentadores de autonomía, con relaciones y contexto sociocultural que facilitan la satisfacción de esta necesidad: tienen la disposición a tomar en cuenta la perspectiva del otro y fomentar la conducta a partir de sus propios intereses, explicando por qué una tarea dada es coherente con sus intereses y, por lo mismo, amerita su tiempo y esfuerzo, lo que lleva finalmente a un mayor compromiso; los ambientes controladores son lo contrario (Reeve, 2010, págs. 109-112).

\subsubsection{Afiliación}

Es la necesidad psicológica de crear y mantener vínculos emocionales cercanos con otras personas, y compartir su intimidad de forma auténtica, afectuosa y significativa, lo que produce bienestar, resistencia al estrés 
y menor incidencia de alteraciones psicológicas. Para sostenerse se requiere la percepción de que la otra persona se interesa y siente afecto por uno, tal como uno es, siendo la calidad de las interacciones mucho más importante que la cantidad de estas. Se incluyen aquí, en general, la familia, las amistades y las relaciones románticas (Reeve, 2010, págs. 119-120).

\subsubsection{Competencia}

La necesidad psicológica de competencia hace referencia al deseo de ejercer las propias habilidades para superar las dificultades en forma eficaz, para lo cual se precisa de realimentación positiva y desafío óptimo.

Realimentación positiva. Para obtenerla se requiere que haya una estructura clara, que es la información acerca de la tarea y la meta que se espera, de manera que se pueda dar una percepción de progreso; de esta forma, se puede obtener realimentación de la tarea misma, del propio desempeño actual en comparación a como era antes o con el de los demás, o de la evaluación de los otros. También requiere alta tolerancia al error para que no se asuma como fracaso, lo que genera temor y conductas de evitación, sino como aprendizaje, en el sentido de que el error es parte del proceso, es decir, no se pueden alcanzar metas importantes si no se comenten errores en el camino (Reeve, 2010, págs. 118-119).

Desafío óptimo. Hay dos factores en relación directa con la necesidad de competencia: la dificultad del desafío y las habilidades personales. Cuando la dificultad es baja, sea baja o alta la habilidad, aparece aburrimiento y apatía porque no supone un reto real, lo que es difícil de mantener durante un tiempo prolongado. Cuando la dificultad del desafío es alta y las habilidades son bajas aparece ansiedad y frustración por la imposibilidad de superarlo. Cuando ambas son excesivamente altas, sí se alcanza a vencer las dificultades, pero con el tiempo aparece cansancio emocional por el sobreesfuerzo que exige (Reeve, 2010, págs. 114-119). En cambio, cuando dificultad y habilidad son de nivel medio o alto, el desafío es óptimo por lo que la persona experimenta una "sensación de flujo" muy satisfactoria y se siente motivada a continuar. 


\subsubsection{Experiencia de flujo}

Esta "experiencia de flujo" fue propuesta por Csikszentmihalyi como un cuarto elemento de motivación intrínseca. La describe como el estado subjetivo caracterizado por: intensa concentración en la actividad presente, de forma que hay una disminución de la percepción del cansancio y del paso del tiempo, sensación de control sobre las dificultades propias de la actividad y alto nivel de gratificación en la realización de la actividad independiente del objetivo final o de las recompensas, por lo que la persona actúa a plena capacidad. Además, las investigaciones muestran que no sólo mejora el rendimiento, sino que protege contra resultados negativos (Nakamura \& Csikszentmihalyi, 2009, págs. 195-196).

Figura 2. Modelo de flujo, según Reeve (2010, p. 116).

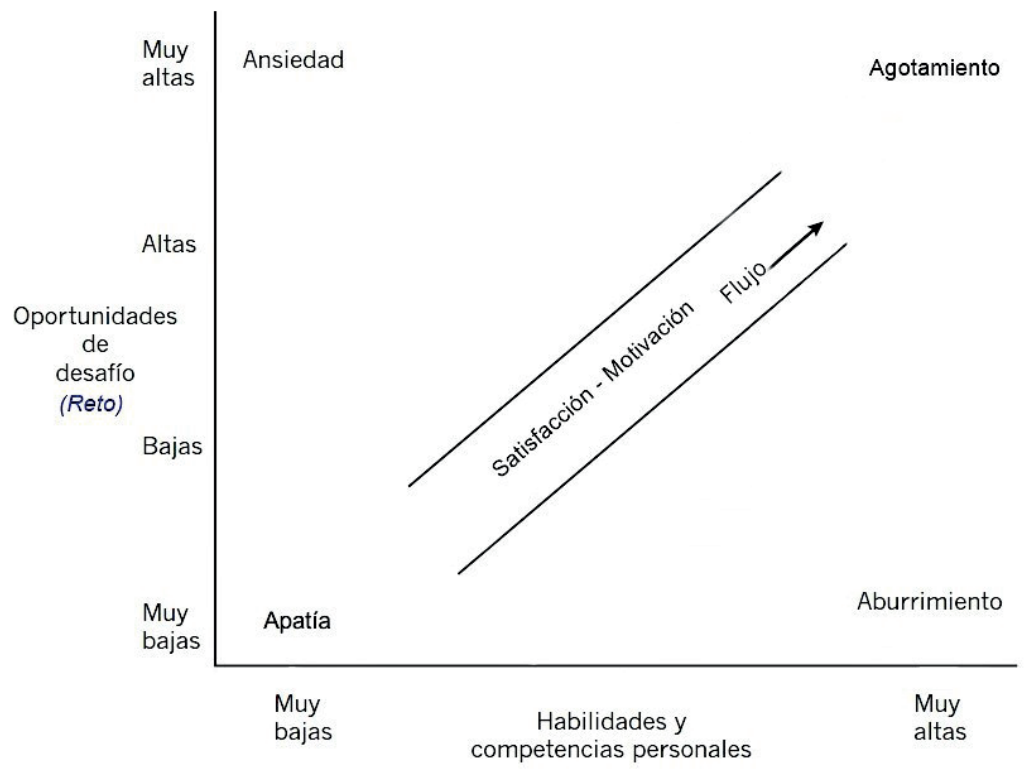

Nota. Adaptado de: Beyond Boredom and Anxiety: The Experience of Flow in Work and Play, de M. Csikszentmihalyi, 1975, San Francisco: Jossey-Bass. 
Programa modelo de educación experiencial orientado al desarrollo de personalidad resistente en estudiantes de atención prehospitalaria

\subsection{Integración}

$\mathrm{Al}$ analizar los planteamientos teóricos anteriores, se encuentra que se pueden integrar en un solo modelo de tres dimensiones: demanda laboral, que hace relación a la exigencia tanto ocupacional como psicosocial; recursos psicológicos, que son los medios de que dispone la persona para responder a esta exigencia; efectos psicológicos, de la interacción de los dos anteriores, tal como se presentará enseguida.

\subsubsection{Demanda laboral}

Actualmente, en general los trabajos tienen una alta demanda psicológica más que física, que induce altos niveles de estrés. Esto es especialmente cierto en el personal de salud, para quienes se han incrementado las exigencias en los siguientes ámbitos.

Ámbito social. Alta expectativa de eficacia terapéutica, que ha aumentado a niveles irreales, y exigencia de actualización permanente, que es muy difícil por la explosión abrumadora del conocimiento y que se enfrenta a la alta información de pobre calidad de los pacientes.

Ámbito organizacional. Alto número de consultantes, escaso tiempo para atender a cada uno, papeleo excesivo, turnos nocturnos y extensos, el bajo reconocimiento por parte de directivos, desequilibrio percibido entre ingresos y responsabilidades en comparación con otras ocupaciones, escasa promoción.

Ámbito emocional. Contacto permanente con el sufrimiento y la muerte, la preocupación por la enfermedad y el manejo del paciente, la probabilidad y realidad de muerte de los atendidos, problemas de interacción con la persona o sus familiares, la prepotencia frecuente de ellos (Gálvez-Herrer, Moreno-Jiménez, \& Mingote-Adán, 2011, págs. 81-91).

\subsubsection{Recursos psicológicos}

Analizando con cuidado los planteamientos teóricos anteriores, se encuentra que se refieren a los recursos psicológicos que tienen las personas para enfrentar las demandas ambientales y que están en relación con cada una de las necesidades psicológicas, tal como se presenta en la siguiente tabla. 
Tabla 1. Tipo de Recursos

\begin{tabular}{llll}
\hline \multicolumn{1}{c}{ Teoría } & \multicolumn{1}{c}{ Autonomía } & \multicolumn{1}{c}{ Necesidad Psicológica } & \\
& Autonomía & Apoyo soción & Competencia \\
\hline Karasek & Autonomía & Retribución & Habilidades \\
Siegrist & Esfuerzo \\
Actitudes de PR & Compromiso - Reto & - & Control \\
$\begin{array}{l}\text { Afrontamiento de } \\
\text { PR }\end{array}$ & $\begin{array}{l}\text { Enfocado en la } \\
\text { resignificación }\end{array}$ & Apoyo social & $\begin{array}{l}\text { Enfocado en la } \\
\text { solución }\end{array}$ \\
\hline
\end{tabular}

Actitudes de PR. Estas se pueden ubicar así. Compromiso con autonomía porque esta actitud hace relación a la predisposición a implicarse en la solución de problemas de acuerdo con los valores y metas personales, es decir, según lo que la persona decide elegir como importante para ella. Reto con la misma porque implica elegir ver los problemas como oportunidades de aprendizaje personal para los propios intereses. Control en competencia porque hace relación a utilizar las propias capacidades para enfrentar los problemas. No hay una actitud de PR directamente relacionada con afiliación.

Afrontamiento de PR. Apoyo social con afiliación, lógicamente. Enfocado en la resignificación con autonomía porque esta estrategia implica elegir una percepción positiva de los problemas según los propios intereses. Enfocado en la solución con competencia dado que comprende las estrategias orientadas a utilizar las capacidades para solucionar el problema.

\subsubsection{Efectos psicosociales}

De acuerdo con la revisión teórica anterior, si la demanda es muy baja, indistintamente del nivel de recursos, no hay un estímulo suficiente satisfacer para la necesidad de competencia, por lo que sobreviene el aburrimiento y la apatía. Si la demanda es muy superior a los recursos, sobreviene el distrés, lo que es muy frecuente, por lo que ha sido considerado como la "enfermedad del siglo XX", que continúa vigente en el siglo XXI y es causa principal de enfermedad laboral (Estefanía-Osorio y Cárdenas-Niño, 2017). En cambio, si los recursos y la demanda son altos (no excesivamente) se da un "desafío óptimo". Esto especialmente si se va acompañado de suficiente 
realimentación positiva, sea de la tarea o por auto/heteroevaluación, gracias a una estructura clara que permita la percepción de progreso e, idealmente, una alta tolerancia al error. De esta forma se satisface la necesidad de competencia y la persona entra en un "experiencia de flujo" muy gratificante, que puede mantenerse por largo tiempo sin afectar psicológicamente a la persona, sino que, por el contrario, genera estado de ánimo positivo que la protege del SDO, tal como lo han ido mostrando varios estudios recientes (Bajwa et al., 2020, p. 2517; Yotsidi, Kourmousi, Dermitzaki, Pezirkianidis, \& Kounenou, 2018); más aún si se satisface también la necesidad de autonomía (LjubinGolub, Rijavec, \& Olčar, 2020, pág. 145) y la necesidad de afiliación (Tse, Fung, Nakamura, \& Csikszentmihalyi, 2018). Esta integración puede observarse en la Figura 3.

Figura 3. Modelo Propuesto: Demandas, Recursos, Experiencia de Flujo.

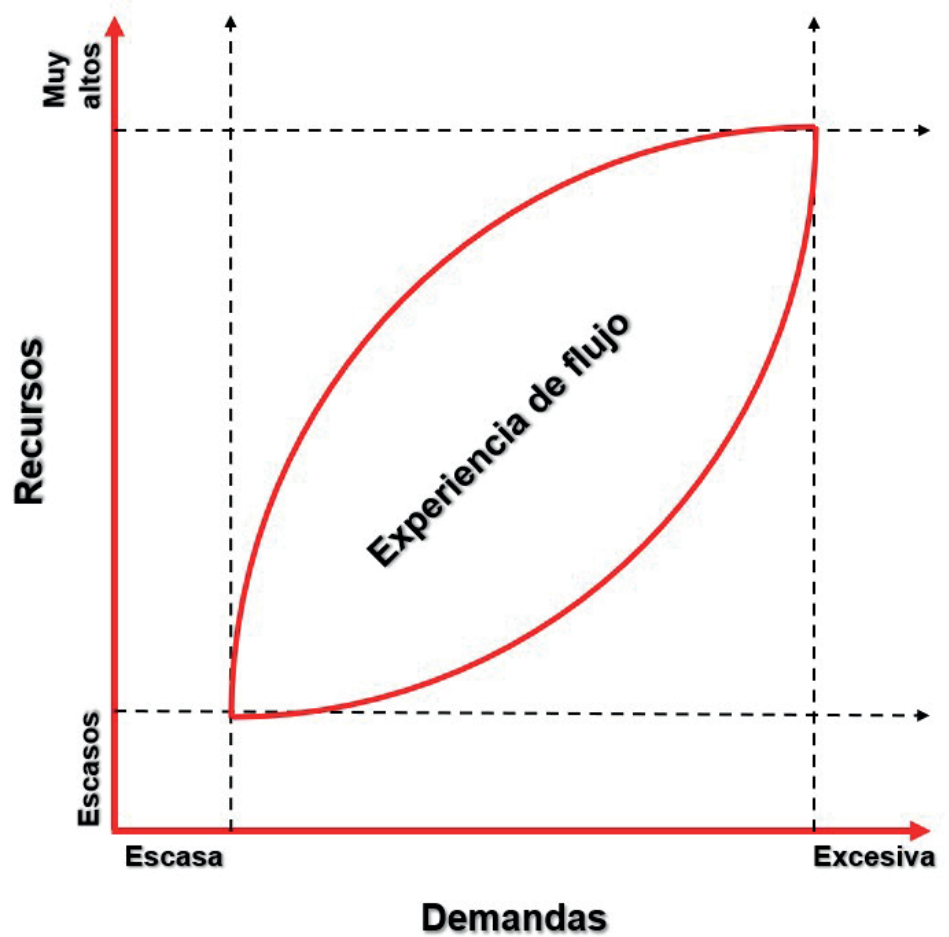




\subsection{Educación experiencial}

\subsubsection{Modelos pedagógicos}

Para facilitar el desarrollo de la personalidad resistente, esto es, actitudes resistentes y estrategias de afrontamiento necesarias para llegar a la "experiencia de flujo" descrita anteriormente, se requiere un proceso educativo, claramente fundamentado en un modelo pedagógico, esto es, en una representación construida colectivamente por comunidades académicas sobre los diferentes elementos del proceso enseñanza-aprendizaje en coherencia con las necesidades del contexto y los propósitos educativos, que esencialmente son los siguientes. El modelo tradicional considera al estudiante como un receptor pasivo del conocimiento ya establecido que tiene y transmite expositivamente el profesor, por lo que el currículo está organizado por contenidos; en este, la relación maestro-estudiante es vertical y tiene como propósito final moldear intelectual y moralmente al educando. El modelo conductista es similar al anterior, pero enfatiza la incidencia de la educación sobre la conducta, de forma que con estímulos y reforzamientos adecuados se puedan conseguir los comportamientos esperados con un propósito técnico-productivo, sin tener en cuenta la influencia del entorno sobre la conducta final de las personas; además, aquí el docente no tiene que estar necesariamente presente, sino que es sólo el intermediario del proceso instruccional. El modelo activista considera al estudiante como el centro del proceso educativo, por lo tanto, los contenidos no están programados de antemano, sino que dependen de los intereses de los estudiantes y este aprende a partir de la manipulación y descubrimiento; aquí, el docente es un auxiliar encargado de preparar los materiales que el estudiante necesita para su aprendizaje por experimentación. El modelo constructivista considera que el aprendizaje se da por la interacción entre los conocimientos previos del estudiante y las nuevas experiencias, lo que lleva a un aprendizaje significativo, en entornos socioculturales; el docente es entonces un facilitador de las experiencias y la meta es acrecentar el desarrollo cognitivo-intelectual del estudiante. El modelo social-cognitivo considera que la educación es política, por lo que se debe combinar con la reflexión crítica sobre los procesos productivos de la realidad social de los estudiantes, de forma que se liberen de las cadenas ideológicas de los poderes presentes en la sociedad y se busquen soluciones colectivas a los problemas de la 
comunidad; así, la relación docente-estudiante es horizontal y la meta es el desarrollo del individuo orientado a la producción material y cultural en su comunidad (Vives-Hurtado, 2016).

Fundamento constructivista. La "educación experiencial" se refiere a la facilitación del "aprendizaje experiencial" mediante programas educativos (AIAE, s.f.). Esta educación experiencial está incluida en la pedagogía constructivista mencionada, ya que en esta el aprendizaje entraña un proceso de construcción y reconstrucción de conocimiento subjetivo, que se genera a partir del conflicto que surge de la interacción entre conceptos previos y nuevas experiencias, en asuntos que son importantes para la persona y, por lo tanto, con un alto componente afectivo. Además, el aprendizaje se da en un contexto que le da sentido y es facilitado por la interacción con otros. (Tafor, Geier, Ogunmuyiwa, \& Addo-Tenkorang, 2016)

\subsubsection{Concepto}

El aprendizaje experiencial es el proceso de construir conocimiento subjetivo a partir de la captación y transformación de las vivencias, o sea, no sólo el resultado sino todo el proceso de reaprendizaje a partir de la solución de los conflictos dialécticos entre los modos opuestos de captación de la experiencia: "vivencia concreta" vs. "conceptualización abstracta", y de transformación de la misma: "reflexión" vs. "acción", lo que involucra a todos los ámbitos de la persona (pensamiento, emoción y conducta) y lleva a la apropiación de conocimiento para ir realizando los proyectos de vida (Kolb, 2015, pp. 50-51).

\subsubsection{Ciclo}

El aprendizaje experiencial comprende cuatro etapas. Experiencia concreta, en la cual la persona percibe y elabora la información proveniente de los sentidos; lo que realiza la corteza cerebral integradora de los lóbulos parietal y temporal, y la amígdala, si se considera una amenaza. (2) Observación reflexiva, en la cual se procesa esta información al compararla con experiencias pasadas y con el proyecto de vida futuro, dotándola de significado y de carga emocional; esto lo realiza la corteza integradora posterior. (3) Conceptualización abstracta, en la cual se evalúan los problemas y 
se planifica una acción para la solución de estos, bajo el impulso de las emociones, por lo que se trata de un proceso creativo en lugar de reflexivo; se da fundamentalmente en la corteza integradora frontal. (4) Experimentación activa, en la que se generan nuevas formas de pensar y actuar, más adaptativas y funcionales, para la solución de dificultades y la realización del proyecto de vida personal, sea explorando diversas posibilidades de acción o modelando a otros (Kolb, 2015, pp. 89-91).

Experiencia concreta. No toda vivencia es una "experiencia concreta", sino sólo cuando esta cumple con las siguientes características. (a) Utilidad: el conocimiento gestionado tiene aplicación pragmática, es decir, corresponde a problemas del mundo real. (b) Contextualización: el conocimiento gestionado está claramente situado en las características del lugar y tiempo a donde se quiere extrapolar. (c) Participación: los asistentes se involucran física, psicológica y socialmente en las actividades. (d) Reto: los asistentes se enfrentan a novedosos desafíos que los sacan de su "zona de confort". (e) Aprendizaje significativo: se confronta la nueva información con el conocimiento ya adquirido, de forma que se va cualificando (Morris, 2020, págs. 1067-1068).

Ciclo de Kolb precisado. De acuerdo con lo anterior, se pueden ajustar los pasos del ciclo de Kolb como sigue. (1) Experiencia concreta "ricamente contextualizada", para hacer pertinente el conocimiento gestionado. (2) Observación reflexiva "crítica", porque el análisis crítico permite la deconstrucción y reconstrucción de nuevos conceptos transferibles a la cotidianidad en forma adaptada a la realidad psicosocial histórica del sujeto. (3) Conceptualización abstracta "especifica del contexto", ya que no debe olvidarse que todo conocimiento proviene de un entorno sociocultural determinado y que, por lo tanto, se debe adaptar al contexto específico del participante. (4) Experimentación activa "pragmática", ya que la gestión del conocimiento realizada en las etapas anteriores debe tener efectos en las conductas cotidianas de los participantes (Morris, 2020, págs. 1070-1073).

\subsubsection{Trabajo en equipo}

La EE se caracteriza por el "trabajo en equipo", dado que los participantes se enfrentan a un reto por solucionar colectivamente, lo que les exige constituirse como equipo de forma que puedan para coordinar sus capacidades para lograr alcanzar la meta, esto es, 
comunicarse eficazmente para planear y coordinar los roles, estrategias y actividades; asumir colectivamente los resultados y realimentarse grupalmente (Cardona-Triana y Trejos-Parra, 2020).

El trabajo en equipo se da a través de cuatro procesos: generar que consiste en la planificación para la consecución del objetivo, a través de la concepción de ideas creativas; elegir que incluye la resolución de los problemas que se van presentando y la toma de decisiones al respecto; negociar que comprende la resolución de conflictos; y ejecutar buscando el máximo desempeño (Molero, Lois, García-Ael y Gómez, 2019, pp. 460-461).

Este trabajo en equipo tiene como ventajas: la complementariedad de recursos y el reparto de responsabilidades, la satisfacción de necesidades sociales que genera emociones positivas e incremento en la motivación, y el aumento en la productividad y el rendimiento; pero tiene como desventaja la necesidad de invertir tiempo para superar las actitudes individualistas que generan dilución de responsabilidad, conflictos y deterioro en las interacciones y el rendimiento (DelgadoLinares, 2019, págs. 114-116). La organización del trabajo en equipo disminuye el agotamiento emocional de los participantes, lo que lleva a una mayor resistencia al estrés laboral (Becker et al., 2016, p. 216) y ayuda a prevenir el Síndrome de Desgaste Ocupacional (GalletaWilliams et al., 2020, p. iv36).

\subsubsection{Eficacia}

La educación experiencial tiene la ventaja de que lleva a las personas a espacios donde actúan tal como son, lo que les facilita la concienciación de los pensamientos y emociones asociados, y así la apropiación de nuevos conocimientos y habilidades, que después pueden llevar a su vida cotidiana (Lagos García, 2012, págs. 62-67). Este ambiente educativo envolvente facilita un mayor aprendizaje que la enseñanza tradicional (Granados-López y García-Zuluaga, 2016, pp. 52-53) y el contexto desafiante permite desestabilizar los patrones cognitivos y promover así el aprendizaje de nuevos (Nogueiras Redondo, 2016, pág. 1), independientemente de si se supera o no el reto propuesto (Foltz-Ramos, 2017, pág. xii). Así, más que la educación convencional, la educación experiencial mejora la capacidad de resolución de problemas (Mayoral 
Rodríguez, Timoneda Gallart y Pérez Álvarez, 2018, p. 308), permite el desarrollo de diversas habilidades sociales que facilitan afrontar los retos, tales como habilidades comunicativas, responsabilidad, liderazgo y gestión de conflictos (Baena \& Mattera, 2015, pág. 38); fomenta el pensamiento crítico, facilita la reflexión sobre el propio aprendizaje $y$, en el campo de la clínica, mejora el manejo de las emociones al facilitar deconstrucción y reconstrucción de las representaciones mentales asociadas (Ferro-Allodola, 2014, pág. 37), en especial cuando se enfatiza la consecución del logro mientras se mantiene una adecuada regulación emocional (Finch, Peacock, Lazdowski, \& Hwang, 2015, pág. 23). Y, además, mejora el trabajo en equipo (Cardona-Triana \& Trejos-Parra, Programa de educación experiencial para mejorar el trabajo en equipo en las organizaciones, 2019, pág. 9).

\subsection{Tesis propuesta}

De acuerdo con lo anterior, se propone que un Programa de Educación Experiencial podría permitirles a las personas, específicamente a los estudiantes de Atención Prehospitalaria, desarrollar las actitudes resistentes y estrategias de afrontamiento necesarias para modular recursos y demandas ante problemas ocupacionales, de forma que puedan mantenerse en un desafío óptimo que les genere emociones positivas y satisfacción de necesidades psicológicas, evitando así la ansiedad y frustración que podrían llevarlos a un SDO. 


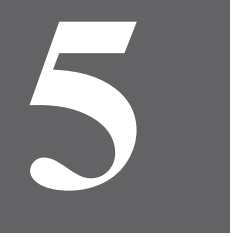

Metodología 


\section{Metodología}

\subsection{Hipótesis}

\subsubsection{Componente cuantitativo}

Hipótesis de investigación. El programa de educación experiencial mejora el nivel de PR en los estudiantes de Atención Prehospitalaria de la Universidad Tecnológica de Pereira, Colombia.

Hipótesis nula. El programa de educación experiencial NO mejora el nivel de PR en los estudiantes de atención prehospitalaria de la Universidad Tecnológica de Pereira, Colombia.

\subsubsection{Componente cualitativo}

Supuesto. El programa de educación experiencial permite la concienciación de los participantes de sus propias actitudes resistentes y estrategias de afrontamiento, la reflexión sobre las mismas a la luz de la teoría, y su transformación mental y conductual hacia el desarrollo de una personalidad resistente, en los estudiantes de atención prehospitalaria de la Universidad Tecnológica de Pereira.

\subsection{Diseño metodológico}

\subsubsection{Paradigma y tipo de investigación}

Método mixto. Se recurrió a un método mixto, cuantitativo y cualitativo, para obtener una mayor comprensión sobre la relación entre las variables: Educación Experiencial y Personalidad Resistente, ya que la evaluación cualitativa explicitó la percepción de los investigados sobre los cambios en sus actitudes de PR a partir de su participación en el programa de EE (Hernández-Sampieri, Fernández-Collado y Baptista-Lucio, 2014a, pp. 538-539).

Se decidió utilizar el método mixto ya que este permite describir de una manera más completa la complejidad del ser humano, ya que, en investigaciones como la presente, además de la valoración 
por medio de instrumentos cuantitativos como las pruebas (test), la indagación cualitativa permite un entendimiento más profundo de la subjetividad de las personas participantes. Esta constituye una postura pragmática, basada en un realismo ontológico, que rechaza la dicotomía de los métodos cuantitativo/cualitativo y acepta la complementariedad (Lucero-Revelo, 2015, págs. 115-117). Actualmente, muchos autores consideran que, si la investigación tiene un plan metodológico riguroso que permita acceder a los fenómenos respetando su naturaleza, se puede utilizar una descripción complementaria cuantitativa y cualitativa para lograr un mejor acercamiento a la realidad, porque examina tanto los datos extrínsecos como los intrínsecos propios del punto de vista del investigado. Por esto, se puede considerar al método mixto cuanticualitativo como un paradigma metodológico emergente en pleno desarrollo, con base en los numerosos artículos científicos que lo han utilizado en los últimos años, así como tesis, manuales, congresos, asociaciones e, incluso, una revista científica: "Journal of Mixed Methods Research" (Núñez-Moscoso, 2017, págs. 635-639). Aunque aún muchos investigadores miran con reserva los métodos mixtos, lo que es lo usual en la historia de la ciencia cuando emerge un paradigma (Delucchi, 2020, pág. 10), el uso de diferentes enfoques permite una mayor profundidad de información que los enfoques singulares aislados (Almalki, 2016, pág. 288). De hecho, una reciente tesis doctoral se orientó a indagar sobre la integración de datos cuantitativos y cualitativos, y concluyó que la utilización de ambos métodos permite una mayor comprensión del objeto de estudio, siempre y cuando los investigadores los conozcan y utilicen apropiadamente, teniendo en cuenta sus potencialidades y limitaciones, y la forma de integrarlos (Guedes-dos-Santos et al., 2017, p. 8).

Diseño explicativo secuencial. Esta investigación utilizó este diseño, en el cual primero se realiza un estudio cuantitativo y después uno cualitativo con base en los resultados del primero para contextualizar y comprender mejor los datos cuantitativos; al final, los descubrimientos de ambos se interpretan conjuntamente para tener una mayor explicación y comprensión del objeto de estudio (Hernández-Sampieri et al., 2014a, p. 544). 


\subsubsection{Componente cuantitativo}

Paradigma pospositivista. El componente cuantitativo se inscribe dentro del paradigma pospositivista, el cual afirma que: (a) la realidad es "real" pero sólo se puede aprehender de forma imperfecta y probable (realismo crítico); (b) el investigador es quien está a cargo del estudio buscando la mayor objetividad posible, aunque es consciente de que esta es imperfecta (epistemología dualista - objetivista modificada); (c) privilegia un diseño experimental que busca la falsación de hipótesis, pero admite la inclusión de datos cualitativos complementario (metodología experimental manipulativa modificada) (Ramos C. A., 2015, págs. 11-12).

Diseño cuasiexperimental. El diseño es de intervención con grupo experimental y de control preformados, pre y posprueba, correspondientes a los estudiantes de atención prehospitalaria de los semestres cuarto y segundo respectivamente; no era posible al azar por posible contaminación experimental (el cambio de actitudes en la mitad de un grupo afecta las actitudes de la otra mitad), además de razones logísticas. Primero se realizó la preprueba con escalas cuantitativas tipo Likert del nivel de actitudes resistentes y estrategias de afrontamiento, y se aplicaron pruebas estadísticas para asegurar la equivalencia inicial de los grupos (prueba M-W). Luego se efectuó la intervención. Y finalmente se determinó si había diferencias significativas entre las pospruebas los dos grupos.

\subsubsection{Componente cualitativo}

Paradigma constructivista. El componente cualitativo se inscribe dentro del paradigma constructivista, el cual afirma que: (a) la realidad es construida mentalmente por cada persona, con base en la socialización y la experiencia (ontología relativista); (b) investigador e investigado interactúan para construir entre ambos el conocimiento (epistemología transaccional subjetivista); y (c) se privilegia una metodología hermenéutica, de comprensión profunda y contextual de las construcciones psicosociales, y dialéctica, de confrontación entre el saber científico del investigador y el saber cotidiano del investigado a través del diálogo (metodología hermenéutica / dialéctica) (Ramos C. A., 2015, págs. 14-15). 
Diseño de estudio de caso. Un "caso" es una unidad sistémica ubicada en un contexto determinado que es objeto de estudio; los estudios de caso pueden ser una investigación en sí misma o servir para confirmar, refinar y ampliar los resultados producidos en una investigación previa, como es el caso de esta tesis. Permiten generar descripciones vívidas sobre las causas, patrones y consecuencias de un fenómeno en su entorno natural y evaluar procesos y programas (Hernández-Sampieri, Fernández-Collado y Baptista-Lucio, 2014b).

Análisis cualitativo. El análisis comprendió los siguientes momentos: exploración de los datos obtenidos de observaciones y entrevistas, descubrimiento y descripción de las categorías presentes en ellos, definición de las relaciones entre ellas, construcción de un mapa categorial en relación con la pregunta de investigación y el contexto de los participantes, generación de relaciones teóricas con base en los datos (Hernández-Sampieri et al., 2014a, p. 418). Para darle credibilidad a esta investigación cualitativa de caso, se utilizó la observación persistente, la triangulación y el control con informantes (Ruiz Olabuénaga, 2012, págs. 108-109).

\subsection{Muestra}

La muestra estuvo constituida por estudiantes de atención prehospitalaria de la Universidad Tecnológica de Pereira, Colombia. Como en la mayoría de los experimentos, fue una muestra no probabilística de sujetos voluntarios, dada la dificultad de manejar grupos grandes en este tipo de investigación, por lo que su validez externa se conseguiría mediante la repetición del estudio (y no mediante la representatividad muestral) (Hernández-Sampieri y MendozaTorres, 2018, p. 217). El grupo experimental con 20 estudiantes estaba cursando cuarto semestre y el grupo control con 36, segundo semestre, $73 \%$ mujeres, entre 17 y 28 años (con media de 19 años y desviación estándar de 2.4) y principalmente de estrato socioeconómico medio. Luego de la información sobre la investigación todos aceptaron participar voluntariamente. 


\subsection{Técnicas e instrumentos de recolección de información}

\subsubsection{Cuantitativas}

Actitudes resistentes. Se midieron mediante la "Escala de Personalidad Resistente", validada para estudiantes universitarios de Chile por Carmona, Garrosa y Moreno en el 2017. Ellos tomaron la encuesta que había desarrollado por Moreno-Jiménez, le cambiaron las palabras del ámbito laboral al académico, hicieron una prueba piloto con 100 estudiantes para asegurar la comprensión de las preguntas y aplicaron la escala resultante a 900 estudiantes entre 18 y 27 años, $56 \%$ mujeres, de $1^{\circ}$ a $4^{\circ}$ año académico de psicología, trabajo social, derecho o kinesiología. Simultáneamente midieron otras variables empírica y teóricamente relacionadas con la PR: escala de satisfacción con la vida, escala de compromiso laboral, inventario de los cinco grandes factores de la personalidad. Al azar, dividieron la población en dos, a una mitad le realizaron un análisis factorial exploratorio; este mostró buenos índices para un análisis factorial, que había 6 ítems que no superaban la carga mínima recomendada por lo que se eliminaron y que quedaban tres factores con 5 ítems cada uno. Un análisis factorial confirmatorio a la segunda mitad mostró tres factores de primer orden: compromiso, control y reto, y uno de segundo orden: PR. Se realizó una matriz de correlaciones que reveló que estas tres actitudes se relacionaban con las otras variables medidas en forma significativa (Carmona-Halty, Garrosa-Hernández y Moreno-Jiménez, 2017, pp. 287-290).

Estrategias de afrontamiento. Se midieron las estrategias de afrontamiento mediante la "Escala de Estilos y Estrategias de Afrontamiento al Estrés" validada en universitarios de varias universidades colombianas. Los investigadores tomaron la "Escala de Estilos y Estrategias de Afrontamiento al Estrés" de FernándezAbascal, de 72 ítems agrupados en 18 estrategias de afrontamiento. Les aplicaron la escala a 786 estudiantes universitarios colombianos, entre 16 y 36 años, 54\% mujeres. Se encontraron buenos índices para el análisis factorial. Para la selección de factores e ítems se definieron los siguientes criterios: factores con valor propio $>1$, con 3 o más preguntas y confiabilidad $>0.5$; y preguntas con carga factorial $\geq 0.50$, en un solo factor y con congruencia conceptual. Sólo 18 ítems agrupados en 4 componentes cumplieron con estos requisitos: reevaluación positiva, 
resolución del problema, apoyo social (instrumental y emocional) y desconexión cognitiva. La escala quedó con un alfa de Cronbach de 0.76 y una varianza total explicada de $62 \%$ (Londoño A, Pérez P y Murillo J, 2009).

\subsubsection{Cualitativas}

Observaciones: se realizaron diarios de campo durante las sesiones de aprendizaje experiencial. Autorreportes: al final de cada sesión escribían sobre los cambios percibidos y al comienzo de las sesiones entregaban un informe sobre lo vivido durante la semana en relación con el tema anterior; y se solicitó un informe final una semana después terminar el programa sobre los cambios percibidos por el programa en las diferentes dimensiones de PR (Hernández-Sampieri et al., 2014b). 


\section{Programa de Educación Experiencial}




\section{Programa de educación experiencial}

Se diseñó y brindó un programa de educación experiencial enfocado a la facilitación del desarrollo de la PR (Actitudes Resistentes y Estrategias de Afrontamiento) en estudiantes de Atención Prehospitalaria, con cuatro sesiones, una por semana, de 1.5 horas cada una. Se describe enseguida el programa general y las sesiones.

\subsection{Programa general}

Para la preparación de las situaciones experienciales se deben tener en cuenta cinco elementos. (a) La población en aprendizaje. (b) Los conocimientos, habilidades y actitudes por aprender. (c) Las situaciones cotidianas específicas en que estos se requieren. (d) Las estrategias formativas experienciales que facilitarán este aprendizaje. (e) El talento humano que debe llenar unas características de formación y experiencia (Reggio, 2010, págs. 166-170).

\subsubsection{Población en aprendizaje}

Para diseñar adecuadamente un programa de EE se debe considerar, en primer lugar, la población a la cual va dirigido, porque los contenidos deben estar orientados según sus necesidades e intereses, y la metodología, según su nivel cognitivo (Casas-Santín, Carranza-Peña, \& Ruiz-Badillo, 2011, pág. 18).

En esta investigación, la población estaba inmersa en la llamada cultura "paisa", que es una identidad regional que prima sobre la nacional. Corresponde al complejo cultural antioqueño o de la montaña, que se caracteriza por la iniciativa, el emprendimiento, el trabajo duro, la importancia de la familia extensa, la solidaridad y la religión católica; esta última tiene una gran influencia sobre las personas y comunidades, en especial en su ética y moral, y estimula el afrontamiento con esperanza de las dificultades de la vida (Ocampo-Villegas, 2015, págs. 103-111).

Específicamente eran estudiantes de Atención Prehospitalaria, de la Universidad Tecnológica de Pereira. Deben adquirir conocimientos y desarrollar habilidades, no sólo en relación con su disciplina, 
sino también en el abordaje integral del ser humano, en especial, el manejo psicoemocional que necesitan para afrontar apropiadamente las problemáticas en salud en situaciones sociales críticas, a veces muy complejas de manejar. Por esta razón, el Programa de Atención Prehospitalaria de la UTP se caracteriza por enfocarse en el ser humano de una forma holística desde tres líneas de trabajo: disciplinar, psicosocial y administrativa, con el fin de que los estudiantes puedan afrontar los diferentes desafíos de su práctica profesional (Comité Curricular TAPH-UTP, 2020).

\subsubsection{Conocimientos, habilidades y actitudes}

Un aspecto central en la elaboración de un programa de EE es definir cuáles son los conocimientos, habilidades y actitudes cuyo aprendizaje se va a facilitar, esto es, qué deben saber, cómo utilizarlo y cómo lograr la disposición a incorporarlo a la propia vida (Zabalza y ZabalzaCerdeiriña, 2010, p. 149).

En esta investigación, los conocimientos, habilidades y actitudes corresponden a la PR, tanto actitudes resistentes como estrategias de afrontamiento, que ya fueron descritas anteriormente, o sea, la intencionalidad del estudio es concientizar los pensamientos y emociones que los estudiantes han venido utilizando al enfrentar situaciones críticas durante su vida académica/ocupacional, luego suscitar la reflexión sobre la utilidad de estos en contraste con los de la PR y finalmente la necesidad de adquirir los conocimientos, habilidades y actitudes necesarias para alcanzar desafíos óptimos, con las emociones positivas y satisfacción de necesidades psicológicas consecuentes, que les ayuden a evitar la ansiedad y frustración crónicas que podrían llevarlos a un SDO.

Esto incluye no sólo la concienciación, validación y transformación de los pensamientos-emociones-conductas personales, sino que trasciende a la comunicación interpersonal en búsqueda del apoyo social, tanto cognitivo para la búsqueda de soluciones como emocional para ayudarse mutuamente en el mantenimiento del compromiso, la percepción de capacidad de control y de reto ante las dificultades. 


\subsubsection{Situaciones cotidianas}

Según la pedagogía constructivista, el aprendizaje se da por la elaboración mental del conocimiento con base en la información proveniente de la realidad, "por lo que el conocimiento se logra a través de la actuación sobre la realidad, experimentando con situaciones y objetos, transformándolos para su comprensión" (Pérez-Torres, 2020, pág. 105). Por esta razón, en los programas educativos experienciales se deben exponer a los participantes a escenarios similares a los que enfrentarán en su vida, en este caso, en su vida laboral. Además, estos deben tener un orden creciente de complejidad con base en los conocimientos que va adquiriendo el estudiante (Pérez-Torres, 2020, pág. 111).

Para la población objeto del programa, las "situaciones cotidianas" comprenden la exposición a eventos traumáticos de atención prehospitalaria, lo que es uno de los principales factores de riesgo para el SDO (Cueva, Cusco y Sánchez, 2017, p. 10). Estas situaciones cotidianas incluyen los siguientes aspectos: el estrés previo a la atención dada la posible gravedad al estar en juego la salud y vida de las personas, la exigencia de una actuación rápida y sin errores, la necesidad de trabajar en equipo con compañeros y otro personal de salud, los escenarios con frecuencia imprevisibles que generan dificultad para encontrar soluciones apropiadas, la imposibilidad reiterada para lograr restablecer la salud o la vida de los atendidos, el menosprecio frecuente de su trabajo por pacientes, compañeros y jefes, y el reproche ante cualquier equivocación (Sanchez-Vera, Loli-Ponce y Sandoval-Vegas, 2015, pp. 120-121).

Escenarios de atención prehospitalaria. Los estudiantes de atención Prehospitalaria se expusieron a los siguientes cuatro escenarios laborales de crisis. (a) El primero fue un trabajo grupal de atención prehospitalaria con problemas graves de comunicación, para enfatizar la concienciación de sus pensamientos, emociones y conductas en el entorno de trabajo grupal. Y en los tres siguientes contextos existían víctimas y riesgo de desastre, que les exigieron poner en práctica sus conocimientos, habilidades y actitudes en atención prehospitalaria, y les permitieron concientizar sus pensamientos, emociones y conductas en este ambiente: (b) el paso en equipo por una estructura en riesgo de 
colapso, (b) el rescate de una bebé de un edificio en riesgo de colapso y (c) el paso de un río en creciente. Se seleccionaron estos porque corresponden a escenarios complejos que permitían trabajar la PR en eventos críticos y porque se presentan con cierta regularidad en especial en Colombia, el cual es el país con el más alto nivel de desastres en América Latina en los últimos 30 años, unos 600 al año, tales como deslizamientos de tierra, inundaciones, incendios y terremotos (PosadaVilla, 2011, pág. 15).

\subsubsection{Estrategias formativas}

Realismo en los escenarios. Se intentó recrear el entorno físico según las situaciones críticas con el mayor realismo posible de acuerdo con los recursos disponibles, incluyendo algunas veces los sonidos correspondientes. Se les explicaba antes de llegar cuál era situación supuesta y la importancia de intentar vivirla como si fuera verdadera, con el fin de concientizar y mejorar su PR, para ayudar a prevenir así el SDO. Luego, continuamente se les recordaban las características del escenario y el reto que debían superar, intentando que lo vivieran de la forma más real posible

Estrategias de facilitación. Antes de comenzar el Programa, se brindó una clase acerca de la PR y su importancia en la prevención del SDO, para facilitar la posterior apropiación de la teoría en la "conceptualización". Se inició con una sensibilización sobre el proyecto de vida personal y la pertinencia del Programa para ellos, para motivar su participación activa. En cada sesión se trabajaron las etapas de EE, para facilitar el aprendizaje o desarrollo de PR a partir de la reflexión sobre la experiencia. Y se cerró cada sesión con una evaluación global, para realimentar todo el proceso, y con una tarea entre sesiones, para trasladar a la cotidianidad los conocimientos y habilidades adquiridos.

Trabajo en equipo. Usualmente las personas no trabajan aisladas sino en grupos, que frecuentemente deben funcionar como equipos para poder alcanzar metas, como es el caso de la atención prehospitalaria. Un trabajo en equipo exige que los participantes asuman una actitud de compromiso y coordinen sus conocimientos y capacidades para lograr los objetivos comunes (claros, medibles y alcanzables), lo cual es equiparable a las actitudes resistentes de compromiso, control y 
reto. El trabajo en equipo comprende las siguientes etapas. (a) Definir el objetivo común: todos los participantes deben conocerlo y deben compartir el compromiso por alcanzarlo. (b) Acordar el sistema de comunicación: que debe ser eficaz en la búsqueda de la meta y eficiente en el consumo de recursos. (c) Elaborar el plan de actuación: en el cual quede claramente definidas las actividades por realizar y el rol de cada participante. (d) Acordar una forma de autoevaluación: para ir corrigiendo las falencias y potenciando los procedimientos exitosos (Barranco-Martos \& Vargas-Fernández, 2014, pág. 89).

Proceso administrativo. Las etapas señaladas para el trabajo en equipo se pueden organizar utilizando el "proceso administrativo", que consiste en el conjunto de etapas necesarias para alcanzar una meta. Estas son las siguientes. (a) Planeación: se define qué se va a hacer para alcanzar los objetivos fijados, anticipando las dificultades que se pudieran presentar. (b) Organización: se define la estructura jerárquica, las tareas por realizar y los roles requeridos. (c) Dirección: se refiere a la toma de decisiones, que en un grupo pequeño corresponde al líder, junto con la motivación, comunicación y resolución de conflictos. (d) Control: se evalúa el proceso para realimentarlo y ajustarlo según las dificultades que se van encontrando (Reza-Trosino, 2017, pág. 111).

\subsubsection{Talento humano}

De acuerdo con el tema de Personalidad Resistente y la estrategia de Educación Experiencial, se consideró que se requerían profesionales en psicología y recreación, por lo cual la planeación, ejecución y evaluación del programa en general, así como de cada sesión, fue realizada por parte del equipo de investigadores bajo el liderazgo del aspirante a Doctor, Investigador Principal de esta tesis. Y para la facilitación práctica de la experiencia se contó con la colaboración de estudiantes de último semestre de Ciencias del Deporte y la Recreación.

\subsection{Sesiones}

\subsubsection{Preliminares}

Conceptualización. Antes de comenzar el programa, se brindó una clase teórica a los estudiantes de atención prehospitalaria sobre los conceptos centrales de PR, tanto actitudes resistentes como estrategias 
de afrontamiento, y del SDO, con el fin de facilitar el proceso de conceptualización durante las sesiones de $\mathrm{EE}$, para que en la ejecución de las sesiones sólo fue necesario recordar estos conceptos y aclarar su pertinencia dentro el Programa y en su vida cotidiana y laboral.

Sensibilización. Para empezar el Programa, se facilitó la concienciación del proyecto de vida laboral real de los participantes y los posibles obstáculos por superar en el futuro, con el fin de aclarar la pertinencia del Programa de EE ofrecido para el proyecto de vida laboral (Doron y Parot, 2008, p. 508) y, de esta manera, incrementar la motivación al aprendizaje de los conocimientos, habilidades y actitudes de PR, y la aplicación de estos a su cotidianidad (Cáliz Lafuente y Pedrosa González, 2015).

\subsubsection{Fase de apertura}

Introducción. Primero se presentaron los facilitadores, las normas de convivencia, la intencionalidad de la investigación y, en forma global, la sesión del día.

Alistamiento. Se realizó un ejercicio lúdico de calentamiento psicomotriz para aumentar la disposición física y mental, y concientizar la importancia del compromiso individual y el trabajo en equipo para superar los desafíos; era de corto tiempo ya que la actividad física subsecuente sería de baja intensidad (Galera-Pérez, 2018, págs. 1-2).

Encuadre. Se llevó a los participantes al escenario y se les explicó: en qué consistía la situación imaginaria, cuál era el desafío que debían superar y cuál era su relevancia en relación con la PR en su vida profesional futura.

\subsubsection{Fase central}

Educación experiencial. Luego se realizaron cada una de las etapas de la educación experiencial en la siguiente secuencia. (a) Experiencia concreta 1: actividad de reto, que tuvo una complejidad progresiva, tanto en la secuencia dentro de cada sesión como entre la primera y última de estas, buscando de esta manera mantener una "desafío óptimo" por el desarrollo progresivo de recursos individuales y de trabajo en 
equipo. (b) Observación reflexiva 1: facilitación de la concienciación de los pensamientos, emociones y conductas de cada uno en relación con la experiencia vivida, la relación de esta concienciación con sus vivencias anteriores y su proyecto de vida, y compartición grupal. (c) Conceptualización abstracta: confrontación de la reflexión recién realizada con la teoría sobre el tema, esto es: identificación de las actitudes y estrategias con que se hacía frente a la situación, ilustración sobre las actitudes resistentes y estrategias de afrontamiento que son más efectivas e importancia del cambio hacia estas últimas para la superación del reto de la prueba presente y de los desafíos similares en su vida profesional futura, buscando siempre una "experiencia de flujo" que les dé una mejor calidad de vida y sirva para prevenir el SDO. (d) Experimentación activa: se les daba tiempo para pensar, dialogar y ensayar cómo podían mejorar la superación de la prueba, cambiando hacia actitudes resistentes y estrategias de afrontamiento con base en la reflexión anterior. (e) Experiencia concreta 2: nuevo intento de superación del reto incorporando lo anterior. (f) Observación reflexiva 2: facilitación de la concienciación de los cambios hacia las actitudes resistentes y estrategias de afrontamiento, y la utilidad de estos, tanto en la situación presente como en situaciones de su vida cotidiana académico-laboral.

\subsubsection{Fase de cierre}

Evaluación. Se dio un espacio final para evaluar y compartir en plenaria (Ortiz-Ocaña y Salcedo-Barragán, 2020). Se realizó una descripción de las actividades realizadas de EE y, a partir de cada aspecto relevante de la experiencia, se preguntó por el proceso de concienciación y transformación de pensamientos, emociones y conductas de los participantes, de la interacción con los demás y el trabajo en equipo, y de la utilidad futura de estos cambios de desarrollo de la PR. Finalmente, se escucharon sugerencias para mejorar la sesión.

Tarea. Se les dejaba como tarea escribir sobre la utilización real las actitudes resistentes y estrategias de afrontamiento en alguna situación estresante durante la semana siguiente y entregarla en la próxima sesión, para facilitar la aplicación de los conocimientos y habilidades aprendidas a su vida cotidiana y laboral. 
Programa modelo de educación experiencial orientado al desarrollo de personalidad resistente en estudiantes de atención prehospitalaria

\subsubsection{Descripción de las sesiones}

La información detallada de las sesiones: alistamiento (introducción, materiales, tiempo, descripción, desarrollo), actividad central (materiales, tiempo, descripción, intencionalidad, escenarios real e imaginario, fases de Kolb) y cierre (evaluación y tarea), se presentan en la bitácora al final de esta tesis. 


\section{Resultados cuantitativos}




\section{Resultados cuantitativos}

\subsection{Escalas}

Unas semanas antes de comenzar la investigación, se realizó un análisis y validación de los instrumentos por utilizar.

\subsubsection{Escala de actitudes resistentes}

Se eligió la "Escala de Personalidad Resistente" que mide las tres actitudes resistentes (Carmona-Halty, et al., 2017). Para esta investigación, que está pensada en relación con la búsqueda de un "desafío óptimo", se hizo una pequeña modificación en tres ítems de la actitud de "reto" orientados hacia la aceptación de nuevas experiencias, en el sentido de que implicaran un desafío, esto es, se les adicionaron las siguientes palabras en cursiva:

- Tengo gran curiosidad por las experiencias académicas nuevas que son retos para mí.

- En la medida que puedo, trato de tener nuevas experiencias que son retos en mis actividades académicas diarias.

- Dentro de lo posible, busco situaciones nuevas y desafiantes en mi ambiente académico.

Se aplicó la escala a 115 estudiantes voluntarios de atención prehospitalaria y, utilizando SPSS 25, se encontró un alfa de Cronbach de 0.815 . Si se eliminaran los ítems anteriores disminuiría la confiabilidad, confirmando que son apropiados. Solamente la eliminación de un ítem de la dimensión control: "No importa lo que me esfuerce en mis actividades académicas, a pesar de mi empeño no suelo conseguir nada", incrementaría la confiabilidad, pero sólo a 0.828 , por lo que se decide dejar. De todas formas, se sugiere mejorar su redacción en futuras investigaciones. Además, se cambió la puntuación de 1-4 por 0-3, para una mejor visualización. Ver anexo A. 


\subsubsection{Escala de estilos y estrategias de afrontamiento al estrés}

Al analizar la escala de estrategias de afrontamiento de Londoño et al. (2009), se observó que: reevaluación positiva tenía siete ítems, desconexión cinco, apoyo social cuatro (3 emocional y 1 cognitivo) y resolución del problema dos. Dado lo anterior, se decidió incluir un ítem en apoyo social cognitivo: "Le pregunto a otros cómo solucionar el problema" y un ítem en resolución del problema: "Intento resolver el problema de alguna manera", para un número más equilibrado de ítems por dimensión. Se aplicó la escala a 115 estudiantes voluntarios de atención prehospitalaria y se encontró un alfa de Cronbach (con SPSS 25) de 0.866. Si se eliminaran los dos ítems adicionales disminuiría la confiabilidad, confirmando que son apropiados. Únicamente la eliminación de un ítem, de la dimensión desconexión cognitiva: "Evito el problema haciendo cualquier cosa", incrementaría la confiabilidad, más sólo a 0.870 , por lo cual se decide dejar. De todas formas, se sugiere mejorar su redacción para futuras investigaciones. Además, se cambió la puntuación de 1-6 por 0-5, para una mejor visualización. Ver anexo A.

\subsection{Variables demográficas}

\subsubsection{Edad}

La población comprendió el grupo experimental conformado por 20 estudiantes de en cuarto semestre y el grupo control integrado por 36 estudiantes de segundo semestre del Programa de Atención Prehospitalaria, de la Universidad Tecnológica de Pereira.

Figura 4. Grupos Etarios Estudiantes 2 y 4 Semestre, Atención

Prehospitalaria, UTP, 2019

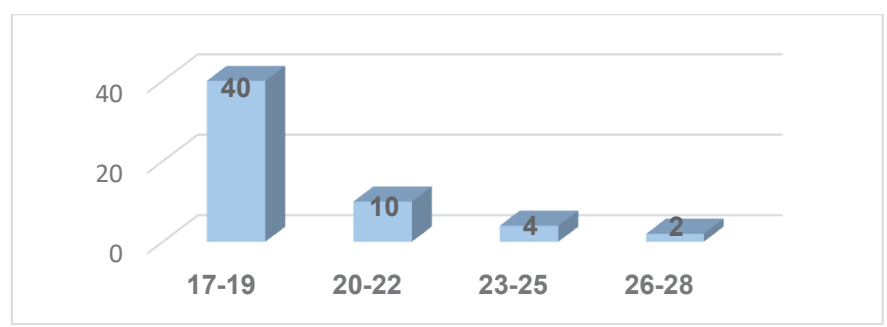


Son adultos jóvenes de 17 a 28 años, el $71 \%$ tiene de 17 a 19 años, con media de 19 años y desviación estándar de 2.4. No se encontró asociación entre edad y PR, igual que en otros estudios (Ríos-Risquez, Carrillo-Garcia y Sabuco-Tebar, 2012). Tampoco se encontró relación entre la edad y estrategias de afrontamiento, aunque esta sí se ha encontrado en otros estudios (Castaño y León-del-Barco, 2010, p. 250); se considera que esto puede explicarse por el rango de edad estrecho, más aún cuando el $71 \%$ está en el corto intervalo de 2 años.

\subsubsection{Sexo}

El grupo investigado contó con la participación de 41 mujeres (73.2\%) y 15 hombres (26.8\%). Según la literatura científica revisada y referenciada a lo largo de este documento, la comparación entre hombres y mujeres arroja una diferencia significativa con respecto la personalidad resistente (Kaur, 2011) y a las estrategias de afrontamiento utilizadas por cada uno (Coppari et al., 2019, p. 1). Sin embargo, en este estudio no se encontraron diferencias, lo que podría deberse al tamaño pequeño de la muestra con un bajo porcentaje de hombres.

\subsection{Preprueba}

\subsubsection{Actitudes resistentes}

Figura 5. Actitudes Resistentes en Estudiantes 2 y 4 Semestre, Atención Prehospitalaria, UTP, 2019.

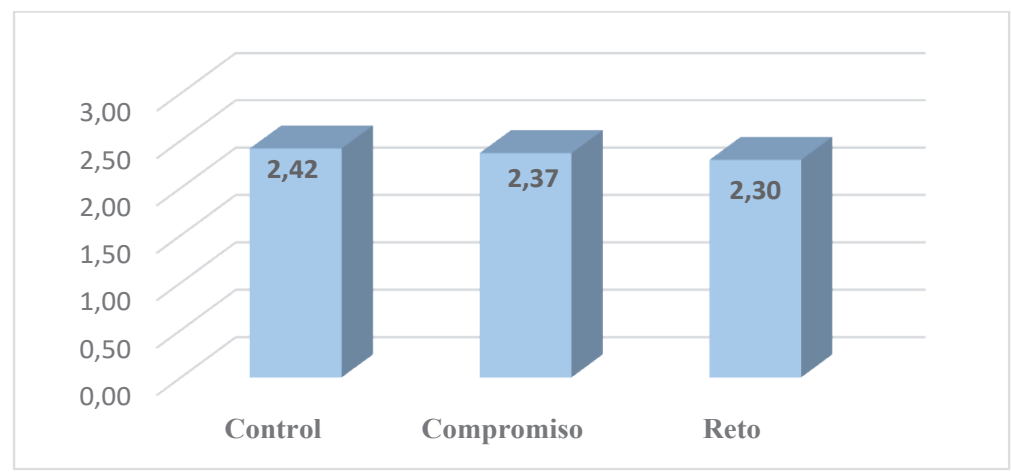


Los estudiantes de Atención Prehospitalaria presentaron medias similares en las tres actitudes resistentes de control, compromiso y reto, con un promedio general de 2.36 y una desviación estándar de 0.61 , lo que es similar a lo encontrado en estudiantes universitarios en otras investigaciones (Carmona-Halty et al., 2017).

\subsubsection{Estrategias de afrontamiento}

Figura 6. Estrategias de Afrontamiento Estudiantes 2 y 4 Semestre, Atención Prehospitalaria, UTP, 2019.

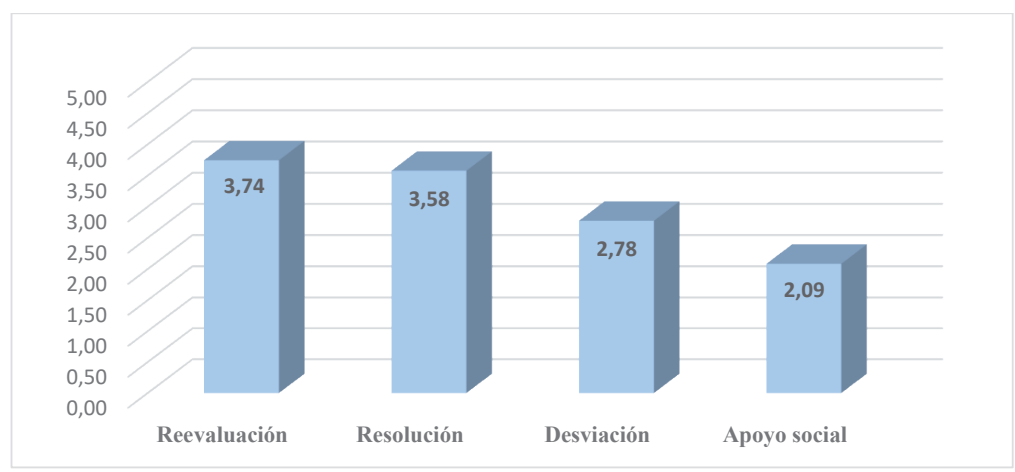

Con una media general de 3.06 y una desviación estándar de 1.38, presentaron niveles más altos de las estrategias útiles de "reevaluación positiva" y "resolución de problemas". Sin embargo, la estrategia "desviación" estaba por encima del puntaje medio y el "apoyo social" por debajo de este. En forma similar, en la literatura se encuentra que las estrategias más utilizadas son "reevaluación positiva" y "resolución de problemas", y la menos utilizada es la "desviación"; sin embargo, el "apoyo social" es también una de las más utilizadas, mientras que en los estudiantes de este estudio fue la menor (Encinas-Orbegoso, 2019, p. 2; Labrague, McEnroe-Petitte, Al Amri, Fronda, \& Obeidat, 2018, p. 289). Además, no se encontraron diferencias por sexo (media 3.3 en mujeres y 3.2 en hombres), aunque en otros estudios sí se han observado diferencias (Cabanach, Fariña, Freire, González y Ferradás, 2013, p. 19). Ambas discrepancias pueden deberse al azar por ser una muestra pequeña. 


\subsection{Posprueba}

\subsubsection{Pruebas estadísticas}

Nivel de significancia estadística. En todas las pruebas de hipótesis en esta tesis se utilizó un a $=0.05$, un intervalo de confianza del $95 \%$, y una sola cola. La principal limitación de este estudio fue el tamaño reducido de la muestra, lo que exige una gran diferencia entre medias para que dé una diferencia significativa.

Pruebas de hipótesis. Como son variables a nivel ordinal, para comparar los grupos se utilizó la prueba de Mann-Whitney (M-W) y para comparar la preprueba con la posprueba de cada grupo se empleó la prueba de Wilcoxon (W).

Tamaño del efecto. Para determinar qué tan grande fue la diferencia entre las medias en la posprueba, se utilizó el programa G*Power: en relación con el test Wilcoxon-Mann-Whitney, un análisis "post hoc", para grupos experimental y control de diferente tamaño. Para esta prueba, se consideró pequeño hasta 0.20 , mediano hasta 0.30 , grande hasta 0.50 (Galindo-Domínguez, 2020, p. 88).

\subsubsection{Resultado global de actitudes resistentes}

Figura 7. Medias Globales de Actitudes Resistentes, Pre y Posprueba, Grupos Experimental y Control

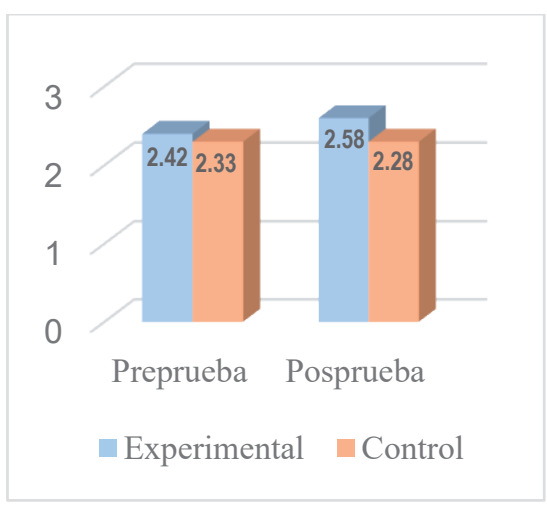


La media del grupo experimental pre-posprueba se incrementó de 0.16 , en cambio la media del grupo control pre-posprueba disminuyó 0.05 .

Tabla 2.Medidas estadísticas de las actitudes resistentes consideradas globalmente.

\begin{tabular}{lccc}
\hline \multirow{2}{*}{ Prueba } & \multicolumn{3}{c}{ Actitudes Resistentes } \\
\cline { 2 - 4 } G. experimental & Pre & Pos & W \\
G. control & $\overline{\mathrm{x}}=\mathbf{2 , 4 2}$ & $\overline{\mathrm{x}}=\mathbf{2 , 5 8}$ & 0,0137 \\
& $\mathrm{~s}=0.25$ & $\mathrm{~s}=0.23$ & \\
M-W & $\overline{\mathrm{x}}=\mathbf{2 , 3 3}$ & $\overline{\mathrm{x}}=\mathbf{2 , 2 8}$ & 0,1533 \\
S general & $\mathrm{s}=0.33$ & $\mathrm{~s}=0.37$ & \\
Tamaño del efecto & 0,0608 & 0,0009 & \\
& & 0.36 & \\
\end{tabular}

Nota . "S general” = desviación estándar de toda la muestra (experimental más control).

Diferencias significativas. No se encontró diferencia significativa en las medias globales de las actitudes resistentes entre las prepruebas de los grupos experimental y control $(\mathrm{p}=0.0608 ; \mathrm{M}-\mathrm{W})$ pero sí entre pospruebas $(\mathrm{p}=0.0009 ; \mathrm{M}-\mathrm{W})$, lo que indica que el Programa de EE produjo cambios significativos en los niveles de AR. Coherentemente, no hay diferencia significativa pre-posprueba en el grupo control $(\mathrm{p}=0.1533 ; \mathrm{W})$ pero sí del grupo experimental $(\mathrm{p}=0.0137 ; \mathrm{W})$.

Tamaño del efecto. El tamaño del efecto encontrado para actitudes resistentes fue de 0.83 , o sea, "muy grande", lo que indica que hubo una mejoría evidente en el grupo experimental en las actitudes resistentes consideradas globalmente, aunque la muestra era relativamente pequeña. 


\subsubsection{Resultado por cada actitud resistente}

Figura 8. Medias de Actitudes Resistentes, Pre y Posprueba, Grupos Experimental y Control.

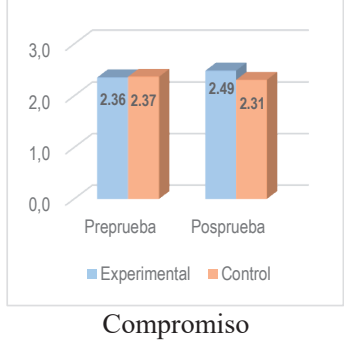

Compromiso

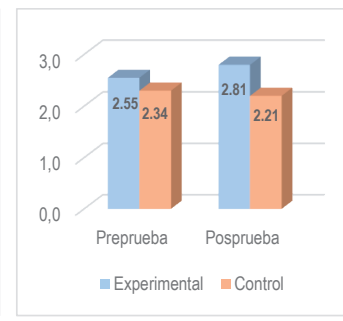

Control

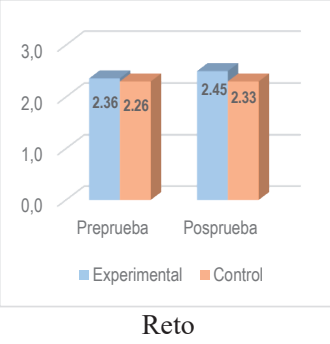

La media del grupo experimental pre-posprueba se incrementó en las tres actitudes resistentes, la media del grupo control pre-posprueba disminuyó en "compromiso" y "control"; pero en "reto", mientras en el grupo experimental subió 0.9 , en el grupo control subió 0.7 .

Tabla 3.Medidas estadísticas de cada una de las actitudes resistentes.

\begin{tabular}{|c|c|c|c|c|c|c|c|c|c|}
\hline \multirow[b]{2}{*}{ Prueba } & \multicolumn{3}{|c|}{ AR Compromiso } & \multicolumn{3}{|c|}{ AR Control } & \multicolumn{3}{|c|}{ AR Reto } \\
\hline & Pre & Pos & w & Pre & Pos & w & Pre & Pos & w \\
\hline G. experimental & $\begin{array}{l}\bar{x}=\mathbf{2 , 3 6} \\
\mathrm{s}=0.29\end{array}$ & $\begin{array}{l}\bar{x}=\mathbf{2 , 4 9} \\
\mathrm{s}=0.31\end{array}$ & 0,0689 & $\begin{array}{l}\bar{x}=\mathbf{2 , 5 5} \\
\mathrm{s}=0.41\end{array}$ & $\begin{array}{l}\bar{x}=\mathbf{2 , 8 1} \\
\mathrm{s}=0.32\end{array}$ & 0,0089 & $\begin{array}{l}\bar{x}=\mathbf{2 , 3 6} \\
\mathrm{s}=0.44\end{array}$ & $\begin{array}{l}\bar{x}=\mathbf{2 , 4 5} \\
\mathrm{s}=0.36\end{array}$ & 0,1100 \\
\hline G. control & $\begin{array}{l}\bar{x}=\mathbf{2 , 3 7} \\
\mathrm{s}=0.37\end{array}$ & $\begin{array}{l}\bar{x}=\mathbf{2 , 3 1} \\
\mathrm{s}=0.41\end{array}$ & 0,1666 & $\begin{array}{l}\bar{x}=\mathbf{2 , 3 4} \\
\mathrm{s}=0.47\end{array}$ & $\begin{array}{l}\bar{x}=\mathbf{2 , 2 1} \\
\mathrm{s}=0.57\end{array}$ & 0,0363 & $\begin{array}{l}\bar{x}=\mathbf{2 , 2 6} \\
\mathrm{s}=0.37\end{array}$ & $\begin{array}{l}\bar{x}=\mathbf{2 , 3 3} \\
\mathrm{s}=0.41\end{array}$ & 0,1900 \\
\hline $\mathrm{M}-\mathrm{W}$ & 0,4448 & 0,0419 & & 0,0560 & 0,0001 & & 0,1774 & 0,1413 & \\
\hline S general & & 0.39 & & & 0.57 & & & - & \\
\hline Tamaño del efecto & & 0,46 & & & 1,05 & & & - & \\
\hline
\end{tabular}

Nota: "S general" = desviación estándar del grupo control más el experimental.

Compromiso y control. En las actitudes resistentes "compromiso" y "control" no se encontraron diferencias significativas entre prepruebas $(\mathrm{p}=0.4448$ y $\mathrm{p}=0.0560, \mathrm{M}-\mathrm{W}$, respectivamente), pero sí entre pospruebas ( $\mathrm{p}=0.0419$ y $\mathrm{p}=0.0001, \mathrm{M}-\mathrm{W}$, respectivamente), lo que indica que el Programa de EE produjo cambios significativos en sus niveles. Sin embargo, en relación con el compromiso, no hay diferencias preposprueba del grupo experimental, aunque estuvo cerca del límite $(\mathrm{p}=0.0689)$, lo que puede deberse al tamaño pequeño de la muestra. 
Reto. En la actitud "reto" no encontró diferencia significativa entre prepruebas ni entre pospruebas $(\mathrm{p}=0.1774 \mathrm{y} \mathrm{p}=0.1413, \mathrm{M}-\mathrm{W}$, respectivamente), ni tampoco entre la pre o posprueba de los grupos control $(\mathrm{p}=0.1900, \mathrm{~W})$ ni experimental $(\mathrm{p}=0.1100, \mathrm{~W})$. Al examinar nuevamente la encuesta, se observó que los ítems de "reto" estaban redactados como la búsqueda activa de situaciones desafiantes (por ejemplo: "dentro de lo posible, busco situaciones nuevas y desafiantes en mi ambiente académico"), en cambio, el concepto de "reto", como "actitud resistente", hace referencia a asumir los problemas que llegan en forma inherente al desarrollo de los proyectos de vida, pero no a buscarlos activamente. Es plausible que esta diferencia aparentemente sutil sea la causa de la falta de mejoría en este punto, o sea, una persona puede asumir como reto las dificultades que le lleguen en el desarrollo de su proyecto de vida (lo que corresponde a la PR), pero no estar interesada en ir a buscarlas sin necesidad. Queda pendiente estudiar en el futuro este aspecto para definir la veracidad de esta posibilidad.

Tamaño del efecto. Para "compromiso" fue de 0.46 (grande) y para "control" fue de 1.05 (muy grande), lo que indica que hubo una mejoría evidente en el grupo experimental en estas dos actitudes resistentes, en especial en el "control", aunque la muestra era relativamente pequeña. No se realizó la prueba para "reto", porque para esta actitud no se encontró diferencia significativa entre las medias de las pospruebas.

\subsubsection{Resultado global de estrategias de afrontamiento}

Figura 9. Medias Globales de Estrategias de afrontamiento, Pre y Posprueba, Grupos Experimental y Control.

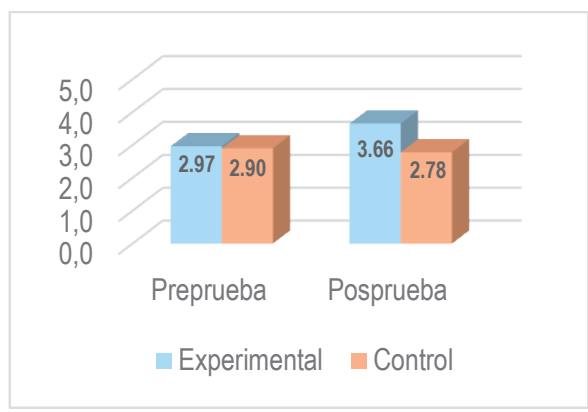


La media del grupo experimental pre-posprueba se incrementó de 0.69 , en cambio la media del grupo control pre-posprueba disminuyó 0.12 .

Tabla 4.Medidas estadísticas de las actitudes resistentes consideradas globalmente.

\begin{tabular}{lccc}
\hline & \multicolumn{3}{c}{ Estrategias de Afrontamiento } \\
Prueba & Pre & Pos & W \\
\hline G. experimental & $\overline{\mathrm{x}}=\mathbf{2 , 9 7}$ & $\overline{\mathrm{x}}=\mathbf{3 , 6 6}$ & 0,0194 \\
& $\mathrm{~s}=0.55$ & $\mathrm{~s}=0.57$ & \\
G. control & $\overline{\mathrm{x}}=\mathbf{2 , 9 0}$ & $\overline{\mathrm{x}}=\mathbf{2 , 7 8}$ & 0,0727 \\
& $\mathrm{~s}=0.46$ & $\mathrm{~s}=0.53$ & \\
M-W & 0,3249 & 0,000001 & \\
S general & & 0.69 & \\
\hline Tamaño del efecto & & 1,28 & \\
\hline
\end{tabular}

Nota. autoría propia. "S general" = desviación estándar del grupo control más el experimental.

Diferencias significativas. Para obtener el promedio general, dado que estrategias de afrontamiento "desviación" tiene una connotación inversa a las demás, o sea, es más útil a menor puntuación, se invirtieron sus valores. No se encontraron diferencias significativas en las medias de las estrategias de afrontamiento entre las prepruebas de los grupos experimental y control $(\mathrm{p}=0.3249 ; \mathrm{M}-\mathrm{W})$ pero sí entre pospruebas $(\mathrm{p}=0.000001 ; \mathrm{M}-\mathrm{W})$, lo que indica que el Programa de EE produjo cambios significativos en los niveles de estrategias de afrontamiento. Coherentemente, no había diferencias entre la pre y posprueba del grupo control $(\mathrm{p}=0.0702 ; \mathrm{W})$ pero sí del grupo experimental $(\mathrm{p}=0.00006 ; \mathrm{W})$.

Tamaño del efecto. Para las estrategias de afrontamiento fue de 1.28 (muy grande), lo que indica que hubo una mejoría evidente en el grupo experimental en las estrategias de afrontamiento consideradas globalmente, aunque la muestra era relativamente pequeña. 
Programa modelo de educación experiencial orientado al desarrollo de personalidad resistente en estudiantes de atención prehospitalaria

\subsubsection{Resultado por cada estrategia de afrontamiento}

Figura 10. Medias de las Estrategias de afrontamiento, Pre y Posprueba, Grupos Experimental y Control

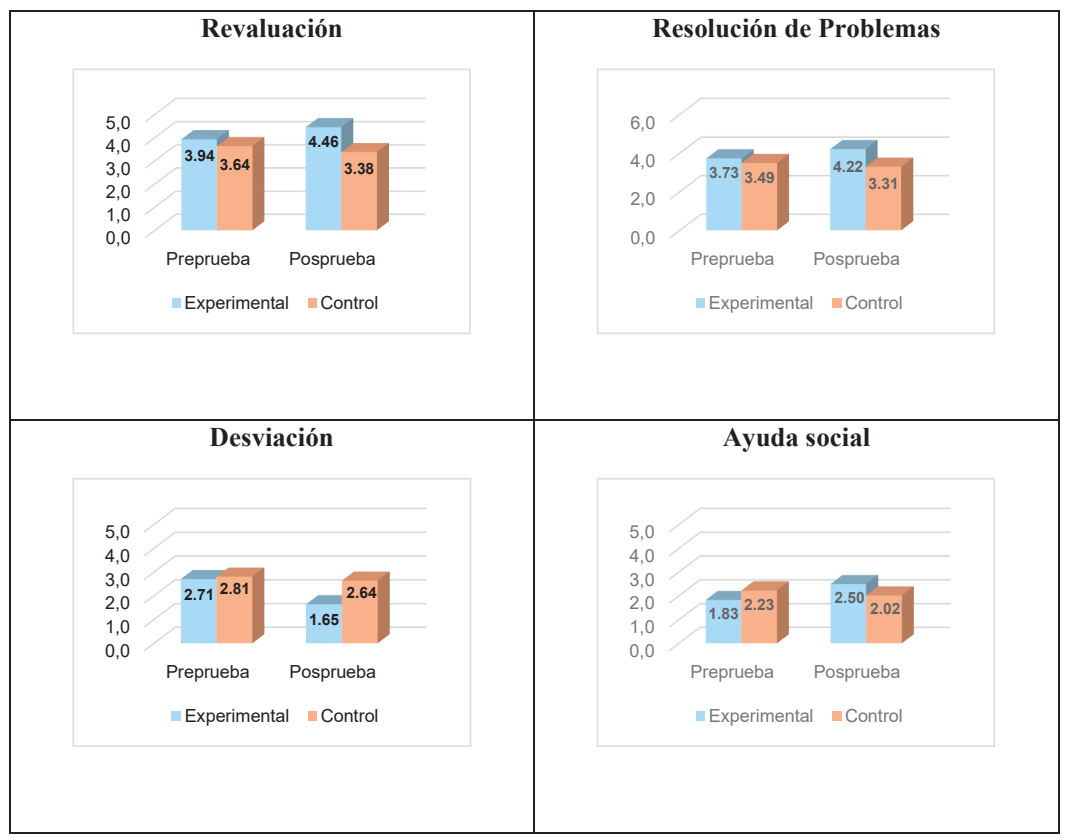

La media del grupo experimental pre-posprueba cambió positivamente en las cuatro estrategias de afrontamiento, y la media del grupo control pre-posprueba cambió negativamente en las cuatro estrategias de afrontamiento.

Tabla 5.Medidas estadísticas de cada una de las estrategias de

\begin{tabular}{|c|c|c|c|c|c|c|c|c|c|c|c|c|}
\hline \multirow[b]{2}{*}{ Prueba } & \multicolumn{3}{|c|}{ EA Resignificación } & \multicolumn{3}{|c|}{ EA Resolución Problemas } & \multicolumn{3}{|c|}{ EA Desviación } & \multicolumn{3}{|c|}{ EA Ayuda Social } \\
\hline & Pre & Pos & W & Pre & Pos & W & Pre & Pos & W & Pre & Pos & W \\
\hline G. experimental & $\begin{array}{l}\bar{x}=3,94 \\
s=0.63\end{array}$ & $\begin{array}{l}\bar{x}=4,46 \\
s=0.45\end{array}$ & 0,0001 & $\begin{aligned} \bar{x} & =3,73 \\
s & =0.86\end{aligned}$ & $\begin{array}{l}\bar{x}=\mathbf{4 , 2 2} \\
\mathrm{s}=0.73\end{array}$ & 0,0028 & $\begin{array}{l}\bar{x}=2,71 \\
s=0.97\end{array}$ & $\begin{array}{l}\bar{x}=1,65 \\
s=1.14\end{array}$ & 0,0005 & $\begin{array}{l}\bar{x}=\mathbf{1 , 8 3} \\
\mathrm{s}=1.17\end{array}$ & $\begin{array}{l}\bar{x}=\mathbf{2 , 5 0} \\
\mathrm{s}=1.18\end{array}$ & 0,0009 \\
\hline G. control & $\begin{array}{l}\bar{x}=3,64 \\
s=0.85\end{array}$ & $\begin{array}{l}\bar{x}=3,38 \\
s=0.96\end{array}$ & 0,0414 & $\begin{array}{l}\bar{x}=\mathbf{3 , 4 9} \\
\mathrm{s}=0.82\end{array}$ & $\begin{array}{l}\bar{x}=\mathbf{3 , 3 1} \\
\mathrm{s}=1.08\end{array}$ & 0,1049 & $\begin{array}{l}\bar{x}=\mathbf{2 , 8 1} \\
\mathrm{s}=0.93\end{array}$ & $\begin{array}{l}\bar{x}=\mathbf{2 , 6 4} \\
\mathrm{s}=1.17\end{array}$ & 0,1151 & $\begin{array}{l}\bar{x}=\mathbf{2 , 2 3} \\
\mathrm{s}=1.07\end{array}$ & $\begin{array}{l}\bar{x}=\mathbf{2 , 0 2} \\
s=1.02\end{array}$ & 0,1652 \\
\hline $\mathrm{M}-\mathrm{W}$ & 0,1235 & 0,00001 & & 0,1992 & 0,0006 & & 0,3064 & 0,0012 & & 0,0774 & 0,0713 & \\
\hline$S$ general & & 0.96 & & & 1.06 & & & 1.24 & & & 1.09 & \\
\hline Tamaño del efecto & & 1,13 & & & 0,86 & & & 0,80 & & & 0,44 & \\
\hline
\end{tabular}

Nota: autoría propia. "S general" = desviación estándar del grupo control más el experimental. 
Reevaluación positiva, resolución de problemas y desviación. En relación con las medias de las estrategias de afrontamiento de los grupos experimental y control, no se encontraron diferencias significativas entre las prepruebas (reevaluación positiva $\mathrm{p}=0.1235$, resolución de problemas $\mathrm{p}=0.1992$ y desviación $\mathrm{p}=0.3064 ; \mathrm{M}-\mathrm{W}$ ), pero sí entre las pospruebas (reevaluación positiva $\mathrm{p}=0.00001$, resolución de problemas $\mathrm{p}=0.0006$ y desviación $\mathrm{p}=0.0012 ; \mathrm{M}-\mathrm{W})$, lo que indica que el Programa de EE produjo cambios significativos en los niveles de estas estrategias de afrontamiento. Coherentemente, había diferencias entre la pre y posprueba del grupo experimental (reevaluación positiva $\mathrm{p}=0.0001$, resolución de problemas $\mathrm{p}=0.0028$ y desviación $\mathrm{p}=0.0005 ; \mathrm{M}-\mathrm{W})$, pero no en el grupo control, excepto en resignificación ( $\mathrm{p}=0.0414 ; \mathrm{W})$, esto es, el grupo control tuvo un empeoramiento significativo en esta estrategia.

Ayuda social. En relación con las medias de las estrategias de afrontamiento de los grupos experimental y control, no se encontraron diferencias significativas entre las prepruebas $(\mathrm{p}=0.0774 ; \mathrm{M}-\mathrm{W}) \mathrm{ni}$ entre pospruebas $(\mathrm{p}=0.0713 ; \mathrm{M}-\mathrm{W})$. Sin embargo, en la preprueba, la media de esta estrategia en el grupo experimental era 0.4 unidades más baja que la del grupo control; al medir el cambio, no se encontraron diferencias significativas entre pre-posprueba en el grupo control $(\mathrm{p}=0.1652 ; \mathrm{W})$, pero sí en el grupo experimental $(\mathrm{p}=0.0009 ; \mathrm{W})$, indicando una influencia significativa del programa de EE también en la estrategia de afrontamiento "ayuda social".

Tamaño del efecto. Para "reevaluación positiva" fue de 1.13 (muy grande), para "resolución de problemas" 0.86 (muy grande), para "desviación" 0.80 (muy grande) y para "ayuda social" 0.44 (grande), lo que indica que hubo una mejoría en el grupo experimental en todas las estrategias de afrontamiento, aunque la muestra era relativamente pequeña 


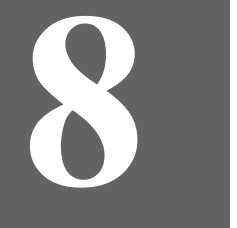

\section{Resultados cualitativos}




\section{Resultados cualitativos}

\subsection{Mapa categorial}

Figura 11. Mapa categorial.

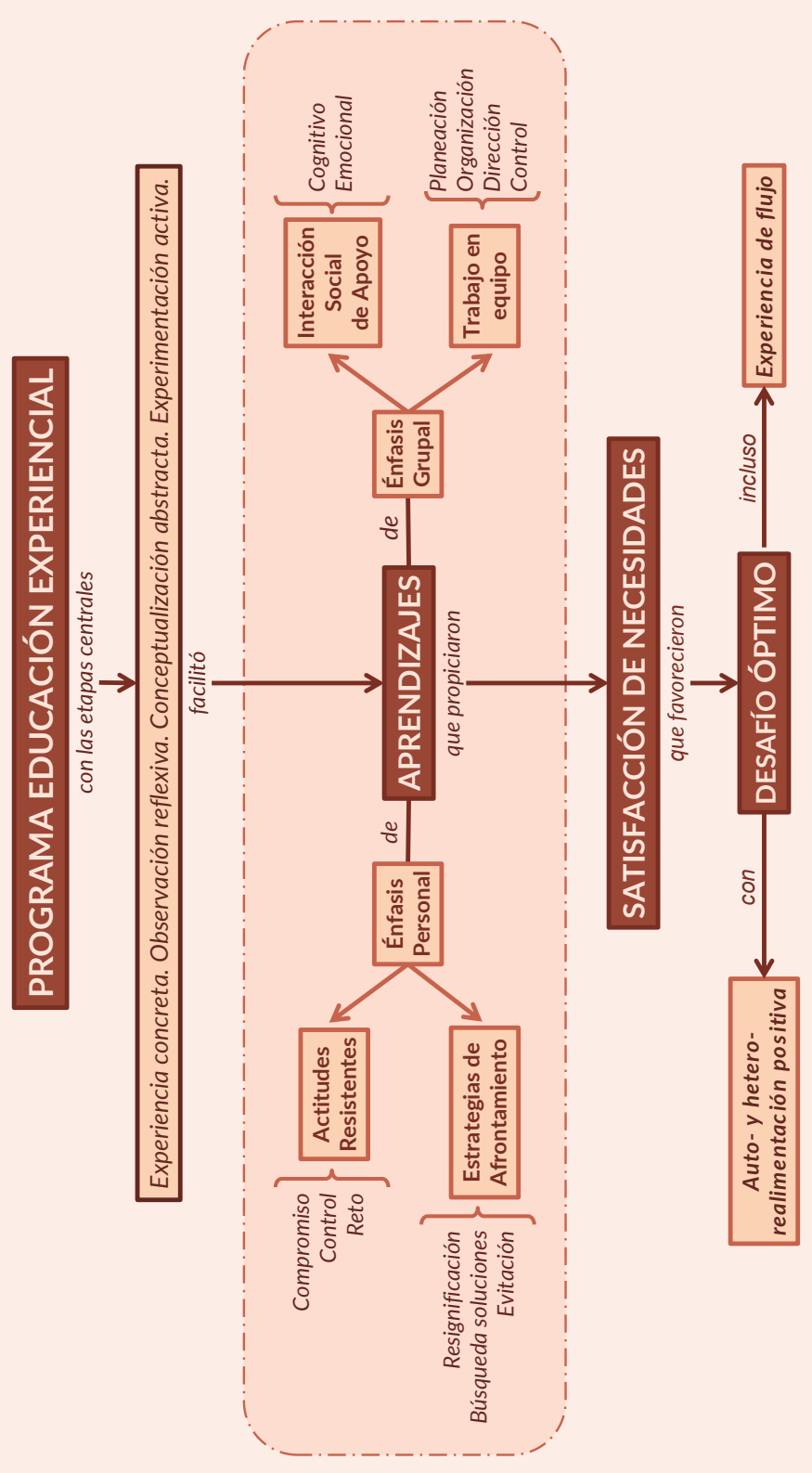


Este resultado cualitativo se obtuvo mediante un proceso inductivo a partir de los cuestionarios semiestructurados que fueron diligenciados por los participantes al finalizar las sesiones y, especialmente, el Programa de EE. Se preguntaron las percepciones en relación con la influencia del Programa en sus actitudes resistentes y estrategias de afrontamiento. Luego de un examen minucioso de los textos se identificó un conjunto de ideas, que se analizaron y agruparon para obtener categorías. Estas categorías se compararon entre sí y con la teoría para definir sus relaciones y, finalmente, encontrar un sentido global. Las descripciones de las categorías se acompañan por citas textuales ilustrativas referenciadas así: iniciales de primer nombre y apellido, número del documento y número de la cita.

Nota de lectura. Para facilitar la comprensión se sugiere: leer en principio el texto sin las citas, que están en cursiva y examinar estas citas cada vez que el lector quiera ver esta evidencia cualitativa.

\subsection{Programa de educación experiencial}

Este programa fue percibido por los participantes como una actividad educativa novedosa: cuando mi profesor llega a clase con tres personas para dar un giro a la normalidad de las clases con actividades por desarrollar $D V$ 22:23, que estaba orientada a sus necesidades académicas: el enfoque está muy acorde a lo que nosotros en nuestra carrera necesitamos conocer LM 22:149 y a concientizar la importancia del trabajo en equipo: siento que las actividades aparte de hacernos reflexionar sobre la importancia de trabajar en equipo, nos dieron la oportunidad de integrarnos como grupo DS 22:106. En relación con las diferentes etapas de EE manifestaron las siguientes consideraciones.

\subsubsection{Sensibilización}

Al finalizar la sensibilización inicial del Programa, los estudiantes manifestaron su decisión de concientizar mejor su proyecto de vida y trabajar para alcanzarlo: quiero encontrarle el verdadero sentido a mi vida MH 25:5; cambiar en ser más dedicada a lo que quiero lograr para mi vida DM 25:28, afrontando las dificultades que se presenten: voy a ser más fuerte ante los retos, voy a afrontar con más valentía 
cada situación que se presente $M B$ 25:3, viéndolas como retos para sus propias capacidades: en vez de ver mis problemas tendré en cuenta todas mis habilidades KL 25:8 y como oportunidades de aprendizaje: voy a dejar de tener tanto miedo a equivocarme y más bien tomaré todo como una enseñanza KL 25:7; mirarlos desde un enfoque más correcto que pueda crear una solución bien adecuada y tomar esos errores $y$ dificultades como una experiencia en mi vida JR 25:20, así como fortaleciendo el apoyo social: voy a buscar algunas viejas amistades que dejé de lado por diversos motivos DP 25:31. Esto implica ejercer la autodeterminación al verse como el protagonista de su proyecto de vida, al realizar elección según los propios intereses, así esta sensibilización inicial fomenta la autonomía de los estudiantes en relación con su proyecto de vida en general y con el Programa de EE en particular.

\subsubsection{Experiencia}

Vivieron las situaciones de reto que se les presentaron en un ambiente envolvente realista como estresantes y difíciles de superar: nos enfrentamos a nuevos retos y pruebas en ambientes que pudieron llegar a ser tensionantes... y un objetivo final, al cual siempre era difícil llegar EV 22:129, lo cual los sacó de su zona de confort y les generó conflictos cognitivos propiciadores de aprendizaje, que era precisamente lo planeado: tuvimos una serie de pruebas experienciales, desafiamos nuestras capacidades y reinventamos un poco nuestra manera de pensar EV 22:130.

\subsubsection{Reflexión}

La meditación sobre la experiencia los llevó a tomar conciencia de la importancia de este proceso para su vida cotidiana: en esto entendi que el pensar en lo que hacemos es bueno ya que nos ayuda a observar cómo mejoraríamos DG 22:27, especialmente porque les permitió identificar y corregir falencias: me analizo personalmente como fue mi desempeño individual y grupalmente para mejorarlo personalmente DM 21:10. Este paso del ciclo de EE llevó entonces a que mejoraran su introspección y autoconocimiento: al final aprendí a conocerme un poquito más de este largo recorrido interior e identificar mis habilidades y capacidades KL 22:42, lo que facilita una mejor calidad de vida personal y grupal, tanto en su actual vida cotidiana y como futura laboral: realizar actividades en clase como las que hicimos, nos 
ayudan a ir tomando conciencia frente a lo que nos enfrentaremos en nuestra carrera y también nos ayuda a tomar en cuenta estas prácticas para nuestro diario vivir DM 22:134, en especial, por la cualificación en el manejo de las emociones: aprender a identificar las situaciones que nos generan estrés, ansiedad LM 22:55 y la utilización de una comunicación asertiva, lo cual mejora la capacidad de resolución de problemas y, por ende, disminuye el riesgo de SDO: se me hace mucho más fácil ponerme de acuerdo con la decisión tomada por otros para evitar conflictos; analizándolo, no está bien puesto que ahora fue frente a un juego, luego será frente a situaciones reales donde por no dar mi opinión con carácter podría verme perjudicada en situaciones de trabajo y encontré que se aprovecharán de eso y pasarán sobre mí DM 22:168.

\subsubsection{Conceptualización}

Para la conceptualización se les presentó la teoría pertinente de acuerdo con el programa de EE diseñado. Luego, con base en la reflexión, personal y colectiva, y la teoría presentada, se les pedía buscar estrategias para superar el reto propuesto: todos aportamos ideas y pensamos en un bien común, pero no lo logramos a la primera, requirió de más planeación JO 11:9. Esto les permitió concientizar la importancia de reflexionar, revisar la teoría y escuchar a los otros para lograr objetivos: al socializar los resultados vemos que podemos mejorar y que hay más formas de desarrollar una actividad o problema y ver la opinión de otro me ayudó a crecer como persona MT 18:12. Y este proceso de conceptualización lo consideraron pertinente no sólo para su actual vida cotidiana sino para su futura laboral: cuando los profesores me corrigieron en algo que no sé, siempre pienso en qué sería de mí si no me hubiese equivocado en ese momento y no en la vida real KL 5:7.

\subsubsection{Experimentación}

Durante la experimentación, pusieron en práctica lo aprendido en las etapas anteriores de reflexión y conceptualización: fue obvio que el segundo intento en las actividades fue el mejor coordinado y ejecutado ST 17:11; fue importante ver cómo personal y grupalmente, logramos mejorar muchas cosas, reflexionar y descubrir habilidades en las que 
éramos muy buenos y otras que tal vez no eran nuestro fuerte DS 22:96. Lo que les permitió poner a prueba las propias capacidades y valorarlas de una forma más real: unos al principio tenían dudas de si iban a ser capaces por las habilidades propias, pero tras la perseverancia esas capacidades de las que dudaban, mejoraban JM 7:13, así como desarrollarlas, tanto en forma personal como en el trabajo en equipo: sabemos que todos tienen habilidades diferentes y en cada prueba todos aportamos algo de eso, pero como todo hubo fallas, pero al final lo logramos JO 11:10 y les facilitó el cambio hacia una actitud de compromiso: al finalizar la actividad se evidenció el cambio de actitud de cada uno de los integrantes del grupo, hubo más compromiso y una mejor disposición de cada uno frente a los retos puestos por los profesores; finalmente logramos solucionar la dificultad AS 16:10. La experimentación llevó a una nueva reflexión, que daba reinicio al ciclo de EE: al final siempre pensaba en qué cosas habiamos fallado en los primeros intentos y qué diferencias habia cuando [en definitiva] se lograba solucionar el problema satisfactoriamente DS 15:11. Además, la experimentación la vivieron no sólo fue durante la sesión, sino también después de ella, en su vida cotidiana: no sólo la practiqué en clase sino por fuera, con alguien muy especial, de la cual me dio un gran resultado $D G$ 22:21.

\subsection{Aprendizajes}

Los participantes manifestaron aprendizajes personales y grupales: me ha traído conocimiento y diferentes pensares, los cuales no sólo me ayudaron a mí sino a mis compañeros $D G$ 22:19. Si bien lo individual impacta lo colectivo y viceversa, los aprendizajes se pueden clasificar según su énfasis, personal: actitudes resistentes y estrategias de afrontamiento, y grupal: interacción social de apoyo y proceso administrativo. Este último no aparece originalmente en la teoría sobre PR, pero es el que le dio estructura a la búsqueda de la superación de un reto colectivo, propio de la EE y del trabajo en atención prehospitalaria, lo cual fue confirmado en este análisis cualitativo. 
Programa modelo de educación experiencial orientado al desarrollo de personalidad resistente en estudiantes de atención prehospitalaria

\subsection{Actitudes resistentes}

\subsubsection{Compromiso}

Los participantes manifestaron que, para llegar adquirir un verdadero compromiso en su vida académico y profesional, primero debe revisar cuáles son los valores y metas personales: debemos tener en cuenta [...] nuestros valores, ¿quién soy?, ¿quién quiero ser?, ¿qué capacidades tengo?, ¿cuál es mi misión? LM 22:150, que para el caso de esta población se relacionan con brindar atención prehospitalaria orientada a salvar la salud y la vida de personas en situaciones críticas: la responsabilidad de salvar vidas es muy grande y si no nos proponemos nosotros, que somos TAPH, nadie lo hará. JO 10:1 y consideraron que sólo si se comprometían podían lograr un rendimiento óptimo: si no soluciono la dificultad que se me está presentando no voy a poder dar lo máximo de mí en las diferentes actividades que realizó en mi día a día PD 2:1. Además, expresaron que el programa de EE inmersivo realista los condujo a un mayor compromiso en el desarrollo de las actividades: Al finalizar la actividad se evidenció el cambio de actitud de cada uno de los integrantes del grupo, hubo más compromiso y una mejor disposición AS 16:10, lo que trascendió a su vida cotidiana, tanto en sus actividades académicas como en las laborales: en el desarrollo de las diferentes clases que se han presentado en psicocrisis he aprendido la forma en que yo como ser humano puedo encontrar la correcta solución y cómo afrontar con tenacidad y empuje, para así comprometerme mucho más con la solución al problema que estoy viviendo, ya sea como en mi caso que trabajo, puede ser tanto laboral como educativa JR 22:74.

\subsubsection{Control}

Manifestaron un cambio positivo en la consideración de sus capacidades como suficientes para vencer los retos propuestos, por un mayor autoconocimiento: la última actividad me enseñó que todo está en mí, qué debo conocer mis habilidades, talentos, fortalezas $y$ capacidades MR 22:81, por el desarrollo de estas: antes de las actividades no sentía que tenía las capacidades suficientes en algunos casos, pero luego entendí que puedo desarrollar esas capacidades LM 8:2, la persistencia: he aprendido la forma en que yo, como ser humano, 
puedo encontrar la correcta solución JR 22:79 o el trabajo en equipo: aprendi a buscar apoyo en los demás ya que hay circunstancias en las que uno solo no puede PD 22:8. Y que este mayor control resistente trascendió a su vida cotidiana: ya que me siento confiado en mí y en qué forma difícil que sea, ser convencido de mí mismo ayudará siempre a lograr cualquier dificultad MT 18:2.

\subsubsection{Reto}

El reto como actitud resistente comprende ver los problemas como oportunidades de aprendizaje no como amenazas aplastantes y como parte normal de la vida; los participantes refirieron que ambos aspectos fueron promovidos por el programa de EE: por más duras que parezcan debemos afrontarlas, no son amenazas, son un camino seguro al éxito JO 11:3; aprendí que no debo rendirme ante cualquier situación difícil

[...] que gracias a ello me hago más fuerte y sabia, la vida está llena de retos que cada vez nos llenan de experiencia MR 22:80, ya que al visualizar los problemas como retos comenzaban a buscar diversas formas de solución de los mismos: aprendi y mejoré mi resistencia, me di cuenta que no hay que rendirse tan fácilmente porque hay múltiples maneras de lograr los objetivos y que los obstáculos se pueden resolver de diversas maneras EV 22:132 y concienciaban capacidades propias que les permitían realizar afrontar y solucionar las dificultades: aprender a conocer mis capacidades y actitudes es necesario y esto pasa cuando veo las dificultades como un reto, es decir, identifico el reto y posteriormente lo acepto sintiéndome capaz de superarlo y de que mejore la situación que se presenta DV 20:3, y esto lo incorporaron a su vida cotidiana y laboral: pienso que la experiencia me va a ayudar a mejorar y a aprender de las dificultades y sobre todo a saber solucionar las de mejor manera cuando vuelvan a surgir DV 20:7.

\subsection{Estrategias de afrontamiento}

\subsubsection{Evitación}

Al preguntarles al final del Programa, parecía que los participantes utilizaban la estrategia de afrontamiento "evitación"; sin embargo, al analizar con más cuidado, realmente lo que evitan es: centrarse en el problema dejando de lado la búsqueda de soluciones: no me gusta pensar mucho en un problema porque puede volverse peor en 
mi mente JM 7:2; cuando quiero lograr superarlas no me centro en ellas porque me centraría en lo que no me dejaría avanzar JhO 11:8; aprendí a no encerrarme en el problema y creer que no soy capaz de resolverlo por el estrés que me crea la situación dificil PD 22:141. En cambio, manifiestan que hay aceptar que hay un problema, pero no enfocarse en él por las emociones negativas que pueden surgir de esta manera, sino buscar y encontrar una solución: es necesario y esencial identificar y aceptar el problema MT 22:111; enfrentando los problemas o dificultades será de gran ayuda para poder salir adelante con el problema AS 16:1; cualquier actividad académica o laboral se debe solucionar no ser postergada ST 17:1.

\subsubsection{Búsqueda de soluciones}

Los participantes manifestaron que desarrollaron la estrategia de afrontamiento "búsqueda de soluciones" y no evitación, como parte de los aprendizajes del Programa de EE: anteriormente no veía o tenía en cuenta todas las capacidades que podía tener y simplemente cuando realizaba el último intento desistía y dejaba que la impotencia me dominara, luego de las prácticas [...] he aprendido a seguir buscando una solución $J M 7: 2$. De forma que aprendieron a examinar los problemas, identificar opciones de solución y planear su ejecución: en el desarrollo de las diferentes clases [...] he aprendido la forma en que [...] puedo encontrar la correcta solución JR 22:79; aprendí a no precipitarme, primero estructurar un plan y un orden para llevarlo a cabo PD 22:9. Además, informaron que la búsqueda de una solución hace que el problema se perciba de menor magnitud y, por lo tanto, más sencillo de solucionar: buscar la solución hace que la perspectiva cambie y mostrar que en realidad no es de tal magnitud DV 20:4.

\subsubsection{Resignificación o reevaluación positiva}

La resignificación como estrategia de afrontamiento consiste en ver los problemas como aprendizajes. Los participantes manifestaron ver las dificultades como oportunidades para su desarrollo humano: siempre hay una manera de solucionarlo y si no es asi entonces será una gran oportunidad para ayudarnos a crecer como personas MT 22:169, lo que lleva al cambio de emociones de fracaso a emociones adaptativas: aprendí que por más difícil que se vea la situación siempre hay que 
buscarle el lado positivo KL 22:39. Además, refirieron que llevaron este aprendizaje a su vida cotidiana: mediante el programa de educación experiencial me ayudaron a saber enfrentar las dificultades durante mis actividades académicas y mi vida diaria, viendo el problema desde un punto de vista diferente AO 22:154.

\subsection{Interacción social de apoyo}

Aunque el "apoyo social" usualmente se incluye dentro de las "estrategias de afrontamiento", Maddi separa "afrontamiento resistente" que es individual, de la "interacción social resistente" que es colectiva y divide esta última en apoyo cognitivo y emocional (Maddi, 2013, pág. 9). Los participantes se refirieron a este apoyo social como esencial para enfrentar y resolver los problemas: me he dado cuenta de que [...] no siempre tengo la solución yo y que necesito del otro para crecer personalmente MT 22:125; aprendí la unión en cada uno, cómo somos de importantes, éramos ese pedacito de bloque para formar una estructura y si uno caía, todo se derrumbaba DG 22:25.

\subsubsection{Apoyo cognitivo}

Varios estudiantes manifestaron que el programa de EE les permitió concientizar la importancia del apoyo social para solucionar los problemas: antes del programa de educación experiencial creía que la ayuda social no era necesaria, pero ahora me doy cuenta que si, que el apoyo de las demás personas es de vital importancia, este ayuda a cambiar de perspectiva y de actitud DV 20:5. Y esto en ambos sentidos, o sea, apoyar y ser apoyado: comprendi la importancia de ayudar al otro y de buscar apoyo en el compañero cuando es necesario $A S$ 22:133, de forma que se puedan aprovechar las capacidades para trabajar en equipo y lograr las metas propuestas: saber aprovechar las virtudes de mis compañeros, en pro de obtener un mejor resultado a la hora de realizar un trabajo en equipo JM 22:50.

\subsubsection{Apoyo emocional}

Manifestaron que este tipo de apoyo es muy útil para manejar apropiadamente los sentimientos negativos que tienden a surgir al enfrentar problemas: algo que me parece increíble es cómo el trabajo 
en equipo nos puede ayudar tanto, como el sentir un apoyo y sentir que no estoy solo, logra cambiar totalmente un pensamiento negativo, de hecho, me pareció algo esencial LM 22:167, al permitir la catarsis: el apoyo emocional me permite dar a conocer mis sentimientos $y$ desahogarme por medio de la escucha activa del otro PD 22:6 y disminuir el estrés de las dificultades: me da más confianza en mí mismo y me ayuda a que la carga sea más liviana MT 18:6, en especial en las situaciones críticas propias de su trabajo: cuando en una situación de emergencia entramos en crisis necesitamos el apoyo emocional de los demás JO 10:6 y en las personas con menos capacidades: aprendí [...] a tener en cuenta a aquellos que no pueden seguir el paso de la misma forma; el hecho de no abandonarlos sino de motivarlos para que ellos mismos no desistan y sean conscientes de que verdaderamente son capaces de superar cualquier reto si se lo proponen JM 22:51.

\subsection{Trabajo en equipo}

Los participantes valoraron como necesario tanto el "trabajo en equipo" como su organización mediante el "proceso administrativo" para unir capacidades y superar los retos propuestos: al inició nos costaba mucho porque no nos escuchábamos, no teníamos nuestra meta fija, nos dispersamos y no teníamos en cuenta a nuestros demás compañeros; en ocasiones habia tanto individualismo, que se olvidaban de ayudar al otro. Luego de ver que si esto pasaba no llegaríamos al objetivo, las cosas empezaron a cambiar EV 22:131; con las actividades me quedó claro que para lograr hacer un buen trabajo en equipo es sumamente importante la planificación, organización, dirección y el control, tener un líder LM 22:58.

\subsubsection{Planeación}

Los estudiantes señalaron reiteradamente que uno de los mayores aprendizajes que les brindó el programa de EE fue planear antes de actuar: cuando empezamos nos gustaba ir directamente al objetivo sin necesidad de un plan alguno, pero [...] fracasamos, tuvimos muchos intentos de los cuales en los primeros tiempos, no lo logramos DG 22:28; durante el pasar de los ejercicios se hizo más notable que el hecho de tomar un tiempo prudente para realizar un plan, en donde se evalue cómo llegar al objetivo teniendo en cuenta las capacidades de todos 
además de las reglas para conseguirlo, era algo de suma importancia $J M$ 7:8. Además, que era un aprendizaje que debían aplicar en su vida cotidiana y laboral: en las actividades realizadas en clase, se evidenció que un buen liderazgo y una buena planeación son prioridades para terminar bien ejecutada cualquier tipo de actividad, trabajo y resolver una situación de cualquier tipo ST 22:117; la planeación en un equipo es muy importante, ya que si no se tiene en cuenta podría costarnos la vida siendo un caso real AO 9:7.

\subsubsection{Organización}

Este proceso comprende la división de las actividades según una estructura jerárquica, con tareas y roles, y las formas de interacción entre los diferentes actores; esta división es necesaria para trabajar en equipo en pro de un objetivo común. Los participantes se hicieron conscientes de la importancia de la sinergia de equipo con el programa de EE: en la primera sesión pude observar que mis compañeros y yo, al realizar la actividad al primer momento, no éramos conscientes de lo importante que era el comunicarnos entre todos para saber cómo era que íbamos a lograr pasar los obstáculos DS 22:91; porque tener una organización es hacer que cada miembro del equipo dé lo mejor de sí mismo, con el objetivo de que el equipo sea una potencia y este coordinado para cumplir sus funciones AO 9:8. Una vez concientizaron la importancia de trabajar en equipo en forma organizada, comenzaron a hacerlo: entre todos definimos con claridad los líderes y tomamos roles que permitieran desarrollar las actividades eficazmente $M B$ 1:9; porque tener una organización es hacer que cada miembro del equipo dé lo mejor de sí mismo, con el objetivo de que el equipo sea una potencia y este coordinado para cumplir sus funciones AO 9:8; aprendimos a comunicarnos mejor, a escuchar a los demás DS 22:94. Y esto lo piensan utilizar en su vida cotidiana: a lo largo de la vida estamos destinados en algún momento a tener que trabajar en equipo [...] es ahi cuando debemos ser conscientes de que necesitamos de varias habilidades para poder trabajar armónicamente con los demás DS 22:85. 
Programa modelo de educación experiencial orientado al desarrollo de personalidad resistente en estudiantes de atención prehospitalaria

\subsubsection{Dirección}

Este proceso incluye varios aspectos, tales como: liderazgo y toma de decisiones, motivación, comunicación y resolución de conflictos. Refieren que el programa de EE les permitió concientizar más la importancia de este proceso: cuando hay un equipo con el cual se debe trabajar, es demasiado importante elegir una líder, para que éste nos guie durante el desarrollo de la actividad o el problema a resolver, esto permite que todos trabajen controladamente y que las ideas que todos tienen se tomen en cuenta y finalmente se elija la mejor opción a seguir JM 22:49 y mejorarlo: siento que mejoré mi capacidad de ser líder, de guiar a mi equipo DS 22:98; también aprendi a no tener tanto miedo a la hora de liderar JM 22:49, para obtener una adecuada comunicación y resolución de conflictos que permita alcanzar el objetivo común: al comienzo [...] fue un caos [...], el designar el liderato a una persona hizo más sencillo el comunicar las instrucciones y resolver los conflictos ST 7:10.

\subsubsection{Control}

Los estudiantes manifestaron que aprendieron a hacer la evaluación y ajuste a las estrategias planeadas, con el fin de identificar las fallas que tenían y realizar los ajustes necesarios para conseguir los objetivos propuestos: al primer intento identificamos las fallas y volvimos a resolver el problema JO 11:12, y esto lo llevaron a su vida cotidiana: al socializar los resultados vemos que podemos mejorar y que hay más formas de desarrollar una actividad o problema; y ver la opinión de otro me ayudó a crecer como persona MT 18:12; me parece importante evaluar después los resultados obtenidos [...] para realizar las respectivas modificaciones y asi poder lograr obtener un mejor resultado LM 8:10).

\subsection{Satisfacción de necesidades psicológicas}

Necesidad de autonomía. Esta necesidad hace referencia al impulso por ser el autor principal de la propia vida. El Programa de EE brindó satisfacción a esta necesidad tal como lo expresan los estudiantes en los puntos "Sensibilización" (de "6.2 Programa de educación experiencial") y "Compromiso" (de "6.4 Actitudes resistentes"). 
Necesidad de competencia. Esta necesidad hace referencia al impulso por ejercer las propias capacidades para dominar dificultades. El Programa de EE también brindó satisfacción a esta necesidad tal como lo expresan en los puntos "Control" y "Reto" (de "6.4 Actitudes resistentes") y "6.5 Estrategias de afrontamiento".

Necesidad de afiliación. $Y$ a esta necesidad, que hace referencia al impulso por crear y mantener vínculos emocionales cercanos con otras personas, también se le ofreció satisfacción según narran en el punto "6.6 interacción social de apoyo", en especial, por el apoyo emocional.

\subsection{Desafío óptimo}

\subsubsection{Realimentación positiva}

En relación con este punto, en el programa de EE se planteaba una tarea claramente definida (similar a alguna de la vida real de atención prehospitalaria), por lo que era fácil de captar si se estaban acercando o no a la meta y, por lo tanto, obtenían una clara realimentación sobre su progreso de la tarea misma y del desarrollo de sus propias capacidades: a medida que intentábamos lo haciamos más fácil, hasta que al final lo logramos y vimos incluso qué teníamos habilidades que no habíamos desarrollado JO 22:72, así como de las evaluaciones positivas de los demás: es muy importante y muy gratificante la felicitación al final de lograr el objetivo y cada reflexión, aprendizaje o idea compartirla con todos, como también saber que había otra oportunidad cuando fallábamos y reevaluar como equipo que estábamos haciendo mal y cambiar las estrategias para asi lograrlo DV 20:12 ; cuando alcanzamos una meta y la cumplimos es reconfortante el apoyo de todos al felicitarnos unos a otros, por lo cumplido LM 13:12. Un aspecto por tener en cuenta en relación con la realimentación positiva es la alta tolerancia al fracaso en el programa de EE, de forma que se vivía como un aprendizaje positivo: todo objetivo que se logró fue satisfactorio para mí y si algún objetivo no se alcanzó lo tomé bien porque me sirve para aprender y evaluarme qué está mal JO 10:12. Sin embargo, a diferencia de lo que sucedió en el Programa de EE, en la vida real los errores pueden afectar la salud o la vida de las personas y se dan en un entorno laboral de muy alta exigencia. 
Programa modelo de educación experiencial orientado al desarrollo de personalidad resistente en estudiantes de atención prehospitalaria

\subsubsection{Experiencia de flujo}

Los participantes refirieron que al principio se sentían intimidados por los retos que se les propusieron, pero en la medida en que se comprometieron a superarlos se dieron cuenta que tenían las capacidades necesarias para lograrlo y al hacerlo sintieron satisfacción: cuando me concentraba tanto para poder encontrar la forma en cómo solucionarlo y veía que sí era posible, se me hacía más fácil buscar varias soluciones, tanto personal como grupalmente, y se sentía muy bien al saber que lo que, en un principio parecia imposible de hacer, luego fue fácil de resolver con la ayuda de los demás MT 23:10; me sentí lleno de paz interior por haber realizado con éxito la actividad del taller, sentí que tenía el control total de mis emociones y eso me tranquiliza, que pude lograr un objetivo lo que me hace sentir una sensación de plenitud JO 23:7. Y expresaron la importancia del trabajo en equipo para unir fortalezas, apoyarse emocionalmente y superar los desafíos: al estar acompañado de varias personas pensando en cómo lograr un objetivo, era menos traumatizante el no encontrar pronto la respuesta y finalmente la satisfacción es completa MT 23:11. Sin embargo, por diferentes situaciones personales ajenas al Programa, por ejemplo, la muerte de un allegado o una crisis familiar, algunos no tuvieron la disposición para comprometerse en la búsqueda de la superación del reto durante el Programa de EE y no vivieron una experiencia satisfactoria: en mi caso fue dificil vivir una experiencia de flujo durante las actividades realizadas en el cuarto semestre, ya que en esos momentos estaba pasando por la situación más difícil de mi vida LM 23:9. 


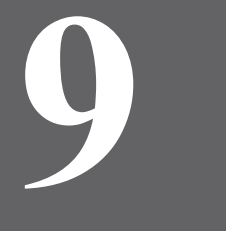

Discusión 


\section{Discusión}

Los profesionales de la salud, en especial los Tecnólogos en Atención Prehospitalaria, se ven enfrentados a situaciones laborales muy exigentes física y psicológicamente por la cantidad de horas trabajadas con turnos nocturnos, usualmente en entornos difíciles, que implican una atención rápida con alto riesgo y ocurrencia de lesión y muerte. Sin embargo, a menudo tienen una baja retribución económica y un bajo reconocimiento social por parte de los pacientes y acompañantes, compañeros de trabajo y jefes, lo que explica la alta prevalencia del Síndrome de Desgaste Ocupacional -SDO- en esta población, el cual es un trastorno que afecta todos los ámbitos de la persona: cognitivo, emocional, psicosomático, social y laboral (Grau et al., 2008; MangingValverde y Csizmadia-Viteri, 2017).

Esta población requiere entonces aumentar su resistencia a la alta exigencia laboral, con poca retribución, para prevenir este SDO. En relación con esto, en la década de 1970 Kobasa y colaboradores encontraron que algunas personas que presentaban ciertas características de la personalidad, que ellos llamaron "Personalidad Resistente" -PR-, no presentaban deterioro psicológico ni físico a pesar de estar sometidas a altos niveles de estrés (Godoy-Izquierdo \& Godoy, 2002). Actualmente la PR incluye tanto las "Actitudes Resistentes" de compromiso (disposición a implicarse en el trabajo en forma coherente con los propios valores), control (disposición a creer que se tiene las capacidades necesarias para superar los problemas) y reto (disposición a ver los problemas como oportunidades de desarrollo personal), como las Estrategias de Afrontamiento, especialmente la orientación a la solución del problema, la evitación del mismo (en esta, cuanto menos mejor), la reevaluación positiva (considerando el problema como un aprendizaje propicio) y el apoyo social, aunque este último lo ponen en otra categoría dado que ya no es psicológico sino psicosocial (Maddi, 2013).

Paralelamente, a partir de la revisión realizada sobre los modelos teóricos más aceptados sobre el estrés en el trabajo, se puede considerar que todos plantean, de una forma u otra, tres grandes categorías: demandas laborales, recursos psicológicos y efectos psicosociales. Los recursos están relacionados con la satisfacción de las necesidades 
psicológicas fundamentales, que para el caso de la PR se da de la siguiente forma. Con la necesidad de competencia: actitud resistente "control" y estrategia de afrontamiento "enfocada en la solución", porque su centro son las propias capacidades; con la necesidad de autonomía: actitudes resistentes "compromiso" y "reto", y estrategias de afrontamiento "enfocada en la resignificación", porque su centro son los propios intereses; y con la necesidad de afiliación: estrategias de afrontamiento "apoyo social", porque su centro es la interacción social. Ahora bien, cuando tanto demandas laborales como recursos están en un nivel similar medio o alto, situación que se ha denominado "desafio óptimo", las personas se sienten motivadas a satisfacer sus necesidades psicológicas fundamentales y el esfuerzo les produce emociones placenteras gratificantes que aportan a la prevención del SDO (Bajwa et al., 2020, p. 2517).

Dado lo anterior, se realizó esta investigación que consistió en el diseño y evaluación de un programa de "Educación Experiencial" -EE- como estrategia para aumentar la PR en estudiantes de Atención Prehospitalaria, ya que la PR es un recurso útil para enfrentar las altas demandas laborales, de forma que se les facilitaría alcanzar un desafío óptimo y de esta manera prevenir el SDO. La EE se fundamenta en la pedagogía constructivista y consiste en la facilitación del aprendizaje mediante la reflexión sobre la vivencia a través de cuatro etapas cíclicas que son: experiencia concreta, es decir, la vivencia; observación reflexiva, momento en que se promueve la concienciación de los pensamientos, emociones y conductas durante la experiencia; conceptualización abstracta, en esta etapa se contrasta lo vivido con la teoría pertinente; y por último la experimentación activa, en la cual, a partir de la conceptualización abstracta, se generan nuevos pensamientos y conductas que pueden ser más útiles para conseguir los objetivos (Kolb \& Kolb, 2009). Todo esto en un entorno de trabajo en equipo orientado a superar desafíos en relación directa con los escenarios laborales y los intereses de los participantes, de forma que se les posibilita la satisfacción de las necesidades psicológicas de afiliación, competencia y autonomía (González-Valencia, 2005, págs. 71-74). Además, la participación inmersa en el simulacro de forma que se vive como si fuera real, también facilita la deconstrucción y reconstrucción del conocimiento que genera nuevos aprendizajes que trascienden a la vida cotidiana (Nogueiras Redondo, 2016, pág. 1). 
Antes de comenzar el programa de EE, se brindó una clase teórica sobre los temas centrales, para facilitar el proceso de conceptualización durante las sesiones de EE, y una sensibilización sobre la importancia del Programa, con el fin de concientizar sobre su pertinencia en la vida cotidiana y laboral de los estudiantes de atención prehospitalaria y motivar su participación activa y el aprendizaje, lo que fue confirmado en la evaluación cualitativa.

El programa comprendió cuatro sesiones de 1.5 horas de actividades de reto, contextualizadas a su realidad laboral y que requerían un trabajo en equipo, el cual se facilitó y gestionó bajo el modelo del proceso administrativo con sus cuatro componentes: planeación, organización, dirección y control. En las actividades de reto se siguieron las etapas cíclicas de la EE descritas por Kolb, un ciclo y medio por sesión así: experiencia, observación, conceptualización y experimentación, y luego experiencia y observación nuevamente; en esta última se contrastó el antes y después de la incorporación de las dimensiones de PR en cuanto a la eficiencia de los intentos por superar el desafío y en cuanto a las diferentes emociones generadas en una y otra circunstancia. Al finalizar cada sesión, se realizaba una plenaria para compartir los aprendizajes y se dejaba una actividad de transferencia de estos a la vida cotidiana. Se utilizó un método mixto para una mayor comprensión del objeto de estudio (Guedes-dos-Santos et al., 2017, p. 8), específicamente un diseño explicativo secuencial: primero cuantitativo de base y luego uno cualitativo para ayudar a contextualizar y comprender mejor los datos cuantitativos (Hernández-Sampieri et al., 2014a, p. 544).

Para el análisis cuantitativo de los datos, se midió la eficacia del programa de EE en la PR utilizando dos instrumentos validados: la "Escala de Personalidad Resistente" (Carmona-Halty et al., 2017) y la escala de estilos y estrategias de afrontamiento al estrés (Londoño A et al., 2009), que en este estudio mostraron un alfa de Cronbach de 0.815 y 0.866 respectivamente. Se observó que la media del grupo control disminuyó, mientras la del grupo experimental se incrementó. No se encontraron diferencias significativas entre las prepruebas de los grupos experimental y control, y sí entre pospruebas; tampoco entre la pre y posprueba del grupo control, pero sí del experimental. Lo que indica que sí hubo mejoría en la PR del grupo experimental, tanto las actitudes resistentes como las estrategias de afrontamiento. Además, 
el tamaño del efecto en actitudes resistentes fue 0.83 y en estrategias de afrontamiento fue 1.28, o sea, "muy grande". Esto es similar a los hallazgos reportados en las escasas investigaciones experimentales de educación experiencial existentes sobre el desarrollo de PR o estrategias de afrontamiento.

Al evaluar cada una de las AR, se encontraron algunas dificultades para el rechazo de la hipótesis nula para actitudes individuales. "Compromiso" no tuvo diferencias pre-posprueba en el grupo experimental, aunque estuvo muy cerca del límite ( $\mathrm{p}=0.0689$ ), lo pudo deberse al tamaño pequeño de la muestra. "Reto" no tuvo diferencia ni entre pospruebas ni entre pre-posprueba experimental; se postula que pudo deberse a la redacción de los ítems de esta actitud: que estaban orientados a buscar activamente desafíos y no a ver los problemas como retos que llegaban como parte del proceso de desarrollo del proyecto de vida.

Al evaluar cada una de las estrategias de afrontamiento, se encontraron diferencias significativas para todas en la posprueba, excepto "ayuda social", dado un bajo nivel en la preprueba del grupo experimental en relación con el grupo control, pero sí se encontró diferencia significativa pre-pos en el grupo experimental.

Cabe anotar que el análisis cuantitativo de este estudio presentó dos limitantes. La primera es el bajo tamaño de la muestra dada la restricción de recursos, lo que disminuye la generalización de los datos. La segunda es la no aleatorización en la selección de los grupos experimental y control, por la necesidad de evitar la contaminación experimental y por razones logísticas, lo que incrementa la posibilidad de sesgo por falta de equivalencia inicial de los grupos.

En el análisis cualitativo complementario se encontró que los estudiantes consideraron apropiado y útil para ellos tanto el Programa de EE en general como cada una de sus etapas, como se describe enseguida. Primero la sensibilización inicial les permitió la concienciación de su proyecto de vida y la pertinencia del Programa para realizar dicho proyecto. En la ejecución del Programa: la experiencia los llevó a conflictos cognitivos que propiciaron el aprendizaje; la reflexión les posibilitó darse cuenta de la importancia de este proceso 
de introspección para solucionar sus problemas en su vida cotidiana y laboral; la conceptualización les brindó las herramientas de la PR, actitudes y estrategias, para enfrentar mejor las dificultades; y la experimentación les facilitó la apropiación de esas herramientas para su vida real.

Además, los estudiantes manifestaron aprendizajes a nivel psicológico y psicosocial sobre la utilidad del trabajo en equipo para alcanzar sus objetivos, que fue facilitado por la aplicación del proceso administrativo de planeación, organización, dirección y control. El proponerse un objetivo, adquirir actitud cooperativa y habilidades comunicativas para poder trabajar en equipo, y finalmente superar la dificultad, es un logro que brindaba satisfacción a los participantes y promocionaba el desarrollo de una PR.

Referían que el desarrollo de la PR, por el Programa de EE, les aportó a la satisfacción las necesidades psicológicas de la siguiente forma. La necesidad de autonomía, al partir de los propios intereses para enfrentar las dificultades; de competencia, al facilitar la utilización y desarrollo de las propias capacidades; y de afiliación, al facilitar el trabajo colaborativo en equipo.

Manifestaron un cambio progresivo de una mejor actitud hacia las dificultades, durante cada sesión y a lo largo del Programa, y su aplicación en la vida cotidiana y laboral. Expresaron enfrentar mejor las dificultades después del Programa al haber apropiado actitudes de compromiso, control y reto, así como, estrategias de búsqueda de soluciones y no evitación, resignificación y apoyo social cognitivo y emocional.

La limitante en el análisis cualitativo fue la falta de evaluación en el grupo control, lo que impidió precisar la percepción de este grupo de las razones por las cuales disminuyó su PR en general, tanto actitudes resistentes como estrategias de afrontamiento, y por qué, en cambio, se incrementaron las actitudes de "reto".

En síntesis, de acuerdo con los análisis cuantitativo y cualitativo, el programa de EE facilitó el desarrollo de la PR; este incremento en los recursos psicosociales llevó del desequilibrio inicial, por la alta 
dificultad del reto propuesto en el Programa de EE, a un desafío óptimo, con realimentación positiva e incluso experiencia de flujo. Se queda en espera de investigaciones similares, idealmente con un mayor número de personas, que permitan confirmar o no los hallazgos de este estudio. 
10

Conclusiones 


\section{Conclusiones}

Dado que los Tecnólogos en Atención Prehospitalaria tienen alta prevalencia del síndrome de desgaste ocupacional, por la alta exigencia laboral y la usualmente poca retribución salarial y social, requieren incrementar las características resistentes de su personalidad para la prevención de este trastorno. Actualmente, la personalidad resistente comprende tres componentes: "actitudes resistentes", "estrategias de afrontamiento resistente" y "autocuidado resistente", todos ellos constituyen actitudes. Sin embargo, como el "autocuidado resistente" se enfoca en estilos de vida que exigen un largo proceso de aprendizaje, no se consideró en esta investigación.

Las dimensiones por los modelos teóricos más aceptados sobre estrés laboral (demanda-control-apoyo social de Karasek y desequilibrio esfuerzo-recompensa de Siegrist) pueden agruparse en tres grandes categorías: las demandas laborales, los recursos psicológicos, en los cuales se incluye la personalidad resistente, y los efectos psicosociales. Cuando demandas laborales y recursos psicológicos están en un nivel similar medio o alto, se da un "desafío óptimo" en el cual las personas se sienten motivadas a satisfacer sus necesidades psicológicas y el esfuerzo les produce emociones placenteras gratificantes que aportan a la prevención del SDO.

Se utilizó un diseño explicativo secuencial. Primero se midió la personalidad resistente utilizando dos instrumentos validados: la "escala de personalidad resistente" y la "escala de estilos y estrategias de afrontamiento al estrés" (que en este estudio obtuvieron un alfa de Cronbach 0.815 y 0.866 respectivamente). Precedido por teoría sobre los temas centrales y sensibilización sobre su importancia, se brindó un programa de educación experiencial que comprendió las etapas propuestas por Kolb, en un entorno realista similar al laboral y colectivo de trabajo en equipo para vencer los desafíos propuestos. El programa de Educación Experiencial mejoró significativamente $(\mathrm{a}=0.05)$ y en grado grande o muy grande (tamaño del efecto) la Personalidad Resistente que comprende las Actitudes Resistentes y las Estrategias de Afrontamiento; sólo la actitud resistente "reto" no se incrementó significativamente, lo que se postula que fue causado por problemas en la redacción de los ítems correspondientes. 
Las principales limitaciones de este estudio fueron el tamaño reducido de la muestra, que disminuye la generalización de los datos, y la no aleatorización en la selección de los grupos experimental y control, que incrementa la posibilidad de sesgo.

En la evaluación cualitativa, los participantes manifestaron que la concienciación de la pertinencia del Programa y la adecuación a sus situaciones laborales reales fueron fundamentales para lograr el aprendizaje, y que la aplicación del proceso administrativo facilitó el trabajo en equipo. Consideraron que el programa facilitó el desarrollo de su PR y la obtención de un desafío óptimo, e incluso experiencia de flujo en algunos, y que este aprendizaje tenía efecto en su vida cotidiana y laboral. La limitante en el análisis cualitativo fue la falta de evaluación en el grupo control, lo que impidió precisar el porqué de los cambios en sus niveles de personalidad resistente.

De acuerdo con los análisis cuantitativo y cualitativo, el programa de EE llevó al desarrollo de la PR que permitieron alcanzar un desafío óptimo, e incluso una experiencia de flujo, y que este aprendizaje impactó la vida cotidiana y laboral de los participantes.

Se recomienda realizar más investigaciones similares para confrontar los resultados de esta investigación, pero con un mayor número de personas. 
11

Bibliografía 


\section{Bibliografía}

AIAE. (s.f.). Introducción al aprendizaje experiencial. Recuperado el 01 de 02 de 2019, de Asociación Internacional de Aprendizaje Experiencial: https://www.aprendizaje-experiencial.org/intro

Ainan, P. L., \& Coralia, F. (2016). Hubungan antara Hardiness dengan Coping Strategy pada Guru Sekolah Inklusi di SDN Putraco Indah Bandung. Prosiding Psikologi, 2(1), 309-314. Obtenido de https://docplayer.info/79462044-Hubungan-antarahardiness-dengan-coping-strategy-pada-guru-sekolah-inklusidi-sdn-putraco-indah-bandung.html

Almalki, S. (2016). Integrating Quantitative and Qualitative Data in Mixed Methods Research-Challenges and Benefits. Journal of Education and Learning, 5(3), 288-296. Obtenido de https:// files.eric.ed.gov/fulltext/EJ1110464.pdf

Almario, J. F. (2016). Una mirada existencial a la adolescencia. Bogotá: El Manual Moderno.

Alva López, V. R., \& Yánac Cierto, E. (2017). Burnout académico y estrategias de afrontamiento en los estudiantes de la Escuela Profesional de Psicología de la Universidad Peruana UniónFilial Tarapoto, 2016. Trabajo de grado, Universidad Peruana Unión, Escuela Profesional de Psicología, Tarapoto. Obtenido de https://repositorio.upeu.edu.pe/handle/UPEU/504

Alvarez, S., \& Jobst-Hendrik, S. (2018). A communication-focused curriculum for dental students - an experiential training approach. BMC Medical Education, 1-6. Obtenido de https:// bmcmededuc.biomedcentral.com/track/pdf/10.1186/s12909018-1174-6.pdf

American Psichological Association. (2020). APA Dictionary of Psychology. Obtenido de https://dictionary.apa.org/stress

American Psychological Association. (03 de 06 de 2010). APA Diccionario Conciso de Psicología. Washington: Manual Moderno. Obtenido de APA Dictionary of Psychology: https:// dictionary.apa.org/stress 
Ano, G. G., \& Vasconcelles, E. B. (2004). Religious coping and psychological adjustment to stress: A meta-analysis. Journal of clinical psychology, 61(4), 461-480. Obtenido de https:// onlinelibrary.wiley.com/doi/abs/10.1002/jclp.20049

Asli-Azad, M., Rajaei, R., Farhadi, T., \& Aghasi,A. (2017). Investigating the relationship between hardiness as well as resiliency and burnout aspects in the care givers of the physically, mentally and multiple retarded patients at the welfare organization in 2015. Repository of research and investigative information, 10(2), 24-32. Obtenido de http://eprints.rums.ac.ir/6804/

Ayala Calvo, J.-C., \& Manzano García, G. (2018). Hardiness as moderator of the relationship between structural and psychological empowerment on burnout in middle managers. Journal of occupational and organizational psychology, 91(2), 362-384. Obtenido de https://onlinelibrary.wiley.com/doi/ pdf/10.1111/joop.12194

Babaeiamiri, N. (2016). Predicting Nurses' Mental Health Based on Their Job Burnout,. Modern Care Journal, 13(2), 1-6. Obtenido de https://www.researchgate.net/publication/308301113 Predicting_Nurses\%27_Mental_Health_Based_on_Their Job_Burnout_Perceived_Social_Support_and_Psychological_ Hardiness

Babaieamiri, N., Gaghighat-dost, S., \& Ashori, J. (2016). The relationship between job burnout, perceived social support and psychological hardiness with mental health among nurses. Avicenna Journal of Nursing and Midwifery Care, 24(2), 120-128. Obtenido de http://nmj.umsha.ac.ir/browse.php?a code $=$ A-10-551-1\&slc_lang $=$ en\&sid $=1$

Baena, V., \& Mattera, M. (2015). Flipped classroom 2.0: aprendizaje experiencial para la generación Y. Educar para transformar: Aprendizaje experiencial - XII Jornadas Internacionales de Innovación Universitaria (págs. 38-45). Madrid: Universidad Europea Madrid. Obtenido de https://abacus. universidadeuropea.es/bitstream/handle/11268/4296/ jiiu_2015_4.pdf? sequence $=2 \&$ isAllowed $=\mathrm{y}$ 
Bajwa, S., Butt, A., Mazhar, N., Warris, S., Tariq, M., \& Ashraf, R. (2020). Relationship between work flow and burnout in medical professionals. The Professional Medical Journal, 27(11), 25172522. Obtenido de http://www.theprofesional.com/index.php/ tpmj/article/view/4650/4347

Bansal, P. (2014). Effects of experiential learning strategies on problem solving ability of adolescents from psychological hardiness perspective. Indian Journal of Health \& Wellbeing, 4(5), 574-578. Obtenido de https://s3.amazonaws.com/academia. edu.documents/46384110/problem_solving.pdf?AWSAcc essKeyId=AKIAIWOWYYGZ2Y53UL3A\&Expires $=155$ $2314976 \&$ Signature $=$ OLKtwFuj1Ve0\%2FuiOfq $2 \mathrm{jWJZ} \% 2$ Fq\%2F4\%3D\&response-content-disposition=inline \%3B\%20filename\%3DEffects_of_Experiential_

Barranco-Martos, A., \& Vargas-Fernández, D. (2014). Intervención en crisis psicológica a personas dependientes. Madrid: CEP.

Barta, K., Flores, M., \& Edwards, A. (2018). Experiential Learning Enhances PhysicalTherapistStudentConfidencein Management of Neurologically Involved Adults and Children. Journal of Physical Therapy Education, 32(3), 295-299. Obtenido de https://journals.lww.com/jopte/Abstract/2018/09000/ Experiential_Learning_Enhances_Physical_Therapist.13.aspx

Becker, S., Konrad, A., Zimmermann, L., Müller, C., Tomczyk, S., Reichler, L., \& Körner, M. (2016). Influence of Teamwork on Wellbeing And Emotional Exhaustion of Staff in German Rehabilitation Clinics. Europepmc, 80(3), 270-277. Obtenido de https://europepmc.org/article/med/27280681

Bedoya-Gaviria, S., García-Castro, G., Estrada-Berrío, Y., MéndezTimaná, J., Restrepo-Guiral, D., Franco-Ramírez, A., \& Grajales-Vargas, C. (2016). Simulación clínica de alta fidelidad en el aprendizaje de la valoración en trauma. Tecné, Episteme y Didaxis: TED(Extraordinario), 1535-1542. Obtenido de https://revistas.pedagogica.edu.co/index.php/TED/article/ download/4780/3912 
Bianco, F., Lombardi, E., Massaro, D., Castelli, I., Valle, A., Marchetti, A., \& Lecce, S. (2019). Enhancing advanced Theory of Mind skills in primary school: A training study with 7- to 8-year-olds. Infant and Child Development, 28, 1-16. Obtenido de https:// onlinelibrary.wiley.com/doi/epdf/10.1002/icd.2155

Cabanach, R. G., Fariña, F., Freire, C., González, P., \& Ferradás, M. (2013). Diferencias en el afrontamiento del estrés en estudiantes universitarios hombres y mujeres. European Journal of Education and Psycholog, 6(1), 19-32. Obtenido de https:// www.redalyc.org/pdf/1293/129327497002.pdf

Cáliz Lafuente, E., \& Pedrosa González, I. (2015). Desarrollo de proyectos de animación cultural. Málaga: IC.

Cardona-Triana, C. P., \& Trejos-Parra, J. J. (2019). Programa de educación experiencial para mejorar el trabajo en equipo en las organizaciones. Pereira: Universidad Tecnológica de Pereira.

Cardona-Triana, C. P., \& Trejos-Parra, J. J. (2020). Estudio cualitativo del aprendizaje experiencial para equipos de trabajo organizacional. Revista de Ciencias Sociales, 26(3), 71-82. Obtenido de https://produccioncientificaluz.org/index.php/rcs/ article/view/33232/34898

Carmona-Halty, M., Garrosa-Hernández, E., \& Moreno-Jiménez, B. (2017). Análisis Psicométrico de la Escala de Personalidad Resistente (EPR) adaptada a estudiantes universitarios chilenos. Interciencia, 42(5), 286-292. Obtenido de https:// www.interciencia.net/wp-content/uploads/2017/08/286-5967CARMONA-HALTY-42-5.pdf

Casas-Santín, M. V., Carranza-Peña, M. G., \& Ruiz-Badillo, A. (2011). Guía para la planeación didáctica en la universidad. México: Universidad Pedagógica Nacional.

Castaño, E. F., \& León-del-Barco, B. (2010). Estrategias de afrontamiento del estrés y estilos de conducta interpersonal. International Journal of Psychology and Psychological 
Therapy, 10(2), pp. 245-257. Obtenido de https://www.redalyc. org/pdf/560/56017095004.pdf

Castro-Correa, A., García-Chacón, G., \& González-Ternera, R. (2017). Psicología clínica: fundamentos existenciales. Barranquilla: Universidad del Norte.

Cavert, C. (2012). Adventure Education: A Historical and Theoretical Perspective of Challenge Course Education. Obtenido de Fun Doing: http://www.fundoing.com/uploads/1/2/4/4/12445824/ adventureedhistoricalperspective_cavert.pdf

Céspedes Lainez, S. P., Gonzales Ustrilla, J., Jacoby Mesina, F., \& Santivañez Salazar, B. G. (2017). Aplicación de sesiones de aprendizaje basadas en la metodología del aprendizaje experiencial para mejorar la capacidad de autorregulación emocional en el área de personal social, educación religiosa y tutoría. Trabajo de Grado, Instituto Pedagógico Nacional Monterrico, Licenciatura en Educación Primaria, Lima. Obtenido de http://repositorio.ipnm.edu.pe/bitstream/ ipnm/74/3/EP-017-CESPEDES.pdf

Cirino-Gerena, G. (2013). Origen, desarrollo y naturaleza de los intereses. Bloomington: Palibrio.

Comité Curricular TAPH-UTP. (2020). Proyecto Educativo del Programa TAPH-UTP. Universidad Tecnológica de Pereira, Programa Atención Prehospitalaria, Pereira.

Coppari, N., Barcelata, B., Bagnoli, L., Codas, G., López-Humada, H., \& Martínez-Cañete, Ú. (2019). Influencia del sexo, edad y cultura en lasestrategias de afrontamiento de adolescentesparaguayos y mexicanos. Universitas Psychologica, 18(1), 1-13. Obtenido de https://revistas.javeriana.edu.co/index.php/revPsycho/ article/view/18200

Corsini, R. J. (2016). The dictionary of psychology. New York: Routledge. 
Cruz-Pérez, G. (2018). Desestigmatizando la función del estrés. Revista electrónica de psicología iztacala, 21(2), 604-620. Obtenido de https://www.iztacala.unam.mx/carreras/psicologia/psiclin/ vol21 num2/Vol21No2Art12.pdf

Cueva, J. I., Cusco, D., \& Sánchez, G. E. (2017). Burnout, una silenciosa amenaza en el servicio de atención prehospitalaria. Revista de investigación académica y educación, 1(2), 7-12. Obtenido de https://www.revistaacademica-istcre.edu.ec/admin/postPDF/t, unasilenciosaamenazaenelserviciodeatenci\%C3\%B3nprehospi talaria.pdf

Dasilva, F. B. (2010). El pensamiento de Merleau Ponty: la importancia de la percepción. Miríada: investigación en ciencias sociales, 3(6), 93-118. Obtenido de https://dialnet.unirioja.es/descarga/ articulo/5024409.pdf

De-Castro-Correa, A. M., García-Chacón, G., \& González-Ternera, R. (2017). Psicología clínica: fundamentos existenciales. Barranquilla (Colombia): Universidad del Norte.

Delgado-Linares, I. (2019). Dinamización grupal. Madrid: Paraninfo.

Delucchi, M. L. (2020). Evolución de las ciencias según Thomas Kuhn. En G. G. Peñalva, \& M. L. Delucchi, Temas de introducción al derecho (págs. 8-28). La Plata: Universidad Nacional de La Plata (EDULP). Obtenido de http://sedici.unlp.edu. $\mathrm{ar} / \mathrm{bitstream} /$ handle/10915/109056/Documento_completo. pdf? sequence $=1 \#$ page $=8$

Dewi, Y., Qur'aniati, N., \& Apriliyanti, T. E. (2018). Impact of Experiential Learning Method on the Knowledge, Attitude, and Coping Mechanisms of Cancer Patient's Companions at the Java Branch of the Indonesian Cancer Foundation. En U. A. Faculty of Nursing (Ed.), Proceedings of the 9th International Nursing Conference, (págs. 717-724). Surabaya. Obtenido de https://www.scitepress.org/Papers/2018/83317/83317.pdf

Doron, R., \& Parot, F. (2008). Diccionario Akal de psicología. Madrid: Akal. 
Encinas-Orbegoso, M. J. (2019). Afrontamiento al estrés, una revisión teórica. Trabajo de Grado, Universidad Señor de Sipán, Escuela Académico Profesional de Psicología, Pimentel (Perú). Obtenido de http://repositorio.uss.edu.pe/bitstream/ handle/20.500.12802/6097/Encinas\%20Orbegoso\%20 Margarita\%20Janet.pdf?sequence $=1 \&$ isAllowed $=\mathrm{y}$

Estefanía-Osorio, J., \& Cárdenas-Niño, L. (2017). Estrés laboral: estudio de revisión. Diversitas: perspectivas en psicología, 13(1), 81-90. Obtenido de http://www.scielo.org.co/pdf/dpp/ v13n1/1794-9998-dpp-13-01-00081.pdf

Fabricatore, A. N., Handal, P. J., Rudio, D. M., \& Gilner, F. H. (2004). Stress, Religion, and Mental Health: Religious Coping in Mediating and Moderating Roles. The International Journal for the Psychology of Religion, 14(2), 91-108. Obtenido de https:// www.tandfonline.com/doi/abs/10.1207/s15327582ijpr1402_2

Fahmi, A. R., \& Widyastuti, W. (2018). Hubungan Antara Hardiness Dengan Burnout Pada Santri Pondok Pesantren Persatuan Islam Putra Bangil. Jurnal Psikologi Poseidon, 1(1), 66-73. Obtenido de http://journal-psikologi.hangtuah.ac.id/index.php/ jurnall/article/view/11

Farahani, A., Soufi, M., Keshavarz, L., \& Bastami, H. (2014). The effectiveness of instructing hardiness factors on occupational burnout among the personal of the Olympic (using canonical correlation analysis). International Research Journal of Applied and Basic Sciences, 8(10), 1531-1533. Obtenido de http://www. irjabs.com/files_site/paperlist/r_2339_140908154452.pdf

Fernández-Abascal, E. G., \& Palmero, F. (1999). Emociones y salud. España: Ariel Psicología.

Ferro-Allodola, V. (2014). The effects of educational models based on experiential learning in Medical Education: an international literature review. tutor, 14(1), 23-49. Obtenido de https://www. researchgate.net/publication/265684027 
Fila, M. J. (2016). The Job Demands, Control, Support Model: Where Are We Now? TKM International Journal for Research in Management2016, 1(1), 15-44. Obtenido de https://kmim. ac.in/wp-content/uploads/2017/03/Article-3.pdf

Fila, M. J., Purl, J. D., \& Bracken, W. (2013). Overdue: MetaAnalyzing Demands, Control and Support on Job Satisfaction and Emotional Exhaustion. Academy of Management Annual Meeting Proceedings, 1, 16912-16912. Obtenido de https:// journals.aom.org/doi/abs/10.5465/ambpp.2013.16912abstract

Finch, D., Peacock, M., Lazdowski, D., \& Hwang, M. (2015). Managing emotions: A case study exploring the relationship between experiential learning, emotions, and student performance. The International Journal of Management Education, 13(1), 23-36. Obtenido de https://www.sciencedirect.com/science/article/ abs/pii/S1472811714000640

Foltz-Ramos, K. (2017). When the simulator dies: experiential education about death designed for undergraduate nursing students. Thesis, University of Buffalo, Department of Learning and Instruction, Buffalo. Obtenido de https://search.proquest. com/openview/62efad4f86aad7cb04e249ccaeb157df/1?pq-ori gsite $=$ gscholar $\& \mathrm{cbl}=18750 \&$ diss $=\mathrm{y}$

Galera-Pérez, A. D. (2018). Orientaciones didacticas sobre el calentamiento previo a la actividad fisica. Universitat Autònoma de Barcelona, Facultad Ciencias de la Educación, Barcelona. Obtenido de https://ddd.uab.cat/pub/recdoc/2014/187663/ Calentamiento_OrDid_DDD_2_.pdf

Galindo-Domínguez, H. (2020). Estadística para no estadísticos: una guía básica sobre la metodología cuantitativa de trabajos académicos. Alicante: 3ciencias. Obtenido de https://www.3ciencias.com/libros/libro/estadistica-parano-estadisticos-una-guia-basica-sobre-la-metodologiacuantitativa-de-trabajos-academicos/

Galleta-Williams, H., Esmail, A., Grigoroglou, C., Zghebi , S. S., Zhou, A. Y., Hodkinson, A., \& Panagioti, M. (2020). The importance of teamwork climate for preventing burnout in UK general 
practices. European Journal of Public Health, 30(Supplement 4), iv36 - iv38. Obtenido de https://academic.oup.com/eurpub/ article/30/Supplement_4/iv36/5902302

Gálvez-Herrer, M., Moreno-Jiménez, B., \& Mingote-Adán, J. C. (2011). El desgaste profesional del médico: revisión y guía de buenas prácticas. Madrid: Díaz de Santos.

García, F. E., Páez, D., Reyes-Reyes, A., \& Álvarez, R. (2017). Religious Coping as Moderator of Psychological Responses to Stressful Events: A Longitudinal Study. Religions, 8(62), 1-13. Obtenido de https://www.mdpi.com/2077-1444/8/4/62/pdf

García-Conde, A., Miaja-Avila, M., Romero-Retes, R., Ibáñez-Guerra, E., \& Soriano-Pastor, J. (2016). Propiedades psicométricas del cuestionario de afrontamiento al estrés para pacientes oncológicos (CAEPO). Psicooncología, 13(2-3), 271-284. Obtenido de https://revistas.ucm.es/index.php/PSIC/article/ view/54436/49739

Godoy-Izquierdo, D., \& Godoy, J. F. (2002). La personalidad resistente: una revisión de la conceptualización e investigación sobre la dureza. Clínica y Salud, 13(2), 135-162. Obtenido de http:/ www.redalyc.org/pdf/1806/180618085001.pdf

Gómez-Maqueo, E. L., Durán-Patiño, C., \& Romero-Godínez, E. (2016). Validación psicométrica de la Escala Infantil de Afrontamiento. Revista Latinoamericana de Medicina Conductual, 6(2), 59-65. Obtenido de https://www.redalyc.org/ pdf/2830/283048876002.pdf

González, M. T., \& Landero, R. (2007). Cuestionario de afrontamiento al estrés (CAE): validación de una muestra mexicana. Revista de Psicopatología y Psicología Clínica, 12(2), 189-198. Obtenido de http://aepcp.net/arc/04_2007(3)_Gonzalez_y_Landero.pdf

González-Valencia, G. A. (2005). Educación experiencial y trabajo en equipo. Trabajo de grado, CINDE - Universidad de Manizales, Maestría en Educación y Desarrollo Humano, Manizales. 
Obtenido de http://biblioteca.clacso.edu.ar/Colombia/alianzacinde-umz/20140804053901/GustavoAlonsoGonzalez2005. pdf

González-W, Y., Ortega-de-Gómez, E., Castillo-de-Lemos, R., Whetsell, M., \& Cleghorn Spencer, D. C. (2017). Validación de la scala inventario de estrategias de afrontamiento, versión española de Cano, Rodríguez, García (2007), en el contexto de Panamá. Enfoque, 21(17), 109-133. Obtenido de https:// revistas.up.ac.pa/index.php/enfoque/article/view/45/37

Granados-López, H., \& García-Zuluaga, C. (2016). El modelo de aprendizaje experiencial como alternativa para mejorar el proceso aprendizaje en el aula. Ánfora, 23(41), 37-54. Obtenido de http://www.redalyc.org/pdf/3578/357848839002.pdf

Grau, A., Flichtentrei, D., Suñer, R., Font-Mayolas, S., Prats, M., \& Braga, F. (2008). El burnout percibido o sensación de estar quemado en profesionales sanitarios: prevalencia y factores asociados. Información psicológica(91-92), 64-79. Obtenido de https://www.researchgate.net/publication/28308383_El_ burnout_percibido_o_sensacion_de_estar_quemado_en_ profesionales_sanitarios_prevalencia_y_factores_asociados

Guedes-dos-Santos, J. L., Erdmann, A. L., Meirelles, B. H., Lanzoni, G. M., Cunha, V. P., \& Ross, R. (2017). Integrating quantitative and qualitative data in mixed methods research. Texto \& Contexto Enfermagem, 26(3), 1-9. Obtenido de https://www.scielo.br/ pdf/tce/v26n3/en_0104-0707-tce-26-03-e1590016.pdf

Ha, D. G., \& Sung, M.-H. (2018). mpact of Job Stress, Coping Behavior, Hardiness on Burnout in Nurses in the Emergency Department. Korean Journal of Occupational Health Nursing, 27(4), 215-223. Obtenido de https://www.koreascience.or.kr/ article/JAKO201809258122142.page

Hatamipour, K., Hoveida, F., Rahimaghaee, F., Babaeiamiri, N., \& Ashoori, J. (2017). The nurses' quality of life based on burnout, perceived social support and psychological hardiness. Journal 
of research development in nursing and midwifery, 14(1), 2228. Obtenido de http://srhcm.goums.ac.ir/jgbfnm/article-1897-en.html

Hernández-Sampieri, R., \& Mendoza-Torres, C. P. (2018). Metodología de la investigación: las rutas cuantitativa, cualitativa y mixta. Ciudad de México: McGraw-Hill Interamericana.

Hernández-Sampieri, R., Fernández-Collado, C., \& Baptista-Lucio, M. d. (2014a). Metodología de la investigación (6 ed.). México D. F.: McGraw-Hill - Interamericana.

Hernández-Sampieri, R., Fernández-Collado, C., \& BaptistaLucio, M. d. (2014b). Metodología de la investigación (6 ed., Vol. Capítulo 4 en línea). México D.F.: McGrawHillEducation. Obtenido de highered.mheducation.com/sites/dl/ free/1456223968/1058642/CAPITULO04.pdf

Hosseinzadeh-Bandaghiri, A., Seyd-Ali-Asghar, R., \& Fazelli, A. (2018). The effect of self-efficiency and psychological hardiness on job burnout through the mediating role of job motivation. Research on Information Science \& Public Libraries, 24(3), 479-494. Obtenido de http://publij.ir/browse. php?a_id=1801\&sid=1\&slc_lang $=$ en

Jachens, L., Houdmont, J., \& Thomas, R. (2019). Effort-reward imbalance and burnout among humanitarian aid workers. Disasters, 43(1), 67-87. Obtenido de https://onlinelibrary. wiley.com/doi/abs/10.1111/disa.12288\#

Jamal, Y.(2017). Coping Strategies and Hardiness as Predictors of Stress among Rescue Workers. Pakistan Journal of Psychological Research, 32(1), 141-154. Obtenido de http://www.pjprnip. edu.pk/index.php/pjpr/article/download/604/522

Karasek, R. A. (1998). Demand / control model: a social, emotional, and physiological approach to stress risk and active behaviour development. En J. M. Stellman, Encyclopaedia of occupational health and safety (págs. 34.6-34.14). Geneva: International Labour Organization. 
Karasek, R. A., \& Töres, T. (1990). Healthy Work: stress, productivity and the reconstruction of working life. Nueva York: Basic Books.

Kaur, J. (2011). Influence of Gender and School Climate on Psychological Hardiness among Indian Adolescents. International Conference on Social Science and Humanity, 5, 319-323. Obtenido de http://www.ipedr.com/vol5/no2/70-H10186.pdf

Kim, B., Kim, E., \& Lee, S. M. (2017). Examining longitudinal relationship among effort reward imbalance, coping strategies and academic burnout in Korean middle school students. School Psychology International, 38(6), 628-646. Obtenido de https://doi.org/10.1177/0143034317723685

Kolb, A. Y., \& Kolb, D. A. (2009). Experiential learning theory: a dynamic, holistic approach to management learning, education and development. En S. Armstrong, \& C. Fukami, The SAGE handbook of management learning, education and development (págs. 42-68). Thousand Oaks (California): SAGE.

Kolb, D. A. (2015). Experimental learning: experience as the source of learning and development (2 ed.). New Jersey: Pearson.

Labrague, L. J., McEnroe-Petitte, D. M., Al Amri, M., Fronda, D. C., \& Obeidat, A. A. (2018). An integrative review on coping skills in nursing students: implications for policymaking. International Nursing Review, 65(2), 279-281. Obtenido de https://onlinelibrary.wiley.com/doi/epdf/10.1111/inr.12393

Ladstätter, F., Cooperthomas, H. D., Moreno-Jiménez, B., Ponsoda, V., Song, S., \& Garros, E. (2018). Deciphering hardiness: differential relationships of novelty seeker, rigid control, and hardy profiles on nurses' burnout and their effects. Nursing and Advanced Health Care, 2(1). Obtenido de https://www.researchgate.net/profile/Felix_Ladstaetter/ publication/326522102_Deciphering_Hardiness_Differential Relationships_of_Novelty_Seeker_Rigid_Control_and Hardy_Profiles_on_Nurses_Burnout_and_their_Effects/ links/5b52473445851507a7b3f147/Deciphering 
Ladstätter, F., Garrosa, E., \& Dai, J. (2014). Neural Network Analysis of Nonlinear Effects of Hardiness on Burnout in Chinese Nurses. Open Journal of Social Science, 2, 96-99. Obtenido de http:// file.scirp.org/pdf/JSS_2014051311030054.pdf

Lagos García, C. (2012). Aprendizaje experiencial en el desarrollo de habilidades "blandas". Trabajo de grado, Universidad Alberto Hurtado, Departamento de Trabajo Social, Santiago de Chile. Obtenido de http://repositorio.uahurtado.cl/bitstream/ handle/11242/5549/TRSLagos.pdf? sequence=1\&isAllowed=y

Lang, C., Fledmeth, A. K., Brand, S., Holsboer-Trachsler, E., Pühse, U., \& Gerber, M. (2015). Stress management in physical education class: an experiential approach to improve coping skills and reduce stress perceptions in adolescents. Journal of Teaching in Physical Education, 35(2), 149-158. Obtenido de https://journals.humankinetics.com/view/journals/jtpe/35/2/ article-p149.xml?content $=$ abstract

Laureano, C. (2008). Coping and psychological well-being of university rugby players. Doctoral Thesis, North-West University, Degree Philosophiae Doctor in Pychology, Potchefstroom (Southern Africa). Obtenido de https://africantheses.org/ abstracts/5205-32817

Lillo, P. R. (2007). Influencia de los estilos de humor sobre las estrategias de afrontamiento en Entre Ríos. Psicodebate, 7, 95-118. Obtenido de https://dspace.palermo.edu/ojs/index.php/ psicodebate/article/download/430/210

Liping, L., Xuhong, S., \& Shilin, X. (2016). The Relation between Hardiness Quality and Burnout of Medical Staff. China Journal of Health Psychology. Obtenido de http://en.cnki.com. cn/Article_en/CJFDTotal-JKXL201611016.htm

Ljubin-Golub, T., Rijavec, M., \& Olčar, D. (2020). Student Flow and Burnout: The Role of Teacher Autonomy Support and Student Autonomous Motivation. Psychological Studies, 65, 145-156. Obtenido de https://link.springer.com/article/10.1007/s12646019-00539-6 
Lo, C.-F. (2017). Stress and coping strategies among university freshmen in Hong Kong: validation of the coping strategy indicator. Psychology, 8(8), 1254-1266. Obtenido de https:// www.scirp.org/html/11-6902155_77308.htm\#txtF6

Londoño A, N. H., Pérez P, M., \& Murillo J, M. N. (2009). Validación de la escala de estilos y estrategias de afrontamiento al estrés en una muestra colombiana. Informes psicológicos, 11(13), 147-163. Obtenido de https://dialnet.unirioja.es/descarga/ articulo/5229809.pdf

López-González, J., Posadas-Tello, M. H., \& León-Noris, M. L. (2018). Estrés y burnout. En M. E. Barradas-Alarcón, R. DelgadilloCastillo, L. Gutiérrez-Serrano, M. H. Posadas-Tello, J. N. García-Andrade, J. López-González, \& E. Denis-Rodríguez, Estrés y burnout - enfermedades en la vida actual (págs. 202222). Bloomington: Palibro.

Lucero-Revelo, S. E. (2015). Capítulo 6. Estudio epistemológico del método mixto transductivo de investigación. En A. R. Rebolledo-Mendoza, J. Flores-Preciado, T. Reyes-Fong, \& J. C. Flores-Carrillo, Investigación en las ciencias de la gestión, innovación, competitividad y tecnologías de la información (págs. 105-135). México D.F.: Competitive Press. Obtenido de https://www.researchgate.net/publication/287206430

Luchman, J. N., \& González-Morales, M. G. (2013). Demands, control, and support: A meta-analytic review of work characteristics interrelationships. Journal of Occupational Health Psychology, 18(1), 37-52. Obtenido de https://www.researchgate.net/ publication/235006331_Demands_Control_and_Support_A_ Meta-Analytic_Review_of_Work_Characteristics_ Interrelationships

Maddi, S. R. (2002). The Story of Hardiness: Twenty Years of Theorizing, Research, and Practice. Consulting Psychology Journal: Practice and Research, 54(3), 175-185. Obtenido de https://pdfs.semanticscholar. org/4850/11b30089c36cc76f7a222286a736a70e76c5.pdf 
Maddi, S. R. (2013). Hardiness: turning stressful circumstances into resilient growth. New York: Springer.

Maddi, S. R., \& Martínez-Martí, M. L. (2009). La personalidad resistente: promoviendo el crecimiento ante condiciones de estrés. En C. Váquez, \& G. Hervás, Psicología Positiva Aplicada (págs. 217-236). Sevilla (España): Desclée de Brouwer.

Manging-Valverde, G., \& Csizmadia-Viteri, D. T. (2017). El síndrome de burnout: revisión literaria de su impacto en el bienestar y desempeño de los profesionales del sector salud. Tesis de Maestría, Universidad de Especialidades Espíritu Santo, Maestría en Dirección de Talento Humano, Guayaquil. Obtenido de http://repositorio.uees.edu.ec/bitstream/123456789/1615/1/ MANGING_VALVERDE_GARDENIA\%20MDTH-OL2015-B-2017-000\%20final\%20\%281\%29.pdf

Marshall, M. M., Carrano, A. L., \& Dannels, W. A. (2016). Adapting Experiential Learning to Develop Problem-Solving Skills in Deaf and Hard-of-Hearing Engineering Students. The Journal of Deaf Studies and Deaf Education, 21(4), 403-415. Obtenido de https://academic-oup-com.ezproxy.utp.edu.co/jdsde/ article/21/4/403/2452862? searchresult $=1$

Martin, R. A., Puhlik-Doris, P., Larsen, G., Gray, J., \& Weir, K. (2003). Individual differences in uses of humor and their relation to psychological well-being: Development of the Humor Styles Questionnaire. Journal of research in personality, 48-75. Obtenido de https://ac.els-cdn.com/S0092656602005342/1s2.0-S0092656602005342-main.pdf?_tid=3d529d63-110e4865-85a8-1df2a117c29f\&acdnat $=1543243953$ _982ceae3145 d72a99d49b5e8996f701d

Maslach, C., \& Leiter, M. P. (2016). Burnout. En G. Fink, Stress: Concepts, Cognition, Emotion, and Behavior (págs. 351-357). San Diego (CA): Academic Press.

Mayoral Rodríguez, S., Timoneda Gallart, C., \& Pérez Álvarez, F. (2018). Eficacia del aprendizaje experiencial para mejorar la planificación cognitiva y su repercusión en la resolución de 
problemas y el rendimiento matemático. Cultura y educación, 30(2), 308-337. Obtenido de https://dialnet.unirioja.es/servlet/ articulo? codigo $=6443368$

Ministerio de Educación de Colombia. (2021). Consulta de Programas. Recuperado el 2021, de Sistema Nacional de Información para la Educación Superior en Colombia: https://hecaa.mineducacion. gov.co/consultaspublicas/programas

Ministerio de Salud y Protección Social. (30 de marzo de 2017). Resolución 926 de 2017. Diario Oficial(50.191). Obtenido de https://www.minsalud.gov.co/Normatividad_Nuevo/ Resolucion\%20No.926\%20de\%202017.pdf

Molero, F., Lois, D., García-Ael, C., \& Gómez, Á. (2019). Psicología de los grupos. Madrid: Universidad Nacional de Educación a Distancia.

Montestruque Orbegoso, L. M. (2018). Burnout y afrontamiento en docentes de una escuela de nivel socioeconómico mediobajo. Trabajo de Grado, Pontificia Universidad Católica del Perú, Facultad de Psicología, Lima. Obtenido de http://tesis. pucp.edu.pe/repositorio/bitstream/handle/123456789/12158/ MONTESTRUQUE_ORBEGOSO_BURNOUT_Y AFRONTAMIENTO_EN_DOCENTES_DE_UNA ESCUELA_DE_NIVEL_SOCIOECONOMICOO_M MEDIO_ BAJO.pdf?sequence $=1 \&$ isAllowed $=\mathrm{y}$

Morris, T. H. (2020). Experiential learning - a systematic review and revision of Kolb's model. Interactive Learning Environments, 28(8), 1064-1077. Obtenido de https://www.tandfonline.com/ doi/abs/10.1080/10494820.2019.1570279

Moscoso, M. S. (2015). Medición de la depresión en psicología de la salud: el modelo conceptual del estrés crónico. Revista de Psicología de Arequipa, 5(2), 214-230. Obtenido de https://www.researchgate.net/profile/Manolete_Moscoso/ publication/295547580_Medicion_de_la_Depresion_en Psicologia_de_la_Salud_El_Modelo_Conceptual_del_Estres CronicoAssessment_of_Depression_in_Health_Psychology_ 
The_Conceptual_Model_of_Chronic_Stress_Span

Nakamura, J., \& Csikszentmihalyi, M. (2009). Flow theory and research. En C. R. Snyder, \& S. J. Lopez, Oxford handbook of positive psychology (2 ed., págs. 195-206). New York: Oxford University Press.

Nogueiras Redondo, G. (2016). Turning points en las trayectorias emocionales de estudiantes en un contexto desafiante de aprendizaje experiencial: una aproximación dinámica. Quinta Jornada de Jóvenes Investigadores de la Universidad de Alcalá: Humanidades y Ciencias Sociales (págs. 245-254). Alcalá: Servicio de Publicaciones UAH Alcalá de Henares. Obtenido de https:/www.researchgate.net/profile/Gloria_Nogueiras2/ publication/305619360_Turning_points_en_las_trayectorias emocionales_de_estudiantes_en_un_contexto_desafiante_ de_aprendizaje_experiencial_una_aproximacion_dinamica Turning_points_in_the_emotional_traj

Núñez-Moscoso, J. (2017). Los métodos mixtos en la investigacion en educación: hacia un uso reflexivo. Cuadernos de pesquisa, 47(164), 632-649. Obtenido de https://www.scielo.br/pdf/cp/ v47n164/1980-5314-cp-47-164-00632.pdf

Obergoso, A. (2016). La motivación intrínseca según Ryan \& Deci y algunas recomendaciones para maestros. Educare, 2(1), 7593. Obtenido de https://revistas.unasp.edu.br/lumen/article/ download/743/pdf

Ocampo-Villegas, M. C. (2015). La promesa del café. Bogotá: Editorial Ibañez.

Organización Mundial de la Salud. (2018). Clasificación Internacional de las Enfermedades Versión 11 (CIE-11). OMS. Obtenido de https://icd.who.int/browse11/1-m/es\#/http://id.who.int/icd/ entity/129180281

Ortiz-Ocaña, A., \& Salcedo-Barragán, M. (2020). La didáctica como proceso de enseñar y evaluar el aprendizaje. Revista Ensayo Pedagógico, 15(2), 193-231. Obtenido de https://www. 
revistas.una.ac.cr/index.php/ensayospedagogicos/article/ view/14722/20403

Osorio, J. E., \& Cárdenas-Niño, L. (2017). Estrés laboral: estudio de revisión. Diversitas: Perspectivas en Psicología, 13(1), 81-90. Obtenido de https://www.redalyc.org/ jatsRepo/679/67952833006/html/index.html

Otero-López, J. M. (2015). Estrés laboral y burnout - en profesores de enseñanza secundaria. Madrid: Díaz de Santos.

Park, M.-K. (2017). Relationship among hardiness, social support and burnout of nurses working in emergency department. Journal of the Korea Convergence Society, 8(10), 397405. Obtenido de https://www.koreascience.or.kr/article/ JAKO201732663240668.page

Pazan, F., \& Esfahani-Asl, M. (2019). Hardiness training on life satisfaction, job burnout and quality of life among the female employees of ganjavian hospital of dezful. Middle Eastern Journal of Disability Studies, 9, 100-100. Obtenido de https:// jdisabilstud.ir/article-1-1602-en.htmlER

Penz, M., Siegrist, J., Wekenborg, M. K., Rothe, N., Walther, A., \& Kirschbaum, C. (2019). Effort-reward imbalance at work is associated with hair cortisol concentrations: Prospective evidence from the Dresden Burnout Study. Psychoneuroendocrinology, 109. Obtenido de https://www. sciencedirect.com/science/article/abs/pii/S0306453019302379

Pérez-Torres, D. M. (2020). Capítulo 7. Aprendizaje situado, ampliando la realidad del educando. En M. Sánchez-Cuevas, \& A. N. Morales-Ballinas, Metodologías y prácticas para la generación de experiencias significativas (págs. 102-116). Puebla: Universidad Popular Autónoma del Estado de Puebla.

Peterson-Ahmad, M. (2018). Enhancing Pre-Service Special Educator Preparation through Combined Use of Virtual Simulation and Instructional Coaching. education sciences, 8(10), 1-9. Obtenido de https://www.mdpi.com/2227-7102/8/1/10/htm 
Posada-Villa, J. A. (2011). Guía de atención en salud mental. Bogotá: Ministerio de la Protección Social. Obtenido de https://www. minsalud.gov.co/sites/rid/Lists/BibliotecaDigital/RIDE/DE/ GT/12.guia-salud-mental-emergencias.pdf

Quezada-Berumen, L., Moral de la Rubia, J., Ibarra-González , L. D., \& González-Ramírez, M. T. (2018). Estudio de validación del Cuestionario de Afrontamiento del Estrés en personas trans de México. Revista de Psicopatología y Psicología Clínica, 121-134. Obtenido de http://revistas.uned.es/index.php/RPPC/ article/view/19367

Rahim-Zadega, Z., Kohan, A., \& Jarahi, L. (2016). Hardiness and occupational burnout among nursing managers in Mashhad University of Medical Sciences. Acta Health Medica, 1(2), 2328. Obtenido de http://medtech.ichsmt.org/index.php/AHM/ article/view/485/286

Rajaei, Z., Shafizadeh, H., Babaeiamiri, N., \& Amirfakhr, A. (2017). The role of job burnout, perceived social support and psychological hardiness in predicting quality of life of nurses. Iran Journal of Nursing, 30(106), 1-10. Obtenido de http://ijn.iums.ac.ir/ article-1-2433-en.html

Ramos, C. A. (2015). Los paradigmas de la investigación científica. Avances en Psicología, 23(1), 9-17. Obtenido de http:// revistas.unife.edu.pe/index.php/avancesenpsicologia/article/ view/167/159

Ramos, K., Quintero, S., \& Gómez, S. (2016). Historia de la atención prehospitalaria en Colombia. Trabajo de grado, Corporación Universitaria Adventista, Tecnología en Atención Prehospitalaria de Urgencias, Emergencias y Desastres, Medellín. Obtenido de http://repository.unac.edu.co/bitstream/ handle/11254/454/Producto.pdf? sequence $=2$ \&isAllowed=y

Reeve, J. (2010). Motivación y emoción (5 ed.). México: McGraw-Hill.

Reggio, P. (2010). El cuarto saber: guía para el aprendizaje experiencial. Valencia (España): CREC. 
Reich, M., Costa-Ball, C. D., \& Remor, E. (2016). Estudio de las propiedades psicométricas de la Brief COPE para una muestra de mujeres uruguayas. Avances en psicología latinoamericana, 34(3), 615-636. Obtenido de https://revistas.urosario.edu.co/ xml/799/79947707014/index.html

Reza-Trosino, J. C. (2017). El gerente efectivo. Los fundamentos de la administración, el trabajo en equipo y el liderazgo. México D.F.: Universidad Nacional Autónoma de México.

Richards, T. D. (2017). The role of self-care and hardiness in moderating burnout in mental health counselors. Dissertation , Old Dominion University, Counseling and Human Services Doctorate of Phylosophy (PhD), Norfolk, Virginia.

Ríos-Risquez, M.-I., Carrillo-Garcia, C., \& Sabuco-Tebar, E. D. (2012). Resiliencia y Síndrome de Burnout en estudiantes de enfermería y su relación con variables sociodemográficas y de relación interpersonal. International Journal of Phsycological Research, 5(1), 88-95. Obtenido de https://www.redalyc.org/ pdf/2990/299023539011.pdf

Ruiz Olabuénaga, J. (2012). Metodología de la investigación cualitativa (5 ed.). Bilbao: Universidad de Deusto.

Ryan, R. M., \& Deci, E. L. (2000). La teoría de la autodeterminación y la facilitación de la motivación intrínseca, el desarrollo social, y el bienestar. American Psychologist, 55(1), 68-78. Obtenido de http://www.davidtrotzig.com/uploads/articulos/2000 ryandeci_spanishampsych.pdf

Ryan, R. M., \& Deci, E. L. (2020). Intrinsic and extrinsic motivation from a self-determination theory perspective: Definitions, theory, practices, and future directions. Contemporary Educational Psychology, In press, 1-11. Obtenido de https://www.sciencedirect.com/science/article/abs/pii/ S0361476X20300254

Sanchez-Vera, K. M., Loli-Ponce, R. A., \& Sandoval-Vegas, M. H. (2015). Prevalencia de estrés laboral en el personal asistencial prehospitalario del programa de sistema de atencion móvil de 
urgencias -Instituto de Gestión de Servicios de Salud. Revista Enfermería Herediana, 8(2), 116-122. Obtenido de https:// revistas.upch.edu.pe/index.php/RENH/article/view/2691/2567

Sanjay, M., \& Abhilash, K. P. (2019). History of Prehospital Care. Current medical issues, 17, 42-43. Obtenido de https:// www.researchgate.net/publication/335484174_History_of_ prehospital_care

Septilla, A. E., \& Syifa Maryanti, N. (2020). Hardiness dan Burnout pada Petugas Penyidik Kepolisian Negara Republik Indonesia (Polri). Jurnal Ilmiah Psikologi MIND SET, 10(2), 127-135. Obtenido de http://journal.univpancasila.ac.id/index.php/ mindset/article/view/1224

Siami-Namin,A., Flores, R., Tavakoli, N., Siami-Namin, S., \& Jones, K. S. (2021). Using Experiential Learning to Teach and Learn Digital Forensics: Educator and Student Perspectives. Computers \& Education Open, 1-24. Obtenido de https://www.sciencedirect. com/science/article/pii/S2666557321000161?via\%3Dihub

Siegrist, J. (2016). Effort-reward imbalance model. En G. Fink, Stress: concepts, cognition, emotion and behavior (Vol. 1, págs. 8186). San Diego (California): Elsevier.

Siegrist, J., \& Wahrendorf, M. (2016). Work stress and health in globalized economy: the model of effort-reward imbalance. Switzerland: Springer.

Tafor, P., Geier, S., Ogunmuyiwa, E. N., \& Addo-Tenkorang, R. (2016). Higher education involving students: a literature research in constructivism, connectivism and experiential learning perspective. International Conference of Education, Research and Innovation, (págs. 852-859). Sevilla. Obtenido de https://www.researchgate.net/profile/Richard_AddoTenkorang/publication/311362925_HIGHER_EDUCATION_ INVOLVING_STUDENTS_A_LITERATURE RESEARCH_IN_CONSTRUCTIVISM_CONNECTIVISM AND_EXPERIENTIAL_LEARNING_PERSPECTIVE/ links/58d7af12a6fdcc1baeae9051/HIGHER-EDUCATIO 
Tanta-Luyo, A. Y., Quispe-Fernández, M., Serpa-Barrientos, A., \& Ardiles-Guevara, D. E. (2019). Diseño y validación de la escala de afrontamiento al estrés en padres de hijos con discapacidad. Revista de Investigación en Psicología, 22(2), 265 - 286. Obtenido de https://revistasinvestigacion.unmsm.edu.pe/index. $\mathrm{php} / \mathrm{psico} /$ article/view/17426/14655

Tarrillo Mendoza, S. E. (2016). Influencia de la personalidad resistente en el sindrome de burnout en médicos residentes del hospital III Goyeneche, Arequipa 2016. Trabajo de grado, Universidad Católica de Santa María, Facultad de Medicina Humana, Arequipa. Obtenido de http://tesis.ucsm.edu.pe/repositorio/bitstream/handle/ UCSM/5529/70.2131.M.pdf?sequence=1\&isAllowed=y

Tse, D., Fung, H., Nakamura, J., \& Csikszentmihalyi, M. (2018). Teamwork and flow proneness mitigate the negative effect of excess challenge on flow state. The Journal of Positive Psychology, 13(3), 284-289. Obtenido de https://www. tandfonline.com/doi/c/10.1080/17439760.2016.1257059?scrol $\mathrm{l}=$ top\&needAccess $=$ true

Universidad Tecnológica de Pereira. (2018). Tecnología en Atención Prehospitalaria. Obtenido de Programas Académicos: https:// programasacademicos.utp.edu.co/plegable/uploads/atencionprehospitalaria.pdf

Universidad Tecnológica de Pereira. (2019). Proyecto Educativo Institucional. Obtenido de Vicerrectoría Académica UTP: https://www.utp.edu.co/vicerrectoria/academica/documentopei.html

Vagni, M., Giostra, V., Maiorano, T., Santaniello, G., \& Pajardi, D. (2020). Personal accomplishment and hardiness in reducing emergency stress and burnout among COVID-19 emergency workers. Sustainability, 12(21). Obtenido de https://www. mdpi.com/2071-1050/12/21/9071/htm

Van den Broeck, A., Van den Broeck, T., Dikkers, J., De Lange, A., \& De Witte, H. (2012). This is funny: On the beneficial 
role of self-enhancing and affiliative humour in job design. Psichothema, 24(1), 87-93. Obtenido de http://www.redalyc. org/pdf/727/72723431014.pdf

Van Dyke, C. J., Glenwick, D. S., Cecero, J. J., \& Kim, S.-K. (2009). The relationship of religious coping and spirituality to adjustment and psychological distress in urban early adolescents. Mental Health, Religion \& Culture, 12(4), 369-383. Obtenido de https:// www.tandfonline.com/doi/abs/10.1080/13674670902737723

Vicente-Pestana, J. (2017). Diálogo y autenticidad en psicoterapia: instrumentalizando ideas de Buber y Binswanger. Anuario de psicología, 47(3), 123-129. Obtenido de https://revistes.ub.edu/ index.php/Anuario-psicologia/article/download/27398/28361

Vives-Hurtado, M. P. (2016). Modelos pedagógicos y reflexiones para las pedagogías del sur. Redipe, 5(11), 1-16. Obtenido de https:// revista.redipe.org/index.php/1/article/view/140/138

Xu, Y., Wang, F., Guo, L., \& Jiang, J. (2012). Stress and Job Burnout:A Theoretical Model for Concept Discrimination and Prewarningintervention Differences. Journal of South China Normal University (Social Science Edition). Obtenido de http://en.cnki. com.cn/Article_en/CJFDTotal-HNSB201206008.htm

Yotsidi, V., Kourmousi, N., Dermitzaki, E., Pezirkianidis, C., \& Kounenou, K. (2018). "Add flow to the fire": flow and hope as a shield against burnout of fire service workers. Psychology, 9, 1291-1305. Obtenido de https://www.scirp.org/pdf/ PSYCH_2018062614505046.pdf

Zabalza, M. A., \& Zabalza-Cerdeiriña, M. A. (2010). Planificación de la docencia en la universidad. Madrid: Narcea.

Zorrilla-Antaurco, E. F. (2017). Adaptación del cuestionario de afrontamiento al estrés en padres de familia de niños con discapacidad del C.E.B.E. Manuel Duato. Trabajo de grao, Universidad César Vallejo, Licenciatura en Psicología, Lima. Obtenido de http://repositorio.ucv.edu.pe/ handle/20.500.12692/3418 
$12^{\text {Sesiones }}$ 


\section{Sesiones}

\subsection{Sesión 1}

En esta primera sesión, la intencionalidad es concientizar pensamientos y emociones en situaciones críticas durante la vida académica/profesional, para predisponer al grupo a la reflexión sobre sus estados internos en relación con la personalidad resistente (PR), que incluye actitudes resistentes (compromiso, control y reto) y estrategias de afrontamiento (reevaluación positiva, resolución de problemas, desviación y apoyo social cognitivo o social); y sobre la necesidad de buscar un "desafío óptimo", o sea, disponer de un nivel medio 0 alto de recursos psicológicos de PR en equilibrio con las demandas de la situaciones. Por esta razón, a diferencia de las siguientes, tiene una primera parte de sólo sensibilización. Luego de esta, sí se ofrece el proceso de educación experiencial (EE) para la concienciación de pensamientos y emociones en entornos académico-profesionales.

\begin{tabular}{|c|c|c|c|}
\hline INTRODUCCIÓN & \multicolumn{3}{|c|}{$\begin{array}{l}\text { - Presentación de los facilitadores. } \\
\text { - Exposición de la intencionalidad de la investigación (desarrollo de la PR). } \\
\text { - Definición de las normas de convivencia (apagar los artefactos electrónicos } \\
\text { durante la intervención, respetar a los demás y a sus opiniones, utilizar un } \\
\text { lenguaje cortés, dejar al final el espacio ordenado y limpio, y guardar } \\
\text { confidencialidad de lo que los demás digan o hagan). } \\
\text { - Descripción global la sesión. }\end{array}$} \\
\hline \multicolumn{4}{|c|}{ Alistamiento: "controla la pelota" } \\
\hline Materiales & Tiempo & Descripción & \begin{tabular}{|c|} 
Desarrollo \\
\end{tabular} \\
\hline $\begin{array}{l}\text { Pelota } \\
\text { mediana de } \\
\text { plástico }\end{array}$ & $\begin{array}{l}15 \\
\text { minutos }\end{array}$ & $\begin{array}{l}\text { Paso de una } \\
\text { pelota por el } \\
\text { suelo sin } \\
\text { levantarla y } \\
\text { dejar que } \\
\text { pase por } \\
\text { entre las } \\
\text { piernas. }\end{array}$ & $\begin{array}{l}\text { Se pide que formen un círculo, con las piernas } \\
\text { abiertas y los pies tocando los de sus compañeros. } \\
\text { Se entrega una pelota poco pesada para que se la } \\
\text { pasen entre ellos, sin levantarla e intentando } \\
\text { pasarla por entre las piernas de alguno de sus } \\
\text { compañeros. Si alguno la levanta o permite que la } \\
\text { pasen entre sus piernas, debe responder una } \\
\text { pregunta del facilitador en relación con el tema } \\
\text { central de esta sesión (que se presentan más } \\
\text { adelante). Al final se pregunta qué relación } \\
\text { encuentran entre la actividad y las dimensiones de } \\
\text { la PR. }\end{array}$ \\
\hline \multicolumn{4}{|c|}{ Sensibilización: "respiro y camino mis emociones" } \\
\hline Materiales & Tiempo & Descripción & Desarrollo \\
\hline Ninguno & $\begin{array}{l}20 \\
\text { minutos }\end{array}$ & $\begin{array}{l}\text { Caminata } \\
\text { en un } \\
\text { espacio } \\
\text { mientras se } \\
\text { van } \\
\text { concienciad }\end{array}$ & $\begin{array}{l}\text { Se pide que caminen en forma errática en el } \\
\text { espacio cerrado al ritmo variable del tambor } \\
\text { tocado por el facilitador. Cada que pasan pocos } \\
\text { minutos, se pide que recuerden una situación que } \\
\text { les produjo una determinada emoción (tristeza, }\end{array}$ \\
\hline
\end{tabular}


Programa modelo de educación experiencial orientado al desarrollo de personalidad resistente en estudiantes de atención prehospitalaria

\begin{tabular}{|c|c|c|c|c|}
\hline & & $\begin{array}{l}\text { o diversas } \\
\text { emociones. }\end{array}$ & \multicolumn{2}{|c|}{$\begin{array}{l}\text { enojo, frustración, satisfacción, alegría) y pongan } \\
\text { una cara que exprese esa emoción. }\end{array}$} \\
\hline \multicolumn{2}{|l|}{ Intencionalidad } & \multicolumn{3}{|c|}{ Plenaria } \\
\hline \multicolumn{2}{|c|}{$\begin{array}{l}\text { Concientizar emociones } \\
\text { para predisponer al grupo } \\
\text { a la reflexión sobre sus } \\
\text { pensamientos/emociones } \\
\text { en relación con la PR, en } \\
\text { especial el compromiso. }\end{array}$} & \multicolumn{3}{|c|}{$\begin{array}{l}\text { Se pregunta qué relación encuentran entre la actividad y las } \\
\text { dimensiones de la PR. }\end{array}$} \\
\hline \multicolumn{5}{|c|}{ Actividad central: "mapeando mi ser" } \\
\hline \multicolumn{2}{|l|}{ Materiales } & \multicolumn{2}{|c|}{\begin{tabular}{|c|c|} 
Tiempo & \\
\end{tabular}} & Descripción \\
\hline \multicolumn{2}{|c|}{$\begin{array}{l}\text { Hojas de papel bond, } \\
\text { lapiceros, video proyector, } \\
\text { parlantes. }\end{array}$} & 60 minutos & \multicolumn{2}{|c|}{$\begin{array}{l}\text { Se plasma en una hoja, reflexiona } \\
\text { y comparte: identidad, proyecto } \\
\text { de vida ocupacional, obstáculos, } \\
\text { capacidades y apoyo social. }\end{array}$} \\
\hline \multicolumn{5}{|c|}{ Intencionalidad } \\
\hline \multicolumn{5}{|c|}{$\begin{array}{l}\text { Concientizar: (1) la propia identidad (quién soy); (2) el proyecto de vida ocupacional (quién } \\
\text { quiero ser); (3) los posibles obstáculos externos (qué temores tengo); (4) las capacidades } \\
\text { personales (qué capacidades tengo); y (5) el apoyo social (quién me apoya). Reflexionar: } \\
\text { cómo, a partir de su identidad, puede buscar la realización del proyecto de vida superando los } \\
\text { obstáculos mediante las propias capacidades y el apoyo social. }\end{array}$} \\
\hline \multicolumn{3}{|c|}{ Escenario real } & \multicolumn{2}{|c|}{ Escenario imaginario } \\
\hline \multicolumn{3}{|c|}{$\begin{array}{l}\text { Estando sentados en un círculo, deben } \\
\text { escribir sobre cinco aspectos de su ser. }\end{array}$} & \multicolumn{2}{|c|}{$\begin{array}{l}\text { Están realizando su práctica profesional en la } \\
\text { EMI. Se están presentando problemas con los } \\
\text { funcionarios de comunicación y realización de } \\
\text { procedimientos conjuntos. Esa situación les está } \\
\text { generando mucho estrés y enojo, puesto que se } \\
\text { sienten menospreciados por los demás. Así que } \\
\text { deciden escribir algunos aspectos de sí mismos } \\
\text { para que les ayude a sentirse mejor y superar el } \\
\text { problema. }\end{array}$} \\
\hline $\begin{array}{c}\text { Experiencia } \\
\text { concreta }\end{array}$ & & $\begin{array}{l}\text { bservación } \\
\text { reflexiva }\end{array}$ & $\begin{array}{c}\text { Conceptualización } \\
\text { abstracta }\end{array}$ & $\begin{array}{c}\text { Experimentación } \\
\text { activa }\end{array}$ \\
\hline $\begin{array}{l}20 \text { minutos. Se le } \\
\text { entrega a cada } \\
\text { participante una hoja } \\
\text { en blanco que deben } \\
\text { marcar con su } \\
\text { nombre y se pide que } \\
\text { escriban los } \\
\text { siguientes aspectos de } \\
\text { su ser en relación con } \\
\text { su proyecto de vida } \\
\text { ocupacional, esto es: } \\
\text { su identidad (quién }\end{array}$ & $\begin{array}{l}20 \mathrm{~m} \\
\text { abre } \\
\text { para } \\
\text { volu } \\
\text { lo es } \\
\text { refle } \\
\text { esto. }\end{array}$ & $\begin{array}{l}\text { minutos. Se } \\
\text { e un espacio } \\
\text { a compartir } \\
\text { untariamente } \\
\text { scrito y } \\
\text { exionar a } \\
\end{array}$ & $\begin{array}{l}15 \text { minutos. En plenaria, } \\
\text { se invita a los } \\
\text { participantes a } \\
\text { reflexionar mediante un } \\
\text { diálogo de saberes (entre } \\
\text { la teoría científica y su } \\
\text { experiencia práctica) } \\
\text { sobre la relación de la PR } \\
\text { con la satisfacción en su } \\
\text { proyecto de vida } \\
\text { ocupacional, así como la } \\
\text { necesidad de utilizar las }\end{array}$ & $\begin{array}{l}5 \text { minutos. Con base } \\
\text { en la concienciación y } \\
\text { conceptualización } \\
\text { anteriores, se pide } \\
\text { escribir un ejemplo } \\
\text { de su vida futura en } \\
\text { que piensen utilizar } \\
\text { cada una de las } \\
\text { anteriores actitudes / } \\
\text { estrategias en relación } \\
\text { con su proyecto de } \\
\text { vida ocupacional. Y }\end{array}$ \\
\hline
\end{tabular}




\begin{tabular}{|l|l|l|}
\hline $\begin{array}{l}\text { soy), proyecto de } \\
\text { vida (quién quiero } \\
\text { ser), obstáculos (qué } \\
\text { temores tengo), } \\
\text { capacidades (qué } \\
\text { capacidades tengo) y } \\
\begin{array}{l}\text { apoyo social (quién } \\
\text { puede apoyarme). }\end{array}\end{array}$ & $\begin{array}{l}\text { actitudes resistentes y } \\
\text { estrategias de } \\
\text { afrontamiento para } \\
\text { mantener la percepción } \\
\text { de las dificultades en un } \\
\text { nivel medio-alto (no } \\
\text { extremo) en coherencia } \\
\text { con las capacidades } \\
\text { individuales y el apoyo } \\
\text { social, para obtener una } \\
\text { satisfactoria "experiencia } \\
\text { de flujo". }\end{array}$ & $\begin{array}{l}\text { participantes que lo } \\
\text { deseen que compartan } \\
\text { lo escrito y se motiva } \\
\text { las presentaciones. }\end{array}$ \\
\hline \multicolumn{2}{|c|}{ Evaluación } & Cierre torno a \\
\hline $\begin{array}{l}\text { En plenaria y partiendo de las } \\
\text { experiencias de la sesión, se preguntó por } \\
\text { la concienciación y transformación de } \\
\text { pensamientos, emociones y conductas, y } \\
\text { trabajo en equipo, en relación con la PR y } \\
\text { su aplicación a su vida cotidiana y } \\
\text { laboral. Y se escucharon sugerencias para } \\
\text { mejorar la sesión. }\end{array}$ & $\begin{array}{l}\text { Se solicitó escribir sobre la utilización real las } \\
\text { actitudes resistentes y estrategias de afrontamiento } \\
\text { en alguna situación estresante durante la semana } \\
\text { siguiente y entregarla en la próxima sesión. }\end{array}$ \\
\hline
\end{tabular}

\begin{tabular}{|c|c|c|c|}
\hline \multicolumn{4}{|c|}{ 10.2 Sesión 2} \\
\hline INTRODUCCIÓN & \multicolumn{3}{|c|}{$\begin{array}{l}\text { - Igual a la sesión } 1 . \\
\text { - Se recibe y se pone en plenaria la experiencia con la tarea sugerida. }\end{array}$} \\
\hline \multicolumn{4}{|c|}{ Alistamiento: "lo opuesto" } \\
\hline Materiales & Tiempo & Descripción & Desarrollo \\
\hline Ninguno & $\begin{array}{l}10 \\
\text { minutos }\end{array}$ & $\begin{array}{l}\text { Caminar en } \\
\text { círculos y luego } \\
\text { intentar sentarse } \\
\text { en las piernas } \\
\text { del otro. }\end{array}$ & $\begin{array}{l}\text { Los integrantes hacen un círculo y caminan en } \\
\text { sentido de las manecillas del reloj entonando } \\
\text { el canto del "arram sam sam" y cuando el } \\
\text { facilitador diga "arruasbi" deben dar un paso } \\
\text { al centro hasta quedar juntos y luego deberán } \\
\text { sentarse en las piernas del otro y sostenerse } \\
\text { entonando la canción de los pollitos. }\end{array}$ \\
\hline \multicolumn{4}{|c|}{ Actividad central: "el camino correcto" } \\
\hline \multicolumn{2}{|c|}{ Materiales } & Tiempo & \begin{tabular}{c|c} 
& Descripción \\
\end{tabular} \\
\hline \multicolumn{2}{|c|}{$\begin{array}{l}\text { Cinta de enmascarar }(70 \\
\mathrm{m}) \text {. }\end{array}$} & 45 minutos & $\begin{array}{l}\text { Para esta actividad el grupo debe } \\
\text { trabajar como un equipo donde } \\
\text { deberán completar un camino que es } \\
\text { incierto y cuya respuesta solo tiene e } \\
\text { facilitador. }\end{array}$ \\
\hline
\end{tabular}




\section{Intencionalidad}

Concientizar y mejorar las actitudes resistentes (compromiso, control y reto) y estrategias de afrontamiento (no evitación, enfoque en la solución, apoyo social y reevaluación positiva).

\begin{tabular}{|c|c|c|c|}
\hline \multicolumn{2}{|c|}{ Escenario real } & \multicolumn{2}{|c|}{ Escenario imaginario } \\
\hline \multicolumn{2}{|c|}{$\begin{array}{l}\text { En el piso se marca una cuadrícula de } 7 \text { x } 15 \\
\text { cuadrados, cada una de } 30 \mathrm{~cm} \text { de lado. Los } \\
\text { facilitadores eligen el conjunto de cuadrados } \\
\text { que conforman el camino, que los } \\
\text { participantes desconocen y deben ir } \\
\text { adivinando por ensayo y error, para pasar de } \\
\text { un lado al otro de la cuadrícula. Uno por uno } \\
\text { debe entrar y pisar un cuadro, y el facilitador } \\
\text { indicará si es o no parte del camino. Si acierta } \\
\text { podrá continuar con otro cuadro; si no, deberá } \\
\text { devolverse por el camino acertado, y lo } \\
\text { intentará otro compañero. }\end{array}$} & \multicolumn{2}{|c|}{$\begin{array}{l}\text { Los participantes se encuentran dentro de un } \\
\text { edificio en riesgo de derrumbarse por un } \\
\text { terremoto ocurrido. Deben salir pronto por el } \\
\text { camino seguro para salvar sus vidas y poder } \\
\text { brindarle la atención a las víctimas que están } \\
\text { fuera del edificio. }\end{array}$} \\
\hline $\begin{array}{c}\text { Experiencia } \\
\text { concreta }\end{array}$ & $\begin{array}{c}\text { Observación } \\
\text { reflexiva }\end{array}$ & $\begin{array}{c}\text { Conceptualización } \\
\text { abstracta }\end{array}$ & $\begin{array}{c}\text { Experimentación } \\
\text { activa }\end{array}$ \\
\hline $\begin{array}{l}15 \text { minutos. Los } \\
\text { participantes deciden } \\
\text { el orden en que } \\
\text { desean intentar pasar. } \\
\text { Es necesario que } \\
\text { finalmente crucen } \\
\text { todos por el camino } \\
\text { acertado. Deben } \\
\text { encontrar una } \\
\text { estrategia que les } \\
\text { permita salir. }\end{array}$ & $\begin{array}{l}10 \text { minutos. Se } \\
\text { disponen los } \\
\text { participantes en un } \\
\text { círculo y se le entrega } \\
\text { a cada uno un } \\
\text { lapicero y una } \\
\text { fotocopia con } \\
\text { preguntas concretas } \\
\text { sobre las actitudes } \\
\text { resistentes y } \\
\text { estrategias de } \\
\text { afrontamiento que } \\
\text { utilizaron durante la } \\
\text { vivencia, las cuales } \\
\text { deben responder } \\
\text { individualmente por } \\
\text { escrito. Luego se pide } \\
\text { que quienes quieran } \\
\text { compartan las } \\
\text { respuestas con sus } \\
\text { compañeros en } \\
\text { plenaria. Se pide } \\
\text { guardar las fotocopias } \\
\text { que después se } \\
\text { volverán a utilizar. }\end{array}$ & $\begin{array}{l}5 \text { minutos. En } \\
\text { plenaria, se invita a } \\
\text { los participantes a } \\
\text { reflexionar mediante } \\
\text { un diálogo de saberes } \\
\text { (entre la teoría } \\
\text { científica y su } \\
\text { experiencia práctica) } \\
\text { sobre la relación de la } \\
\text { PR con la satisfacción } \\
\text { en su proyecto de vida } \\
\text { ocupacional, así como } \\
\text { la necesidad de } \\
\text { utilizar estas actitudes } \\
\text { resistentes y } \\
\text { estrategias de } \\
\text { afrontamiento para } \\
\text { mantener la } \\
\text { percepción de las } \\
\text { dificultades en un } \\
\text { nivel medio-alto (no } \\
\text { extremo) en } \\
\text { coherencia con las } \\
\text { capacidades } \\
\text { individuales y el } \\
\text { apoyo social, para } \\
\text { obtener una } \\
\text { satisfactoria }\end{array}$ & $\begin{array}{l}5 \text { minutos. Con base } \\
\text { en la concienciación } \\
\text { y conceptualización } \\
\text { anteriores, se pide } \\
\text { escribir qué } \\
\text { propuestas tienen } \\
\text { para mejorar la PR } \\
\text { en la actividad, y de } \\
\text { ahí en su vida } \\
\text { futura en que } \\
\text { piensen utilizar cada } \\
\text { una de las anteriores } \\
\text { actitudes / } \\
\text { estrategias en } \\
\text { relación con su } \\
\text { proyecto de vida } \\
\text { ocupacional. Y luego } \\
\text { se pide a los } \\
\text { participantes que lo } \\
\text { deseen que } \\
\text { compartan lo escrito } \\
\text { y se motiva la } \\
\text { reflexión en torno a } \\
\text { las presentaciones. }\end{array}$ \\
\hline
\end{tabular}




\begin{tabular}{|l|l|l|}
\hline & \multicolumn{1}{|c|}{$\begin{array}{l}\text { "experiencia de } \\
\text { flujo". }\end{array}$} & \multicolumn{1}{|c|}{ Conservación reflexiva 2 } \\
\hline $\begin{array}{l}\text { Se disponen los participantes en un círculo. } \\
\text { Se pide que por el reverso de la fotocopia abstracta 2 } \\
\text { escriban los cambios en la vivencia después } \\
\text { de apropiar las actitudes resistentes y } \\
\text { estrategias de afrontamiento. }\end{array}$ & $\begin{array}{l}\text { Teniendo en cuenta las vivencias, reflexiones } \\
\text { y conceptualizaciones de la sesión, se realiza } \\
\text { plenaria para discutir propuestas de los } \\
\text { participantes para la incorporación de la PR a } \\
\text { su vida cotidiana. }\end{array}$ \\
\hline \multicolumn{2}{|c|}{ Evaluación } \\
\hline $\begin{array}{l}\text { Cierre } \\
\text { la sesión, se preguntó por la concienciación y } \\
\text { transformación de pensamientos, emociones y } \\
\text { conductas, y trabajo en equipo, en relación } \\
\text { con la PR y su aplicación a su vida cotidiana } \\
\text { y laboral. Y se escucharon sugerencias para } \\
\text { mejorar la sesión. }\end{array}$ & $\begin{array}{l}\text { Se solicitó escribir sobre la utilización real las } \\
\text { actitudes resistentes y estrategias de } \\
\text { afrontamiento en alguna situación estresante } \\
\text { durante la semana siguiente y entregarla en la } \\
\text { próxima sesión. }\end{array}$ \\
\hline
\end{tabular}

\begin{tabular}{|c|c|c|c|c|}
\hline \multicolumn{5}{|c|}{ 10.3 Sesión 3} \\
\hline INTRODUCCIÓN & \multicolumn{4}{|c|}{$\begin{array}{l}\text { - Igual a la sesión } 1 . \\
\text { - Se recibe y se pone en plenaria la experiencia con la tarea sugerida. }\end{array}$} \\
\hline \multicolumn{5}{|c|}{ Alistamiento: "el rollo humano" } \\
\hline Materiales & Tiempo & Descripción & \multicolumn{2}{|c|}{ Desarrollo } \\
\hline Ninguno. & $\begin{array}{l}10 \\
\text { minutos }\end{array}$ & $\begin{array}{l}\text { Realizar } \\
\text { una cadena } \\
\text { humana } \\
\text { tomados de } \\
\text { las manos. }\end{array}$ & \multicolumn{2}{|c|}{$\begin{array}{l}\text { Los estudiantes se toman de las manos. Realizan } \\
\text { un rollo con el fin de quedar unidos. Nombran las } \\
\text { cualidades del grupo en voz alta. Se desenrollan } \\
\text { teniendo precaución y cuidado del otro. }\end{array}$} \\
\hline \multicolumn{5}{|c|}{ Actividad central: "la evacuación" } \\
\hline \multicolumn{2}{|c|}{ Materiales } & \multicolumn{2}{|c|}{$\begin{array}{l}\text { Tiempo } \\
\end{array}$} & Descripción \\
\hline \multicolumn{2}{|c|}{$\begin{array}{l}2 \text { rollos de cuerda elástica }(10 \\
\mathrm{m} \text { cada uno). }\end{array}$} & \multicolumn{2}{|c|}{45 minutos } & $\begin{array}{l}\text { Para esta actividad el grupo } \\
\text { debe trabajar como un equipo } \\
\text { donde deberán completar un } \\
\text { circuito elaborado con } \\
\text { dificultades y que todos } \\
\text { deberán superar tomados de } \\
\text { las manos, sin nunca soltarse } \\
\text { ni hablar }\end{array}$ \\
\hline \multicolumn{5}{|c|}{ Intencionalidad } \\
\hline \multicolumn{5}{|c|}{$\begin{array}{l}\text { Concientizar y mejorar las actitudes resistentes y estrategias de afrontamiento. } \\
\text { Adicionalmente, el trabajo en equipo: planificación (objetivo y reglas), organización (tareas y } \\
\text { roles), dirección o liderazgo (comunicación y resolución de conflictos) y control (evaluación y } \\
\text { realimentación). }\end{array}$} \\
\hline
\end{tabular}




\begin{tabular}{|c|c|c|c|}
\hline \multicolumn{2}{|c|}{ Escenario real } & \multicolumn{2}{|c|}{ Escenario imaginario } \\
\hline \multicolumn{2}{|c|}{$\begin{array}{l}\text { Con cuerda elástica se crea una especie de } \\
\text { cúmulo de telarañas de } 6 \mathrm{~m} \text { de ancho por } 7 \mathrm{~m} \\
\text { de largo, con espacios que forman un camino, } \\
\text { altos o bajos, anchos o angostos, cuya } \\
\text { dificultad para pasar aumenta al avanzar; } \\
\text { tiene una entrada y una salida por donde } \\
\text { deben pasar sin tocar la cuerda elástica. }\end{array}$} & \multicolumn{2}{|c|}{$\begin{array}{l}\text { Los participantes se encuentran en la entrada } \\
\text { de un edificio completamente en riesgo de } \\
\text { derrumbarse por un terremoto presentado, } \\
\text { dentro hay un bebé de aproximadamente } 3 \\
\text { meses en llanto que quedó atrapado y está } \\
\text { completamente solo, lloró un buen rato y } \\
\text { luego se detuvo por lo que existe la duda que } \\
\text { le haya podido pasar algo grave como haberse } \\
\text { quedado sin oxígeno o sufrir un golpe. Deben } \\
\text { entrar muy pronto por él y brindarle la } \\
\text { atención necesaria, sin tocar la cuerda elástica } \\
\text { porque el edificio se puede derrumbar dado el } \\
\text { debilitamiento de la estructura. }\end{array}$} \\
\hline $\begin{array}{c}\text { Experiencia } \\
\text { concreta }\end{array}$ & $\begin{array}{l}\text { Observación } \\
\text { reflexiva }\end{array}$ & $\begin{array}{c}\text { Conceptualización } \\
\text { abstracta }\end{array}$ & $\begin{array}{c}\text { Experimentación } \\
\text { activa }\end{array}$ \\
\hline $\begin{array}{l}15 \text { minutos. Los } \\
\text { participantes se } \\
\text { ubican } \\
\text { estratégicamente en } \\
\text { una fila donde todos } \\
\text { deben ir tomados de } \\
\text { las manos. Además, } \\
\text { para superar } \\
\text { satisfactoriamente el } \\
\text { circuito deben } \\
\text { guardar silencio para } \\
\text { aumentar la } \\
\text { dificultad. Es } \\
\text { necesario que crucen } \\
\text { sin tocar ninguna } \\
\text { cuerda elástica la cual } \\
\text { conforma "el } \\
\text { edificio" o este será } \\
\text { derrumbado. Deben } \\
\text { pensar en una } \\
\text { estrategia para entrar } \\
\text { y salir efectivamente, } \\
\text { rescatar el bebé y } \\
\text { brindarle los primeros } \\
\text { auxilios oportunos. }\end{array}$ & $\begin{array}{l}10 \text { minutos. Se } \\
\text { disponen los } \\
\text { participantes en un } \\
\text { círculo y se le entrega } \\
\text { a cada uno un } \\
\text { lapicero y una } \\
\text { fotocopia con } \\
\text { preguntas concretas } \\
\text { sobre las actitudes } \\
\text { resistentes y } \\
\text { estrategias de } \\
\text { afrontamiento que } \\
\text { utilizaron durante la } \\
\text { vivencia, las cuales } \\
\text { deben responder } \\
\text { individualmente por } \\
\text { escrito. Luego se pide } \\
\text { que quienes quieran } \\
\text { compartan las } \\
\text { respuestas con sus } \\
\text { compañeros en } \\
\text { plenaria. Se pide } \\
\text { guardar las fotocopias } \\
\text { que después se } \\
\text { volverán a utilizar. }\end{array}$ & $\begin{array}{l}5 \text { minutos. En } \\
\text { plenaria, se invita a } \\
\text { los participantes a } \\
\text { reflexionar mediante } \\
\text { un diálogo de saberes } \\
\text { (entre la teoría } \\
\text { científica y su } \\
\text { experiencia práctica) } \\
\text { sobre la relación de la } \\
\text { PR con la satisfacción } \\
\text { en su proyecto de vida } \\
\text { ocupacional, así como } \\
\text { la necesidad de } \\
\text { utilizar estas actitudes } \\
\text { resistentes y } \\
\text { estrategias de } \\
\text { afrontamiento para } \\
\text { mantener la } \\
\text { percepción de las } \\
\text { dificultades en un } \\
\text { nivel medio-alto (no } \\
\text { extremo) en } \\
\text { coherencia con las } \\
\text { capacidades } \\
\text { individuales y el } \\
\text { apoyo social, para } \\
\text { obtener una } \\
\text { satisfactoria } \\
\text { "experiencia de } \\
\text { flujo". }\end{array}$ & $\begin{array}{l}5 \text { minutos. Con base } \\
\text { en la concienciación } \\
\text { y conceptualización } \\
\text { anteriores, se pide } \\
\text { escribir qué } \\
\text { propuestas tienen } \\
\text { para mejorar la PR } \\
\text { en la actividad, y de } \\
\text { ahí en su vida } \\
\text { futura en que } \\
\text { piensen utilizar cada } \\
\text { una de las anteriores } \\
\text { actitudes / } \\
\text { estrategias en } \\
\text { relación con su } \\
\text { proyecto de vida } \\
\text { ocupacional. Y luego } \\
\text { se pide a los } \\
\text { participantes que lo } \\
\text { deseen, que } \\
\text { compartan lo escrito } \\
\text { y se motiva la } \\
\text { reflexión en torno a } \\
\text { las presentaciones. }\end{array}$ \\
\hline
\end{tabular}




\begin{tabular}{|l|l|}
\hline \multicolumn{1}{|c|}{ Observación reflexiva 2 } & \multicolumn{1}{c|}{ Conceptualización abstracta 2 } \\
\hline $\begin{array}{l}\text { Se disponen los participantes en un círculo. } \\
\text { Se pide que por el reverso de la fotocopia } \\
\text { escriban los cambios en la vivencia después } \\
\text { de apropiar las actitudes resistentes y } \\
\text { estrategias de afrontamiento. }\end{array}$ & $\begin{array}{l}\text { Teniendo en cuenta las vivencias, reflexiones } \\
\text { y conceptualizaciones de la sesión, se realiza } \\
\text { plenaria para discutir propuestas de los } \\
\text { participantes para la incorporación de la PR a } \\
\text { su vida cotidiana. }\end{array}$ \\
\hline \multicolumn{2}{|c|}{ Cierre } \\
\hline $\begin{array}{l}|c| \\
\text { Enaluación } \\
\text { la sesión, se preguntó por la concienciación y } \\
\text { transformación de pensamientos, emociones y y } \\
\text { conductas, y trabajo en equipo, en relación } \\
\text { con la PR y su aplicación a su vida cotidiana } \\
\text { y laboral. Y se escucharon sugerencias para } \\
\text { mejorar la sesión. }\end{array}$ & $\begin{array}{l}\text { Se solicitó escribir sobre la utilización real las } \\
\text { actitudes resistentes y estrategias de } \\
\text { afrontamiento en alguna situación estresante } \\
\text { durante la semana siguiente y entregarla en la } \\
\text { próxima sesión. }\end{array}$ \\
\hline
\end{tabular}

\begin{tabular}{|c|c|c|c|c|}
\hline \multicolumn{5}{|c|}{ 10.4 Sesión 4} \\
\hline INTRODUCCIÓN & \multicolumn{4}{|c|}{$\begin{array}{l}\text { - Igual a la sesión } 1 . \\
\text { - Se recibe y se pone en plenaria la experiencia con la tarea sugerida. }\end{array}$} \\
\hline \multicolumn{5}{|c|}{ Alistamiento: "Ia treintaiuna" } \\
\hline Materiales & Tiempo & Descripción & & Desarrollo \\
\hline $\begin{array}{l}\text { Una pelota de } \\
\text { plástico. }\end{array}$ & $\begin{array}{l}10 \\
\text { minutos }\end{array}$ & $\begin{array}{l}\text { Trasladar el } \\
\text { paciente } \\
\text { (pelota) } \\
\text { solo } \\
\text { empleando } \\
31 \text { golpes. }\end{array}$ & $\begin{array}{l}\text { Los part } \\
\text { El facilit } \\
\text { actividac } \\
\text { Para hac } \\
\text { 31. La p } \\
\text { que tiene } \\
\text { una angi } \\
\text { necesita } \\
\text { la pelota } \\
\text { los partic } \\
\text { podrán t } \\
\text { cuerpo q } \\
\text { algún pa } \\
\text { requerid } \\
\text { traslado } \\
\text { extremo. }\end{array}$ & $\begin{array}{l}\text { e ubican formando un círculo. } \\
\text { xplica que el objetivo de la } \\
\text { lar la pelota de un lado al otro. } \\
\text { realizar } 31 \text { golpes y no más de } \\
\text { senta la vida de una persona } \\
\text { ión arterial y acaba de sufrir } \\
10 \text { inestable, por lo tanto, } \\
\text { nédica inmediata. Para trasladar } \\
\text { articipante podrá hablar. Todos } \\
\text { berán tocar la pelota. Solo } \\
\text { pelota utilizando la parte del } \\
\text { el facilitador; en el caso de que } \\
\text { no cumpla las condiciones } \\
\text { oo debe empezar de nuevo el } \\
\text { te (pelota) hacia el otro }\end{array}$ \\
\hline \multicolumn{5}{|c|}{ Actividad central: "ríos" } \\
\hline \multicolumn{2}{|c|}{ Materiales } & \multicolumn{2}{|c|}{ Tiempo } & Descripción \\
\hline \multicolumn{2}{|c|}{$\begin{array}{l}20 \text { metros de cuerda, } 8 \\
\text { octavos de goma EVA, } 1 \\
\text { vendaje ocular, } 1 \\
\text { inmovilizador de miembro } \\
\text { inferior. }\end{array}$} & \multicolumn{2}{|c|}{45 minutos } & $\begin{array}{l}\text { Trasladar a todos los } \\
\text { miembros del equipo, } \\
\text { incluidos dos personas } \\
\text { lesionadas (una con daño } \\
\text { ocular y otra con una }\end{array}$ \\
\hline
\end{tabular}




\begin{tabular}{|c|c|c|c|}
\hline & & $\begin{array}{l}\text { inmovi } \\
\text { inferio } \\
\text { hasta e } \\
\text { las con } \\
\text { activid }\end{array}$ & $\begin{array}{l}\text { ización de miembro } \\
\text { desde un cuadrado } \\
\text { otro cumpliendo con } \\
\text { diciones de la } \\
\text { d. }\end{array}$ \\
\hline & Intenci & nalidad & \\
\hline $\begin{array}{l}\text { Concientizar y mejora } \\
\text { Adicionalmente, el tra } \\
\text { dirección o liderazgo ( } \\
\text { realimentación). }\end{array}$ & $\begin{array}{l}\text { las actitudes resistentes } \\
\text { ajo en equipo: planifica } \\
\text { comunicación y resoluci }\end{array}$ & $\begin{array}{l}\text { y las estrategias de afron } \\
\text { ción (objetivo), organiza } \\
\text { on de conflictos) y contr }\end{array}$ & $\begin{array}{l}\text { tamiento. } \\
\text { ión (tareas y roles), } \\
1 \text { (evaluación y }\end{array}$ \\
\hline Escen: & rio real & Escenario & maginario \\
\hline $\begin{array}{l}\text { En un espacio se dema } \\
\text { metros cuadrados sepa } \\
\text { de distancia; entre ella } \\
\text { goma EVA equidistant }\end{array}$ & $\begin{array}{l}\text { can dos áreas de dos } \\
\text { ados por diez metros } \\
\text { van } 8 \text { octavos de } \\
\text { es. }\end{array}$ & $\begin{array}{l}\text { Se dice a los participan } \\
\text { avalancha en la cual se } \\
\text { rodeado por un río y lo } \\
\text { (de guerrilla). La única } \\
\text { es atravesar el río de un } \\
\text { de las piedras, pero gua } \\
\text { existe la posibilidad de } \\
\text { grupos armados al mar } \\
\text { los participantes se enc } \\
\text { uno cuenta con una inn } \\
\text { miembro inferior y otrc } \\
\text { bilateral. }\end{array}$ & $\begin{array}{l}\text { es que hubo una } \\
\text { inundó un pueblo } \\
\text { alizado en zona roja } \\
\text { manera de salir de éste } \\
\text { lado al otro a través } \\
\text { rdando silencio porque } \\
\text { ser atacados por } \\
\text { en de la ley. Dos de } \\
\text { lentran lesionados, } \\
\text { ovilización en un } \\
\text { con vendaje ocular }\end{array}$ \\
\hline $\begin{array}{l}\text { Experiencia } \\
\text { concreta }\end{array}$ & $\begin{array}{l}\text { Observación } \\
\text { reflexiva }\end{array}$ & $\begin{array}{c}\text { Conceptualización } \\
\text { abstracta }\end{array}$ & $\begin{array}{c}\text { Experimentación } \\
\text { activa }\end{array}$ \\
\hline $\begin{array}{l}15 \text { minutos. Se } \\
\text { explica a los } \\
\text { participantes la } \\
\text { actividad y las } \\
\text { siguientes } \\
\text { condiciones: sólo } \\
\text { puede haber un pie } \\
\text { apoyado por piedra y } \\
\text { ninguno puede hablar } \\
\text { durante la actividad, } \\
\text { excepto un líder. Se } \\
\text { le pide al grupo que } \\
\text { escoja un líder y los } \\
\text { dos compañeros que } \\
\text { actuarán como } \\
\text { lesionados: } \\
\text { inmovilizar la pierna } \\
\text { de uno y vendar los } \\
\text { ojos del otro. Se da el } \\
\text { tiempo que ellos }\end{array}$ & $\begin{array}{l}10 \text { minutos. Se } \\
\text { disponen los } \\
\text { participantes en un } \\
\text { círculo y se le entrega } \\
\text { a cada uno un } \\
\text { lapicero y una } \\
\text { fotocopia con } \\
\text { preguntas concretas } \\
\text { sobre las actitudes } \\
\text { resistentes y } \\
\text { estrategias de } \\
\text { afrontamiento que } \\
\text { utilizaron durante la } \\
\text { vivencia, las cuales } \\
\text { deben responder } \\
\text { individualmente por } \\
\text { escrito. Luego se pide } \\
\text { que quienes quieran } \\
\text { compartan las } \\
\text { respuestas con sus }\end{array}$ & $\begin{array}{l}5 \text { minutos. En } \\
\text { plenaria, se invita a } \\
\text { los participantes a } \\
\text { reflexionar mediante } \\
\text { un diálogo de saberes } \\
\text { (entre la teoría } \\
\text { científica y su } \\
\text { experiencia práctica) } \\
\text { sobre la relación de la } \\
\text { PR con la satisfacción } \\
\text { en su proyecto de vida } \\
\text { ocupacional, así como } \\
\text { la necesidad de } \\
\text { utilizar estas actitudes } \\
\text { resistentes y } \\
\text { estrategias de } \\
\text { afrontamiento para } \\
\text { mantener la } \\
\text { percepción de las } \\
\text { dificultades en un }\end{array}$ & $\begin{array}{l}5 \text { minutos. Con base } \\
\text { en la concienciación } \\
\text { y conceptualización } \\
\text { anteriores, se pide } \\
\text { escribir qué } \\
\text { propuestas tienen } \\
\text { para mejorar la PR } \\
\text { en la actividad, y de } \\
\text { ahí en su vida } \\
\text { futura en que } \\
\text { piensen utilizar cada } \\
\text { una de las anteriores } \\
\text { actitudes / } \\
\text { estrategias en } \\
\text { relación con su } \\
\text { proyecto de vida } \\
\text { ocupacional. Y luego } \\
\text { se pide a los } \\
\text { participantes que lo } \\
\text { deseen que }\end{array}$ \\
\hline
\end{tabular}




\begin{tabular}{|l|l|l|l|}
\hline $\begin{array}{l}\text { definan para planear } \\
\text { la estrategia de } \\
\text { traslado. Todos deben } \\
\text { cruzar hasta el otro } \\
\text { lado en un tiempo } \\
\text { límite de diez } \\
\text { minutos, cumpliendo } \\
\text { plenaria. Se pide } \\
\text { las condiciones } \\
\text { explicadas } \\
\text { anteriormente. }\end{array}$ & $\begin{array}{l}\text { que después se } \\
\text { volverán a utilizar. }\end{array}$ & $\begin{array}{l}\text { nivel medio-alto (no } \\
\text { extremo) en } \\
\text { coherencia con las } \\
\text { capacidades } \\
\text { individuales y el } \\
\text { apoyo social, para } \\
\text { obtener una } \\
\text { satisfactoria } \\
\text { "experiencia de } \\
\text { flujo". }\end{array}$ & $\begin{array}{l}\text { compartan lo escrito } \\
\text { y se motiva la } \\
\text { reflexión en torno a } \\
\text { las presentaciones. }\end{array}$ \\
\hline $\begin{array}{l}\text { Observación reflexiva 2 } \\
\text { Se pide que por el reverso de la fotocopia } \\
\text { escriban los cambios en la vivencia después } \\
\text { de apropiar las actitudes resistentes y } \\
\text { estrategias de afrontamiento. }\end{array}$ & $\begin{array}{l}\text { Teniendo en cuenta las vivencias, reflexiones } \\
\text { y conceptualizaciones de la sesión, se realiza } \\
\text { plenaria para discutir propuestas de los } \\
\text { participantes para la incorporación de la PR a } \\
\text { su vida cotidiana. }\end{array}$ \\
\hline \multicolumn{2}{|c|}{ Cierre } \\
\hline $\begin{array}{l}\text { Evaluación } \\
\text { Se pisponen los participantes en un círculo. } \\
\text { escriban los cambios en la vivencia después } \\
\text { de apropiar las actitudes resistentes y } \\
\text { estrategias de afrontamiento. }\end{array}$ & $\begin{array}{l}\text { Se solicitó escribir sobre la utilización real las } \\
\text { actitudes resistentes y estrategias de } \\
\text { afrontamiento en alguna situación estresante } \\
\text { durante la semana siguiente y entregarla en la } \\
\text { próxima sesión. }\end{array}$ \\
\hline
\end{tabular}


13

Anexos 


\section{Anexo A. Instrumentos}

\section{UNIVERSIDAD TECNOLÓGICA DE PEREIRA - FACULTAD CIENCIAS DE LA \\ SALUD}

PROGRAMA TECNOLOGÍA EN ATENCIÓN PREHOSPITALARIA

INVESTIGACIÓN: Programa Modelo de Educación Experiencial Orientado al Desarrollo de Personalidad Resistente

\section{en Estudiantes de Atención Prehospitalaria}

Se busca determinar la eficacia de este programa para aportar a la Prevención del Síndrome de Desgaste Profesional de muy alta prevalencia en Tecnólogos en Atención Prehospitalaria. La información personal será manejada con total confidencialidad. Se agradece la sinceridad en las respuestas lo que permitirá medir adecuadamente la utilidad del programa y cualificarlo.

Nombre: Asignatura

Edad: ___ Sexo:

\section{PERSONALIDAD RESISTENTE}

Piense en sus actividades académicas y prácticas en ÚLTIMAMENTE y señale la opción que mejor le represente:

01. Tengo gran curiosidad por las experiencias académicas nuevas que considero retos para mí.

02. Considero que mis actividades académicas son de valor para la sociedad y me gusta dedicarle todos mis esfuerzos.

03. Mis actividades académicas me satisfacen y hacen que me dedique totalmente a ellas.

04. Aunque me esfuerce en mis actividades académicas, no consigo nada.

05. Mis propios sueños son los que hacen que siga adelante con la realización de mis actividades académicas.

06. Realmente me esfuerzo e identifico con mis actividades académicas.

07. Me atraen las actividades académicas que tienen un desafío personal.

08. No importa lo que me esfuerce en mis actividades académicas, a

pesar de mi empeño no suelo conseguir nada.

09. A menudo trabajo duro, pues es la mejor manera para alcanzar mis metas académicas.

10. No me esfuerzo en mis actividades académicas ya que, de cualquier forma, el resultado es el mismo.

11. En la medida que puedo, trato de tener nuevas experiencias que son retos en mis actividades académicas diarias.

12. En mis actividades académicas, prefiero aquellas que enseñan novedades en la forma de hacer las cosas.

13. No vale la pena que me esfuerce académicamente, ya que haga lo que haga las cosas nunca me salen. 
Programa modelo de educación experiencial orientado al desarrollo de personalidad resistente en estudiantes de atención prehospitalaria

14. Aunque haga un buen trabajo, jamás alcanzaré mis metas académicas.

15. Dentro de lo posible, busco situaciones nuevas y desafiantes en mi ambiente académico.

\begin{tabular}{|c|c|c|c|c|c|c|}
\hline $\begin{array}{l}\text { ESTILOS Y ESTRATEGIAS DE AFRONTAMIENTO } \\
\text { Piense en los problemas importantes que ha tenido } \\
\text { ÚLTIMAMENTE } \\
\text { y conteste según su forma de enfrentarlos }\end{array}$ & हु & 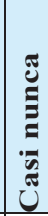 & $\begin{array}{l}\tilde{8} \\
e \\
\overline{0} \\
4\end{array}$ & 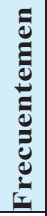 & 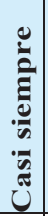 & $\frac{\mathfrak{b}}{\mathrm{E}}$ \\
\hline 01. Pienso que la experiencia siempre aporta algo positivo & & & & & & \\
\hline 02. Pido ayuda a mis amigos sobre cómo actuar & & & & & & \\
\hline 03. Busco a alguien en quien confiar y descargar mis emociones & & & & & & \\
\hline $\begin{array}{l}\text { 04. Me propongo cambiar positivamente la forma en que veo el } \\
\text { problema }\end{array}$ & & & & & & \\
\hline 05. Pienso en cosas diferentes a lo sucedido & & & & & & \\
\hline 06. Intento aprender de esta experiencia & & & & & & \\
\hline 07. Evito el problema haciendo cualquier otra cosa & & & & & & \\
\hline 08. Me responsabilizo en hacer algo para solucionar el problema & & & & & & \\
\hline 09. Busco consuelo en mis amigos & & & & & & \\
\hline 10. Me empeño en sacarle aspectos positivos al problema & & & & & & \\
\hline 11. Procuro olvidar mi malestar & & & & & & \\
\hline 12. Procuro distraerme para no pensar en el problema & & & & & & \\
\hline $\begin{array}{l}\text { 13. Intento sacarle lo que pueda tener de bueno a todo lo que } \\
\text { está sucediendo }\end{array}$ & & & & & & \\
\hline 14. Pienso en un plan para resolverlo & & & & & & \\
\hline 15. Evito el problema concentrándome en otras actividades & & & & & & \\
\hline $\begin{array}{l}\text { 16. Pienso en que los problemas me sirven para crecer como } \\
\text { persona }\end{array}$ & & & & & & \\
\hline 17. Confío mis sentimientos a un amigo & & & & & & \\
\hline 18. Le pregunto a otros cómo solucionar el problema & & & & & & \\
\hline $\begin{array}{l}\text { 19. Procuro ver los problemas desde otro punto de vista para } \\
\text { observar lo positivo }\end{array}$ & & & & & & \\
\hline 20. Intento resolver el problema de alguna manera & & & & & & \\
\hline
\end{tabular}


Actualmente, los profesionales sanitarios están sometidos a cargas laborales excesivas con enfrentamiento continuo de sufrimiento y muerte, lo que les genera altos niveles de estrés crónico. Esto aunado a frecuentes bajos salarios y reconocimiento social lleva al síndrome de desgaste ocupacional o burnout, incluso en una tercera parte, el cual comprende agotamiento emocional, despersonalización de la atención y baja realización personal, y afecta todos los ámbitos de la persona. Es pues necesario y urgente producir y aplicar conocimiento orientado a su prevención, más aún en la atención prehospitalaria por las situaciones complejas e imprevistas que implica, sin los recursos intrahospitalarios y con alto riesgo de muerte.

En este libro se presenta la fundamentación y validación de un programa de "Educación experiencial" (EE) para el desarrollo de "Personalidad Resistente" (PR). La EE consiste en vivenciar situaciones similares a la realidad según objetivos definidos y luego reflexionar sobre estas situaciones, para lograr aprendizaje a partir de la experiencia. La PR comprende actitudes, afrontamiento, interacción social y autocuidado resistentes que constituyen un factor de prevención del síndrome de desgaste ocupacional.

El libro, primero sigue los lineamientos de la metodología de la investigación, y al final presenta un programa modelo de educación experiencial orientado al desarrollo de la personalidad resistente en el marco de la atención prehospitalaria, aunque puede ser útil para la atención en salud y para la resistencia al estrés laboral en general.

Facultad Ciencias de la Salud Colección Trabajos de Investigación

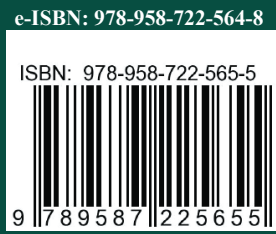

